\title{
Backtracking approaches for the delineation of contamination sources
}

\author{
Dissertation \\ Zur Erlangung des mathematischen- naturwissenschaftlichen Doktorgrades \\ "Doctor rerum naturalium" \\ der Georg-August Universität Göttingen \\ im Promotionsprogramm Geowissenschaften \\ der Georg-August University School of Science (GAUSS)
}

vorgelegt von

\section{Katrin Thomas-Thielsch}

aus Georgsmarienhütte 


\section{Betreuungsausschuss:}

Prof. Dr. Thomas Ptak-Fix Angewandte Geologie, Universität Göttingen

Dr. Maria Herold Angewandte Geologie, Universität Göttingen

Prof Dr. Martin Sauter Angewandte Geologie, Universität Göttingen

Mitglieder der Prüfungskommission:

Referent: Prof. Dr. Thomas-Ptak-Fix

Angewandte Geologie, Universität Göttingen

Korreferentin: Dr. Maria Herold

Angewandte Geologie, Universität Göttingen

Korreferent: Prof. Dr. Martin Sauter

Angewandte Geologie, Universität Göttingen

weitere Mitglieder der Prüfungskommission:

Prof Dr. Thomas Graf

Institut für Strömungsmechanik und Umweltphysik im Bauwesen, Universität Hannover

Prof. Dr. Heiko Faust

Abteilung Humangeographie, Universität Göttingen

PD Dr. Chicgoua Noubactep

Angewandte Geologie, Universität Göttingen

Tag der mündlichen Prüfung: 15. Juli 2013 


\section{Acknowledgements}

My supervisors Prof. Dr. Ptak, Dr. Maria Herold and Prof. Dr. Martin Sauter deserve special thanks for their ideas and their technical assistance.

Sincere thanks to the members of the disputation committee, Prof Dr. Thomas Graf, Prof. Dr. Heiko Faust, PD Dr. Chicgoua Noubactep.

For the funding I mainly have to thank the EU Life + project and Prof. Dr. Martin Sauter.

The employees of the company Fugro Consult I am indebted to the support and the award of contract.

Brigitta Jamnik, Mitja Janza, Petra Meglic and Marko Prapertnik: I thank you for the collegial cooperation within the project.

Heiko Uhlmann and Steffen Fischer, our departement technicans, have drilled the most of my needed wells. It was a pleasure to work with you.

Alexander Wolf was on hand with help and advice for me in programming questions. Thank you very much!

Many integrated warnings and security settings within ModBack would not be so resourceful and comprehensively without "my students" of my numerously supervised ArcGIS courses.

Dr. Rui Hu. You were the best. With help and advice, you were always by my side. It was stantly rely on you - since 10 years. You're more than just my colleague. You are my friend.

Special thank to Frieder Maier, Olav Hillebrand and Phillip Oberdorfer. The "KOPF- Zimmer" is unbeatable.

There were always valuable discussions during the coffee and lunch breaks with all the colleagues of the department. THANK YOU!

Everything is nothing without love and backing. ... My family ... my boyfriend... and best friends... What should I have done without you? ... 


\section{Abstract}

Contaminated groundwater poses a serious threat to drinking water resources all over the world. Even though contaminated water might be detected in observation wells, a proper clean-up is often only successful if the source of the contamination is detected and subsequently removed, contained or remediated. However, it is possible to significantly reduce the high costs of groundwater remediation when a focus is placed on source zone detection from the outset of a clean-up project.

ModBack is a software that combines several existing modelling tools into one easy to use ESRI ArcGIS 10-based interface, helping to delineate potential contaminant source zones in the subsurface. This software is written in Visual Basic 3.5 and uses the ArcObjects library to implement all required GIS applications. It can run without modification on any Microsoft Windows based PC with sufficient RAM and at least Microsoft .NET Framework 3.5. Using ModBack requires additional installation of the following software: Processing Modflow Pro 7.0, ModPath, CSTREAM (Bayer-Raich et al., 2003a, Bayer-Raich et al., 2003b, Bayer-Raich et al., 2004), Golden Software Surfer, Microsoft Excel and NAS (a natural attenuation software).

The graphical user interface (GUI) of ModBack is separated into four blocks of procedures dealing with data input, groundwater modelling, particle backtracking and analyses. Geographical data input is needed for a geographical overview of the test site. The input includes all georeferenced information pertaining to the study site information on subsurface contamination is gathered either by conventional sampling from monitoring wells or by conducting integral pumping tests at control planes with a specific sampling scheme. Hydraulic data from these pumping tests together, with all other available information, are then used to set up a groundwater flow model of the study site, which provides the flow field. This will then provide a flow field for transport simulations within the subsequent contamination backtracking procedures, starting from the defined control planes. The backtracking results are then analysed within ModBack. The potential areas of contamination source presence or absence are determined based on the procedure used by Jarsjö et al. (2005). The contaminant plume length can be estimated using plume length statistics, first order rate degradation equations, or calculations based on site specific hydraulic and chemical parameters. Furthermore, an analytical tool is included to identify the distribution of contaminants across a 
control plane. All relevant output can be graphically displayed and saved as vector data to be later used in GIS- Software. ModBack has been used to delimit the zones of source presence or absence at several test sites in Slovenia and Southern Germany. The delineations at the test site in Southern Germany are comparable to previous local investigations and supported the functionality of ModBack. With ModBack, a tool is now available which already enables environmental consultants, engineers and environmental agencies to delineate possible sources of contamination at the planning stage of site investigation and remediation measures, helping to significantly reduce costs of contaminated site management.

\section{Kurzfassung}

Verunreinigtes Grundwasser stellt eine ernsthafte Bedrohung für die TrinkwasserRessourcen auf der ganzen Welt dar. Verunreinigte Grundwasser können zwar in Brunnen detektiert werden, eine ordnungsgemäße Sanierung ist jedoch häufig nur erfolgreich, wenn die Quelle der Verunreinigung erfasst und entfernt wird. Wenn von Anbeginn eines Sanierungsprojektes ein Schwerpunkt auf die Erkennung und Eingrenzung des Verunreinigungsherdes gelegt wird, kann die Sanierung direkt an dieser Stelle ansetzen und zudem hohe Grundwasser-Sanierungskosten verringert werden.

ModBack ist eine Software, die mehrere bestehende Modellierungs-Werkzeuge in einer, einfach zu verwendenden, ESRI ArcGIS 10-basierten Schnittstelle vereinigt und hilft mögliche Schadstoffquelle Zonen im Untergrund abzugrenzen. Diese Software ist in Visual Basic 3.5 geschrieben und verwendet ArcObjects Bibliotheken, um die erforderlichen GISAnwendungen zu implementieren. Es kann ohne Änderung auf allen Microsoft Windowsbasierten PC's mit ausreichend RAM und mindestens Microsoft. NET Framework 3.5 verwendet werden. Die Nutzung von ModBack erfordert zusätzliche Installation der folgenden Software: ProcessingModflow Pro 7.0 (PMWin), MODPATH, CSTREAM (Bayer-Raich et al, 2003a, Bayer-Raich et al, 2003b, Bayer-Raich et al, 2004), Golden Software Surfer, Microsoft Excel und NAS (eine Software zur Berechnung des natürlichen Schadstoffabbaus).

Die grafische Benutzeroberfläche (GUI) von ModBack ist in vier Verfahrensschritte Dateneingabe, Grundwassermodellierung, Partikel Backtracking und Analysen getrennt. Geographischen Eingangsdaten werden für eine geografische Übersicht des Testfeldes benötigt. Sie be- 
stehen meist aus georeferenzierten Informationen des Testfeldes und Informationen zur unterirdischen Grundwasserverunreinigungen. Grundwasseranalysen werden entweder durch konventionelle Probennahme aus Grundwassermessstellen oder durch die Durchführung integraler Pumpversuche an Kontrolleben mit eine bestimmten Konzentration/Zeit- Serie (CTseries) gesammelt. Aus den Pumpversuchen resultierende hydraulische Daten werden zusammen mit allen anderen verfügbaren Informationen zur Erstellung eines grundlegenden Grundwasserströmungsmodells des Testfeldes verwendet. Nachfolgende Backtracking Verfahren, als auch die Berechnung von advektivem Schadstofftransport beziehen sich auf dieses Strömungsfeld und werden entlang einer zuvor definierten Kontrollebene berechnet. Eine Analyse der Backtracking-Ergebnisse erfolgt innerhalb ModBack. Die potenzielle Quelle von Kontaminationen oder deren Abwesenheit werden basierend auf dem Verfahren nach Jarsjö et al. (2005) bestimmt. Die Länge einer Schadstofffahne kann anhand von Fahnenlängen Statistiken und /oder dem Abbau erster Ordnung Abbau Gleichungen oder Berechnungen auf ortsspezifische hydraulischen und chemischen Parametern beruhen. Ferner ist ein analytisches Instrument enthalten, um die Verteilung der Verunreinigungen über eine Steuerebene zu identifizieren. Alle relevanten Ergebnisse können als Vektordaten in ModBack graphisch dargestellt und gespeichert werden und sind somit kompatibel mit weiteren GISSoftware Produkten. ModBack wurde bereits an Testgebieten in Slowenien und Süddeutschland angewendet, um die möglichen Zonen der Verunreinigungsquelle oder deren Abwesenheit zu begrenzen. Auf dem Testgelände in Süd-Deutschland sind diese Abgrenzungen vergleichbar mit früheren Untersuchungen vor Ort und unterstützt somit die Funktionalität der Software ModBack. Mit ModBack, steht ein Werkzeug zur Verfügung, die bereits jetzt Umwelt-Beratern, Ingenieuren und Umwelt-Agenturen ermöglicht denkbare Quellen der Verunreinigung bei der Planung der Untersuchungen vor Ort und Sanierungsmaßnahmen abzugrenzen, und hilft Kosten deutlich zu senken. 


\section{Table of Contents}

Acknowledgements III

Abstract IV

Kurzfassung V V

List of Figures and Tables

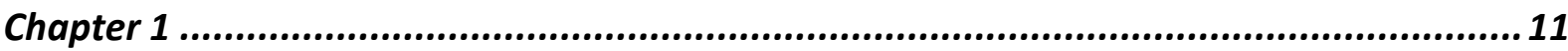

$\begin{array}{ll}\text { Introduction } & 11\end{array}$

1.1 Motivation $\quad 12$

1.2 Aims and Objectives 13

$\begin{array}{ll}1.3 \text { Structure } & 13\end{array}$

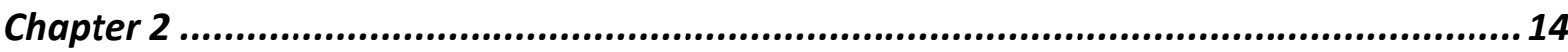

$\begin{array}{ll}\text { Literature Background } & 14\end{array}$

$\begin{array}{ll}2.1 \text { Mass Flux } & 17\end{array}$

2.2 Plume length estimations 28

2.3 Contaminant source zone characterisation $\quad 34$

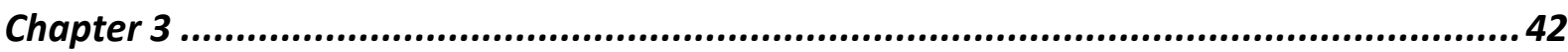

ModBack Development $\quad 42$

3.1 About ModBack $\quad 42$

3.2 System Requirements 43

3.3 Development 44

3.3.1 Libraries and Controls $\quad 46$

3.3.2 Advanced Tools 50

3.3.2.1 Integrated Features $\quad 51$

3.3.2.2 Innovative Features $\quad 55$

3.3.3 Supplement 65

3.4 Structure 66

3.4.1 Graphical User Interface (GUI) 67

3.4.1.1 Table of Contents 68

3.4.1.2 Data Frame $\quad 69$

3.4.1.3 Toolbar 69

3.4.1.4 Main Menu $\quad 71$

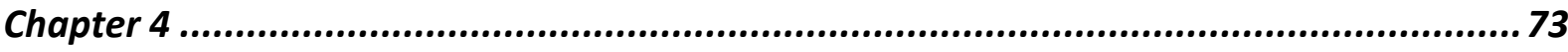

$\begin{array}{ll}\text { ModBack Application } & 73\end{array}$

$\begin{array}{ll}4.1 \text { Case Study } & 73\end{array}$

$\begin{array}{ll}\text { 4.1.1 Geographical Data Input } & 74\end{array}$

4.1.2 Groundwater Modelling $\quad 75$

$\begin{array}{ll}\text { 4.1.3 Backtracking } & 77\end{array}$

4.1.4 Result illustration $\quad 77$

4.2 Comparative View $\quad 82$

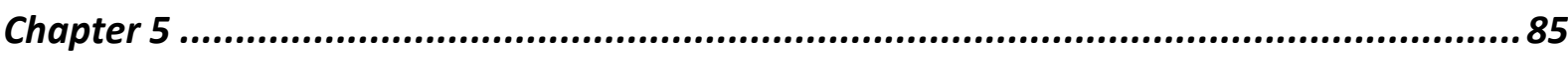

Discussion and Outlook $\quad 85$

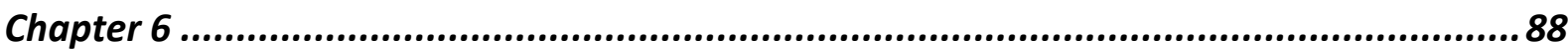

$\begin{array}{ll}\text { References } & 88\end{array}$ 


\section{List of Figures and Tables}

Fig. 2-1: Physico-chemical processes of mass transport in the subsurface can be explained as advective, dispersive and diffusive transport in groundwater, sorption and desorption at aquifer material, based on contaminant solution into the groundwater. (Modified after Weber, 2002).

Fig. 2.1-2: Mass flux for varying hydraulic conductivities under constant conditions. As shown for contaminant concentration and hydraulic gradients for fine sand, gravelly sand and sand. (ITRC, 2010).

18

Fig. 2.1-3: Point scale measurements (black dots) and integral pumping test (IPT) in comparison. (Jarsjö et al., 2005).

Fig. 2.1-4: Determination of total pollutant loads (Fracht) by monitoring $\mathrm{C}(\mathrm{t})$ across multiple levels (Messposition) $\left(z_{j}, z_{j+1}\right)$ of control plane (Kontrollquerschnitt). The pumping rate $(Q)$, specific contaminant concentration $\left(\mathrm{c}_{\mathrm{i}}\right)$, a related pumping time $(\mathrm{T})$ in different multilevel monitoring wells (Brunnen). (Herford et al., 2000, in: Ptak et al., 2004). 22

Fig. 2.1-5: Principle of integral approach by capturing the total groundwater discharge using one or multiple pumping wells downgradient from a possible source zone at defined control planes to define the total mass discharge. The contaminant concentrations are given as a function of time in the discharge of the wells during pumping (CT-series). (Bockelmann et al., 2003).

Fig. 2.1-6: Basic principle of integral pumping tests. (Ptak and Teutsch, 2000). 23

Fig. 2.1-7: Technical drawing of a multilevel Sampler with different packers and membranes. (Ronen et al. 1987).

26

Fig. 2.2-1: Transport of different contaminants (LNAPLs and DNAPLs) in groundwater, according to transport processes in the aquifer. (Schüth, 1994). 28

Fig. 2.2-2: Contaminant movement geometries in $\mathrm{x}_{-}, \mathrm{y}_{-}, \mathrm{z}-$ direction. (Domenico and Robbins, 1986).

29

Fig. 2.2-3: Temporal behaviour of a contaminant plume (2D view). (Teutsch and Rügner, 1999).

30

Fig. 2.2-4: Binary reaction between the electron donor and an electron acceptor in a homogenous aquifer. (Liedl et al., 2005).

Fig. 2.3-1: Theoretical model of possible source zones of a contaminant plume. (Mirghani et al., 2009).

Fig. 2.3-2: Identification of contamination source with electrical resistance tomography. (Aghasi et al., 2012).

Fig. 2.3-3: Transverse Hydrodynamic Dispersion Effects on Isotope Signals in Plumes (Breukelen and Rolle, 2012).

Fig. 2.3-4: Delineation of source zone and source zone absence, after Jarsjö et al. (2005). With (a) particle tracking streamlines, (b) for inert compounds, (c) for reactive compounds, with: LMin as minimum plume length, LMax as maximum plume length. (Jarsjö et al., 2005).

Fig. 3.1-1: Flow chart of ModBack with explanation on right side from i-iv: Input data, Groundwater model, Backtracking model and result illustration.

Fig. 3.3-1: ArcGIS structure of the individual products (i-iv), the red box indicates the used products. (Modified after Cameron et al., 2004a). 
Fig. 3.3.1-1: Structure tree of $\operatorname{ArcGIS}^{\circledR}$ Desktop Developer Kit main libraries, used are highlighted in colour, unused are shaded in grey, speech bubbles comprise the purpose of libraries. (Modified after Cameron et al., 2004a).

Fig. 3.3.1-2: Specification tree of $\operatorname{ArcGIS}^{\circledR}$ Desktop Developer Kit UI Libraries, used are highlighted in colour, unused are shaded in grey, speech bubbles contain the function of libraries. (Modified after Cameron et al., 2004b).

Fig. 3.3.2.1-2: Screenshot of PMPath GUI. (Wen-Hsing Chiang, 2005). 52

Fig. 3.3.2.1-3: GUI of the analytical backtracking tool. (Rothschink, 2007). 53

Fig. 3.3.2.2-1: Flow chart of advanced tools and results within ModBack. Legend is in the opposite site.

Fig. 3.3.2.2-2: Input window Add .dxf files.

Fig. 3.3.2.2-3: Input mask of the Convert Table function. 57

Fig. 3.3.2.2-4: Add x/y Data... functions.

Fig. 3.3.2.2-5: Mask of function Points to Line. 58

Fig. 3.3.2.2-6: GUI screenshot of advanced tool Calculate plume length, according to Liedl et al. (2005).

Fig. 3.3.2.2-7: $1^{\text {st }}$ order decay analytical function with parameter input fields. The composition formula and pollution distribution are given on the right site of the form. $\quad 60$

Fig. 3.3.2.2-8: Cut Pathlines command as input window. $\quad 61$

Fig. 3.3.2.2-9: Create Polygon. $\quad 61$

Fig. 3.3.2.2-10: Advanced tool Delimit Source Zone. $\quad 62$

Fig. 3.3.2.2-11: Function of angle calculation in advanced tool Delimit Source Zone. $\quad 62$

Fig. 3.3.2.2-12: Input Mask Save as Shapefile 63

Fig. 3.3.2.2-13: Input Mask Select Symbology... 63

Fig. 3.4.1-1: ModBack - Graphical User Interface (main menu and toolbar in the the upper orange box, the Data Frame at the right-hand side (blue box), the TOC at the left-hand side (lilac box), coordinates in the lower left corner, green arrow ). (Modified after Thomas-Thielsch et al., 2012).

Fig. 3.4.1.1-1: TOC Toolbar Menu. 68

Fig. 3.4.1.3-1: Toolbar. The red arrows indicate the affiliation of the individual tools, grouped in $\mathrm{i}$, ii, iii and iv.

Fig. 3.4.1.3-2: Editor and descriptions in different colours for each theme. 71

Fig. 3.4.1.4-1: Main Menu structure 71

Fig. 3.4.1.4-2: Menu File, highlighted here is the Add Data... function with Add Pathlines header.

Fig. 3.4.1.4-3: Main Menu of Hydrogeological Model with submenus a) Control Plane and b) Numerical Model

Fig. 4.1.1-1: Geographical overview of the test site in Southern part of Germany within ModBack. The monitoring wells are coloured in orange, the cross-sections (controlplanes) are highlighted in red and the topographical base map is drawn in grey. The labelling of CP differs from Herold et al. (2009).

Table 4.1.2-1: Pumping information. (Modified after Herold et al. 2009). 75

Fig. 4.1.2-1: Position of control planes at the test site, and boundary conditions of the original numerical flow and transport model. (Herold et al,. 2009).

Fig. 4.1.2-2: Boundary conditions of the two extreme models of the test site in a) left hand site extreme model, b) right hand site extreme model, with: red lines as constant head boundaries, blue lines as recharge boundary, thick green line as river and grey lines as model mesh. 
Fig. 4.1.4-1: Calculated contaminant transport in ModBack from both extreme models, with: B86 pathlines in green lines, B98 pathlines ins purple lines, B99 pathlines in blue lines and B101 pathlines in brown lines, wells as orange points, cross-sections as red lines, and topography as grey lines.

78

Fig. 4.1.4-2: Delineation of $\Sigma \mathrm{CHCs}$ source zone presence and absence, with: source zone presence as the red area and source zone absence as the green area for a) well B86, b) well B98, c) well B99 and d) well B101.

Fig. 4.1.4-3: Delineation of Benzene source zone presence and absence. With: Source zone presence as red area, source zone absence as green area for a) well B86, b) well B98, c) well B99, d) well B101.

Fig. 4.1.4-4: Amount of source zone presence (red) and absence (green) for $\Sigma$ CHCs (a) and Benzene (b). 81

Fig. 4.2-1: Assessment of (a) Benzene and (b) $\Sigma \mathrm{CHCs}$ source zone presences and source zone absences in South Germany with altering concentration limits. (Jarsjö et al., 2005). 82

Fig. 4.2-2: Direct comparison of the source zone absences between (a) after Jarjsö et al. (2005) and (b) within ModBack show equivalent dimensions.

Fig. 4.2-3: Direct comparison of the source zone presences between (a) after Jarjsö et al. (2005) and (b) ModBack show equivalent dimensions.

Table 2.1-1: Mass flux rate equations. (Kübert and Finkel, 2006).

Table 2.2-1: Statistical approach of plume length estimations after Schiedeck et al. (1997) for five groups of organic substances: CHCs, Phenol, BTEX, Benzene and others.

Table 3.3.1-1: Integrated ArcObjects Libraries separated main libraries, UI libraries and "finegrained" libraries according to ArcGIS ${ }^{\circledR}$ Desktop and ArcGIS ${ }^{\circledR}$ Engine Developer Kit. $\quad 46$

Table 4.1.3.1-1: Contaminant mass flux at control plane CP2 neu. (Modified after Herold et al., 2009). 


\section{Chapter 1}

\section{Introduction}

Over the past two decades numerous scientific studies have dealt with the remediation of contaminated sites. Any contamination in groundwater poses a serious threat to drinking water resources. Water resources, even though contaminated water, might be detected and subsequently removed, contained or remediated. Despite some remedial measures, it is possible that drinking water may still be contaminated with pollutants (Kolb, 2004). As a result of this possibility, groundwater remediation is demonstrated to be necessary. A proper clean-up is often only successful if the source of the contamination is known. However, if a contamination was detected, it is not always guaranteed that the origin will be determined. Having unknown sources of groundwater pollution can cause high costs of remediation and can result in permanent environmental problems/effects. If a focus is placed on source zone detection during the initial planning of remediation, many of these problems can be averted. Regarding the development of various strategies to locate the contaminants and the determination of their origin, different approaches, divisible into practical and computational applications, have been accomplished. The practical application has a particular use for various field methods, such as conducting exploration drillings, point scale measurements and Integral Pumping tests (IPTs) for the analysis of limitation and spreading of pollutants. The transport and mass flow can be estimated with IPTs (e.g. Yare, 1975, Bear and Sun, 1998, Ptak et al., 2000, Peter et al., 2004, Bauer et al., 2004, Jarsjö et al., 2002, 2005, Weiß et al., 2004, Herold et al., 2009, Leschink, 2010, Alberti, 2011, Luciano et al., 2012) and more recently, in subsurface investigations, tomographic studies, isotopic analyses are used (e.g. Aghasi et al., 2012, Seferou et al., 2012, Breukelen and Rolle, 2012). For the computational application approach, the determination of the real plume lengths are considered and limited by Schiedeck et al. (1997), Rügner et al. (2001), Ham et al. (2004), Cirpka et al. (2006), Liedl et al. (2005), Liedl et al. (2011) and Yadaf et al. (2013). The numerical groundwater modelling is the basement for analytical analyses. An inverse modelling approach as well as backtracking procedures (e.g. Neupauer et al., 2000, Neupauer et al., 2007 and Mahar and Datta, 1997) completes the investigations. Even the usage of Geographical Information Systems (GIS) is used to limit the source zone (e.g. Facchinelli et al., 2001, Flügel and Michl, 
2005, Anderson et al., 2011, Hossein et al., 2013).

This thesis mainly deals with the state of the art backtracking investigations and the development of the coded computer software ModBack. ModBack combines several existing modelling tools into one easy to use GIS-based interface, helping to delineate potential contaminant source zones in the subsurface under consideration of previous approaches, mainly done by Jarsjö et al. (2005).

\subsection{Motivation}

Groundwater remediation is often performed by resident consultants or engineering companies. In most cases, their timing and financial framework is usually controlled by municipal authority or government contracting. Within European countries, guidelines and regulations have prescribed pollution threshold values and their accompanying or associated remediation measures. Especially in the eastern states of the The European Union (EU) in times of socialism, the prevalent protection policies and associated guidelines for groundwater differed from current conditions. Since the political change in EU an economic change has occurred. Examples were potential variations in industrial sites, extensive applications or illegal discharges. Finding the sources is often proved to be difficult, because of a lack of knowledge in terms of the groundwater flow regime and the subsurface conditions. To analyse the degree of contamination in groundwater as well as the limitation of contaminant source locations, a variety of scientific approaches are used. Currently, the contamination source zone and / or the source zone absence can be determined by analysis of Integral Pumping tests (IPTs, e.g. Teutsch et al., 2000, Ptak et al., 2000), inverse numerical groundwater and transport modelling with PMPath, backtracking approaches such as CSTREAM (Bayer-Raich et al., 2003a, Bayer-Raich et al., 2003b, Bayer-Raich et al., 2004) or by using simple analytical approaches. An integrated consideration of the whole scope is rather the exception, but firstly done by Jarsjö et al. (2005).

The European Union supports environmental and natural projects in Slovenia, with the aim to delimit unknown contamination sources. The projects connected seven conservation projects, like the INCOME EU Life+ project, an Improved management of contaminated aquifers by integration of source tracking, monitoring tools and decision strategies in research groups from government agencies, universities and the private sector with six different scopes and 33 various procedures for discovering and supervising sources of pollution and measures for 
improving the groundwater condition. The University of Göttingen was acting as a subcontractor to FUGRO Consult Company (formerly geo-log GmbH, Braunschweig, Germany). This thesis is part of the direct push methods arrangement and the backtracking approach.

\subsection{Aims and Objectives}

Previously, the investigations of source zone presences and source zone absences were evaluated by hand and it was not possible to combine interactive analytical and numerical investigations as well as the automatic result illustration.

This thesis comprises of a backtracking approach for the delineation of unknown contamination sources in saturated aquifers, including a comprehensive literature review of preceding research and current opportunities in contaminant source zone delimitation. A GIS-based and user friendly interface is developed for environmental consultants, engineers and environmental agencies and universities, to delineate the source zone presences and source zone absences in saturated, porous aquifers usable already at the planning stage of site investigation and remediation measures. Similar to the investigation of Jarsjö et al. (2005), the limitation of the groundwater pollution sources may be detected by characterisation of pollutant concentration distribution in the aquifer and obtained by the combination of anaIytical and numerical approaches. Existing procedures using mass flux, IPT (e.g. Teutsch et al., 2000, Ptak et al., 2000), numerical groundwater and transport modelling as well as the backtracking modelling with CSTREAM are integrated. Additional tools allow interactive analysis and a concluding graphical statement. .

\subsection{Structure}

This dissertation is written as a monograph in six chapters.

The introduction, motivation, aims and objective is given in chapter 1.

The theoretical background in chapter 2 provides with respect to the approaches of the contaminant transport in relation to different pollution sources in groundwater.

The development of ModBack is given in chapter 3. Aspects of programming as well as the outline of the Graphical User Interface (GUI) are established.

Chapter 4 deals with ModBack implementation process, applied to KORA project.

A summarised discussion is given in chapter 5 .

The references are listed in chapter 6 . 


\section{Chapter 2}

\section{Literature Background}

In the case of groundwater contamination, the remediation of the pollution is indispensable. Upon close examination of the subsurface and the aquifer, as well as the estimation of the mass flow and mass flux, it is fundamental to limit the pollutant transport and the source zone or its absence.

Understanding of contaminant transport is based on the knowledge of the transport conditions. According to the transport medium, the conditions depend on various physicochemical processes. In saturated, porous aquifers, contaminant transport takes place mostly by (i) advective, (ii) dispersive and (iii) diffusive processes. The dissolution and sorption within the aquifer material are decisive as well. A simplified schematic representation of different transport mechanisms for BTEX in saturated, unsaturated and subsurface zones is shown below in Fig. 2-1.

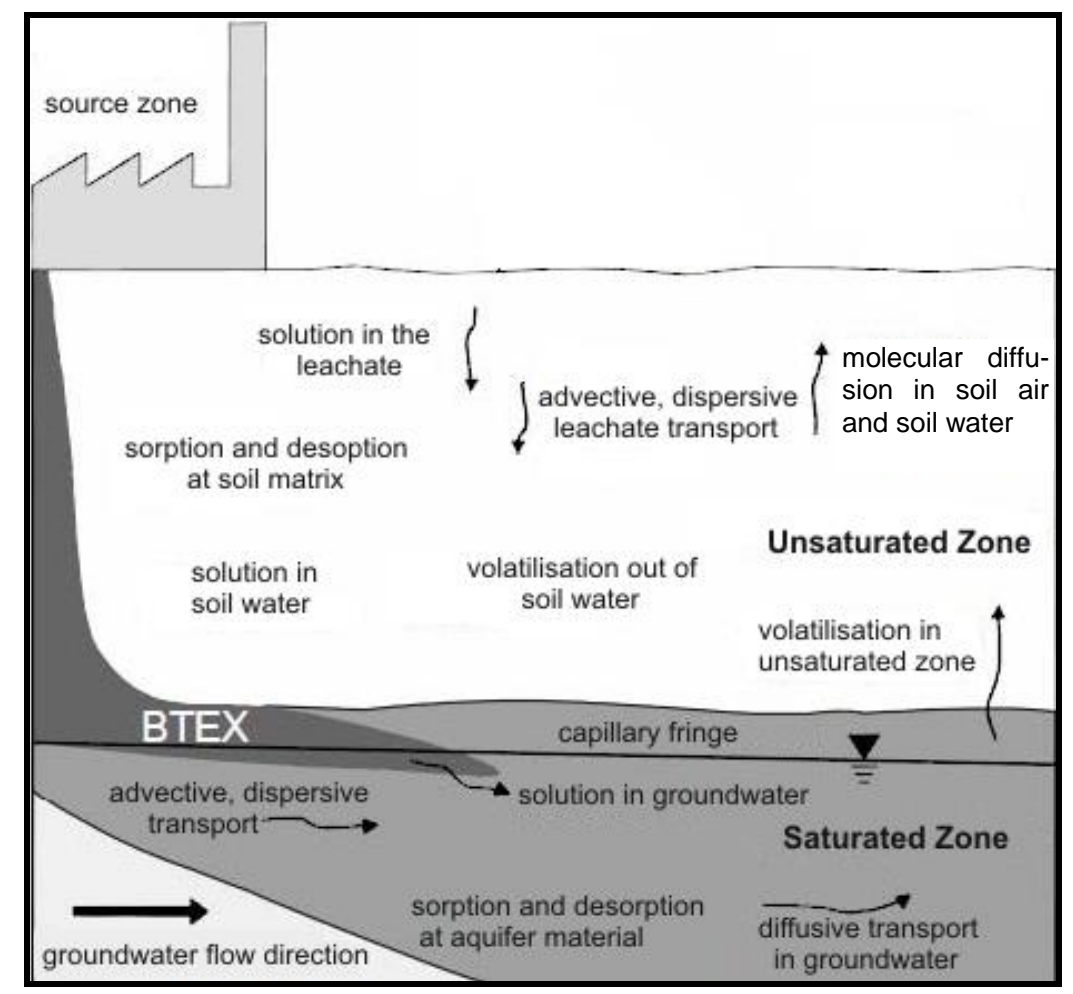

Fig. 2-1: Physico-chemical processes of mass transport in the subsurface can be explained as advective, dispersive and diffusive transport in groundwater, sorption and desorption at aquifer material, based on contaminant solution into the groundwater. (Modified after Weber, 2002). 
The empirical specification of advection, dispersion and diffusion in groundwater is given in basic terms by Fick (1855), Bertsch (1978), Fetter (1999), Weber (2002) and Mohrlock (2009). It is described and schematically shown below in Fig. 2-2 a-c.

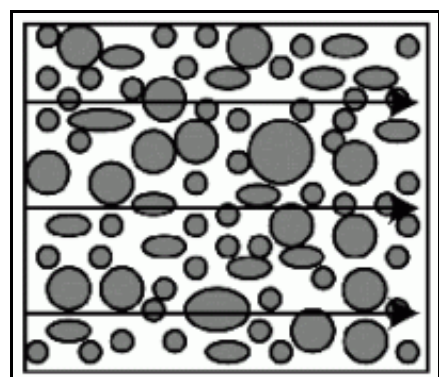

a)

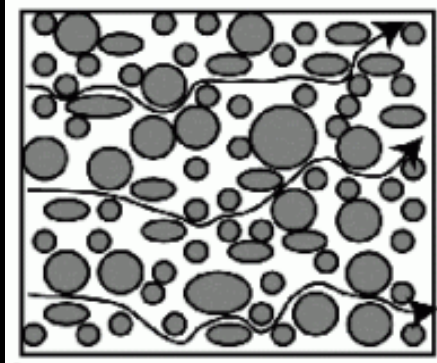

b)

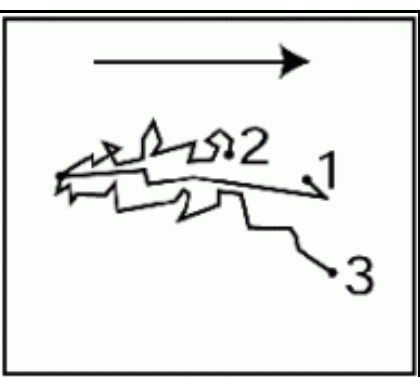

c)

Fig. 2-2: Transport process in porous aquifers for (a) laminar advective transport, (b) turbulent dispersive transport and (c) diffusive transport. (König, 1996).

After Fetter (1999) and Weber (2002) advection (i) (Fig. 2-2 a) is the laminar translocation of substances in a flow system, inducted by pore water velocity, effective porosity and contaminant concentration (Eq. 2-1). This balance includes gravimetric leachate transport and groundwater flow due to potential and mass. Convection is often used as a synonym and additionally involves heat controlled fluid movements (Hölting, 1996).

$$
F=v * n_{e} * C
$$

With: $F$ as mass flux per unit area and time $\left[M L^{-2} T^{-1}\right], v$ as average pore water velocity in $\left[L T^{1}\right], n_{e}$ as effective porosity [-], C concentration $\left[\mathrm{M} \mathrm{L}^{-3}\right]$.

Applied to the 1D temporal change of concentration due to advection, the formula is slightly modified (Eq. 2-2) after Fetter (1999), in:

$$
\frac{\partial C}{\partial t}=-v * \frac{\partial C}{\partial x}
$$

With: $\partial x$ as horizontal distance in $[L]$ and $\partial t$ as time in [T].

Dispersion (ii) (Fig. 2-2 b) is a turbulent transport of substances in flowing fluids (advection) (Bear, 1972). The mechanical mixing of components, resulting from the difference in flow velocity, pore size distribution, path length and direction, is known as (hydro)mechanical dispersion. The flow rate depends on the pore geometry. The dispersive mass or energy flux is described in the following equations Eq. 2-3 and Eq. 2-4 by Bertsch (1978), according to the diffusion and Fick's $1^{\text {st }}$ law:

$$
J=-D_{l} * \frac{\partial C}{\partial z}
$$


and:

$$
D_{l}=\alpha_{L} * v
$$

With: $D_{l}$ as longitudinal, mechanical dispersion-coeffient in $\left[L^{2} T^{-1}\right]$, and $\alpha_{L}$ as dynamic, longitudinal dispersivity in [L].

Molecular diffusion (iii) (Fig. 2-2 c) is a process that is independent from the groundwater movement (König, 1996). It is based on the thermal properties of molecular motion, the Brownian motion, and leads to a concentration equilibrium. Fick (1855) described the diffusion for steady (Eq. 2-5) and unsteady (Eq. 2-6) conditions. The one-dimensional (1D) diffusion $\left[\mathrm{ML}^{-2} \mathrm{~T}^{-1}\right]$ is proportional to the concentration gradient opposite to the diffusion direction $\left(\partial C / \partial z,\left[\mathrm{ML}^{-4}\right]\right)$. The constant of proportionality is the diffusion coefficient $\left(D_{w},\left[\mathrm{~L}^{2} \mathrm{~T}^{-1}\right]\right)$.

$$
J=-D_{w} * \frac{\partial C}{\partial z}
$$

Under non-steady conditions, the formula contains a changing time factor and is transformed with respect to the conservation of mass in:

$$
\frac{\partial C}{\partial t}=D \frac{\partial^{2} C}{\partial x^{2}}
$$

With: $\partial^{2} \mathrm{C} / \partial x^{2}$ as proportional concentration gradient in $\left[\mathrm{ML}^{-4}\right], \partial t$ as time in $[T]$.

Related to the contaminant transport for non-reactive dissolved contaminants, the advection-dispersion equation (ADE, Eq. 2-7) was developed by Bear (1979) and Domenico and Schwartz (1998), based on the individual transport processes and under the conservation of mass (Bear, 1979, Domenico and Schwartz, 1998, Bear and Cheng, 2010, Konikow, 2011). It can be regarded as a standard formula in contaminant modelling.

$$
\frac{\partial(\varepsilon C)}{\partial t}=\frac{\partial}{\partial x_{i}}\left(\varepsilon D_{i j} \frac{\partial C}{\partial x_{j}}\right)-\frac{\partial}{\partial x_{i}}\left(\varepsilon C V_{i}\right)-C^{\prime} W^{*}
$$

With: $C$ as concentration $\left[M L^{-3}\right], D_{i j}$ as coefficient of hydrodynamic dispersion $\left[L^{2} T^{-1}\right], C^{\prime}$ as solute concentration in the source or sink fluid $\left[\mathrm{M} \mathrm{L}^{-3}\right], V_{i}$ as average linear velocity $\left[\mathrm{L} \mathrm{T}^{-1}\right], t$ as time $[\mathrm{T}], \mathrm{W}^{*}$ as volumetric flux per unit volume $\left[T^{-1}\right]$ and $x_{i}$ as Cartesian coordinates $[L]$.

Using the ADE is helpful, but insufficient for the delimitation of the contamination source zones. For the most part, more analytical and/or numerical estimations are needed to get trustworthy results in pollutant source zones. The next three sections include a selection of previous studies dealing with contaminated aquifers in respect to mass transport, contaminant plumes and source zone definition. These studies represent the latest advanced research and illustrate the applicability of a simplified, integrated approach. 


\subsection{Mass Flux}

Estimations of mass flux and mass discharge are fundamental in determining the contaminant transport, the considerations and handling of contaminant plumes, for estimations of natural attenuation and for further approaches to delimit the possible source zones with transport models and transport phenomena in general (e.g. Hemond and Fechner-Levy, 2000, Gnanapragasam et al., 2000, Newell et al., 2003, Bockelmann et al., 2003, Bauer et al., 2004, Soga et al., 2004, Jarsjö et al., 2005, Kübert and Finkel, 2006, Bird, 2007, Schwede and Cirpka, 2010, Dietze and Dietrich, 2011, Jarsjö et al., 2011). The analyses of contaminant mass flux / mass discharge in groundwater constitute the priority of test site options (Rao et al., 2002).

The field based measurement of the mass flux and mass discharge can generally be separated into three techniques: (i) transect method, (ii) integral method and (iii) passive method. The transect method (i) is a method to quantify the mass flux and mass discharge estimations based on point scale measurements at multi-level wells along control planes, orthogonal to the direction of groundwater flow. Mass flux estimations supplemented point scale measurements in a wide network of monitoring wells during periodically sampling of groundwater across a control plane (Fig. 2.1-1), according to Buscheck and Alcantar (1995), Zhou (1996), Puls and Paul (1997), King et al. (1999), Einarson et al. (2000), Bockelmann et al. (2003) and Bauer et al. (2004).

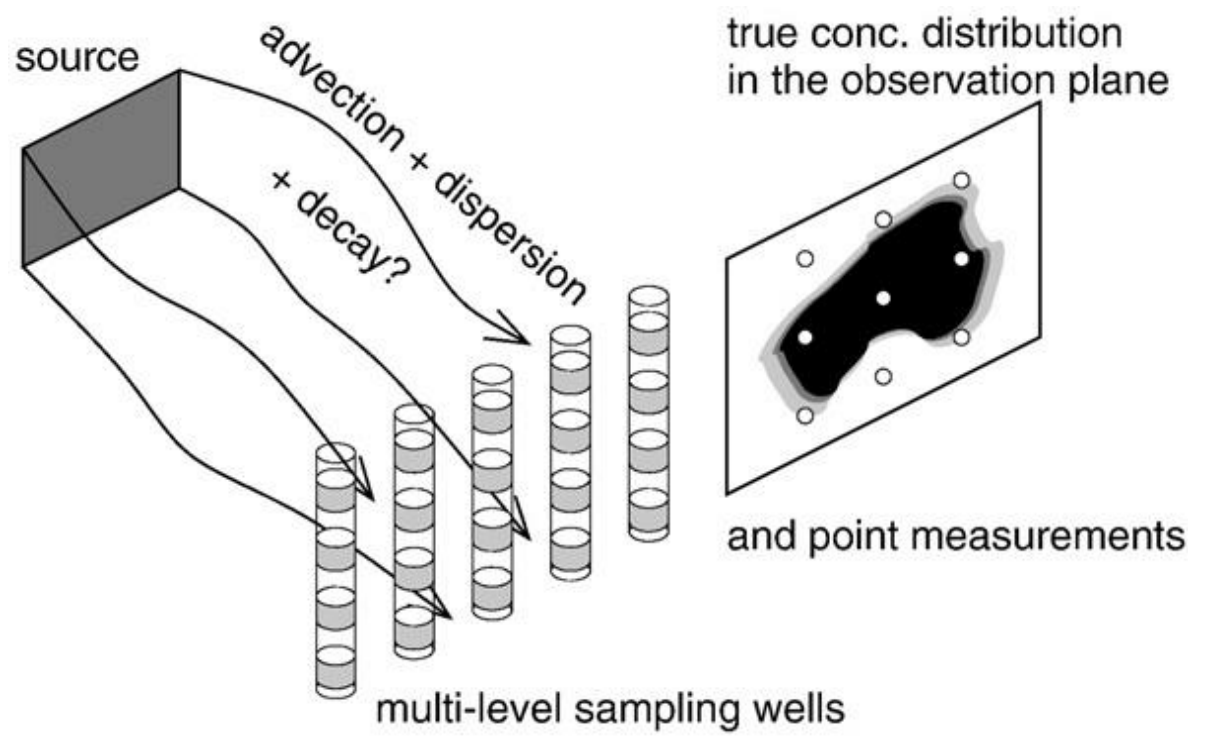

Fig. 2.1-1: General overview of mass transport from a source to multilevel monitoring wells, under the influence of transport and decay processes. (Schwede and Cirpka 2010). 
Kao and Wang (2009) and Bockelmann et al. (2003) handled the mass discharge as an overpass of the sampling plane, evaluated by assuming constant fluxes. The mass discharge, entering the capture zone of the pumping wells under steady-state conditions, is equal to the product of the pumping rate and pumping well effluent concentration (Holder et al., 1998, Einarson and Mackay, 2001, Bockelmann et al., 2003). The approximations included the advection and dispersion decay.

Mass flux and mass discharge evaluations at a test site offer a complete understanding of the subsurface conditions when connected to a conceptual, geological test site model. In heterogeneous aquifer systems the contaminant mass distribution as well as the mass flux is irregular. This is due to the spatial distribution of hydraulic and transport parameters, based on the spatial irregularity and temporal release of contaminants (Ptak et al., 2004), as shown in Fig. 2.1-2. Varying groundwater velocities result in varying mass fluxes: The more conductive the aquifer material, the higher the mass flux.

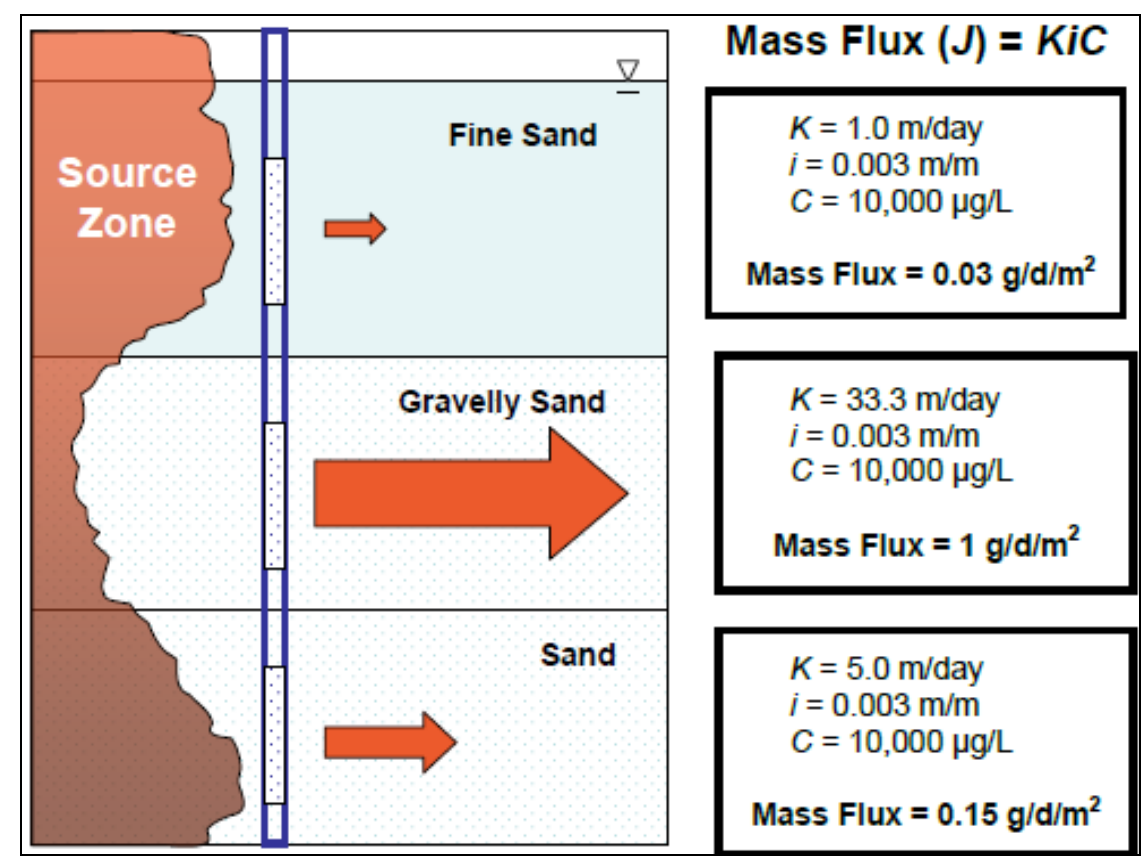

Fig. 2.1-2: Mass flux for varying hydraulic conductivities under constant conditions. As shown for contaminant concentration and hydraulic gradients for fine sand, gravelly sand and sand. (ITRC, 2010).

When generalised, the total contaminant mass flux in groundwater can be described as product of the contaminant concentration and groundwater flow, Eq. 2.1-1:

$$
J=q_{0} * C=-K * i * C
$$

With: $J$ as mass flux $\left[\mathrm{M} \mathrm{T}^{-1} \mathrm{~L}^{-2}\right], C$ as contaminant concentration $\left[M L^{-3}\right], q_{0}$ as groundwater flux, $\left[L^{3} L^{-2} T^{-1}\right], i$ as hydraulic gradient [-], K as saturated hydraulic conductivity [LT $]$. (ITRC, 2010). 
The quantification of mass flux rates has been of major importance and was developed stochastically over the years. The following list (Tab. 2.1-1) shows the levels of development and their respective authors. It is a comprehensive list of the equation for the product of contaminant concentration and groundwater flow rate, given in Eq. 2.1-2 as follows after Kübert and Finkel (2006):

$$
W=C * Q=C * q * A=F * A=C * K * i * A
$$

With: W as mass discharge $\left[M T^{-1}\right], C$ as concentration $\left[M L^{-3}\right], Q$ as groundwater volume flow rate $\left[L^{3} T^{1}\right], q$ as specific discharge $\left[L T^{-1}\right], F$ as mass flux $\left[M L^{-2} T^{-1}\right], K$ as hydraulic conductivity $\left[L T^{-1}\right], i$ as hydraulic gradient $[-]$ and $A$ as source area (cross-sectional) $\left[L^{2}\right]$. (Kübert and Finkel, 2006).

Table 2.1-1: Mass flux rate equations. (Kübert and Finkel, 2006).

$$
\begin{aligned}
& W_{\mathrm{cp}}=\sum_{n=1}^{n_{\text {well }}}\left(\sum_{m=1}^{n_{\text {ver }}}\left(F_{n, m} \cdot A_{n, m}\right)\right) \\
& W_{\mathrm{cp}}=\sum_{n=1}^{n_{\text {well }}}\left(\sum_{m=1}^{n_{\text {ver }}}\left(C_{n, m} \cdot q_{n, m} \cdot A_{n, m}\right)\right) \\
& W_{\mathrm{cp}}=i_{\mathrm{cp}} \cdot \sum_{n=1}^{n_{\text {well }}}\left(\sum_{m=1}^{n_{\text {ver }}}\left(C_{n, m} \cdot K_{n, m} \cdot A_{n, m}\right)\right) \\
& W_{\mathrm{cp}}=\sum_{n=1}^{n_{\text {well }}}\left(i_{n} \cdot \sum_{m=1}^{n_{\text {ver }}}\left(C_{n, m} \cdot K_{n, m} \cdot A_{n, m}\right)\right) \\
& W_{\mathrm{cp}}=i_{\mathrm{cp}} \cdot \sum_{n=1}^{n_{\text {well }}}\left(C_{n} \cdot K_{n} \cdot A_{n}\right) \\
& W_{\mathrm{cp}}=\sum_{n=1}^{n_{\text {well }}}\left(i_{n} \cdot C_{n} \cdot K_{n} \cdot A_{n}\right)
\end{aligned}
$$

References

Hatfield et al. $(2002,2004)$

$$
\text { Ballard (1996) }
$$

Béland-Pelletier et al. (2004)

Newell et al. (2003)

Bockelmann et al. (2003)—modified

Bockelmann et al. (2003)

Borden et al. (1997), King et al. (1999), Kao and Wang (2001)

Mass discharge is defined as the total mass of a solute, released to the groundwater from a given source. It is interconnected with mass flux, but not limited to a defined area. Mass discharge is calculated by merging the Darcy velocity of groundwater with concentration data. By integrating the dissolved concentration, the total contaminant mass in the plume at any time can be calculated with the following equation (Eq. 2.1-3, Falta et al. 2005a, 2005b):

$$
M_{\text {dissolved }}(t)=A \varnothing \mathrm{C}_{0}(1-X) e^{-\beta t} \int_{0}^{v t / R} e^{\frac{x}{v}\left(\beta R-\lambda_{p}\right)} d x
$$

With: $M_{\text {dissolved }}$ as total mass [M], $C_{0}$ as solute concentration $\left[\mathrm{ML}^{-3}\right], \emptyset$ as porosity [-], $x$ as Cartesian coordinate [L], $t$ as time $[T], A$ as source area (cross-sectional) $\left[L^{2}\right]$. 
Konecny and Fürst (2007) facilitated the assumptions by Falta et al. (2005a)and Falta et al. (2005b) in the total mass of a simulated solute plume as an integral function of porosity, solute concentration and Cartesian position (Eq. 2.1-4). Through the integration of Cartesian coordinates, a conclusion can be made about the exact position of the solute plume.

$$
M=\int n(x) C(t, x) d x
$$

With: $M$ as total mass $[M], C(t, x)$ as solute concentration $\left[\mathrm{ML}^{-3}\right], n$ as porosity $[-], y$ and $x$ as Cartesian coordinate [L].

With the help of mass discharge from a known upgradient source and pumping rate at the monitoring well, Einarson and Mackay (2001) and Newell et al. (2003) defined the maximum contaminant concentration in a downgradient monitoring well (Eq. 2.1-5). Individual monitoring points for concentration data and flow data obtained from tracer or aquifer drilling tests were used. This estimation can be helpful for further plume length estimations.

$$
C_{\text {receptor }}=\frac{M_{d}}{Q_{\text {receptor }}}
$$

With: $C_{\text {receptor }}$ as concentration of contaminant in monitoring well $\left[M V^{1}\right], M_{d}$ as the mass discharge from the upgradient source $\left[M T^{-1}\right]$, and $Q_{\text {receptor }}$ as the pumping rate at the receptor $\left[V T^{-1}\right]$.

The transection method can determine a consistent contaminant concentration distribution for plumes with small widths downstream of the contaminant source zone by point-scale measurements. The positioning of the individual wells is dependent on the subsurface and flow conditions. In order to capture the entire margin of the groundwater contamination, a very narrow meshed network would be necessary. The critical number of measuring points is discussed in Hornbruch et al. (2009). For plumes with larger widths, the transection method is rather unsuitable (Bockelmann et al., 2003). From the chemical point of view, the uncertainty of spatial distribution of all electron acceptors and donors causes methodical constraints and subsequent inconsistency in source and flow direction (Wilson et al., 2004). Another problem is the probability that some pollutants are situated between the monitoring wells. It seems reasonable to assume that there is a high probability the contaminant will remain undetected. (Rivett et al., 2001, Rivett and Allen-King, 2003, see Fig. 2.1-3). Another method limitation could be an inaccuracy in groundwater sample analysis (Crumbling et al., 2001). 


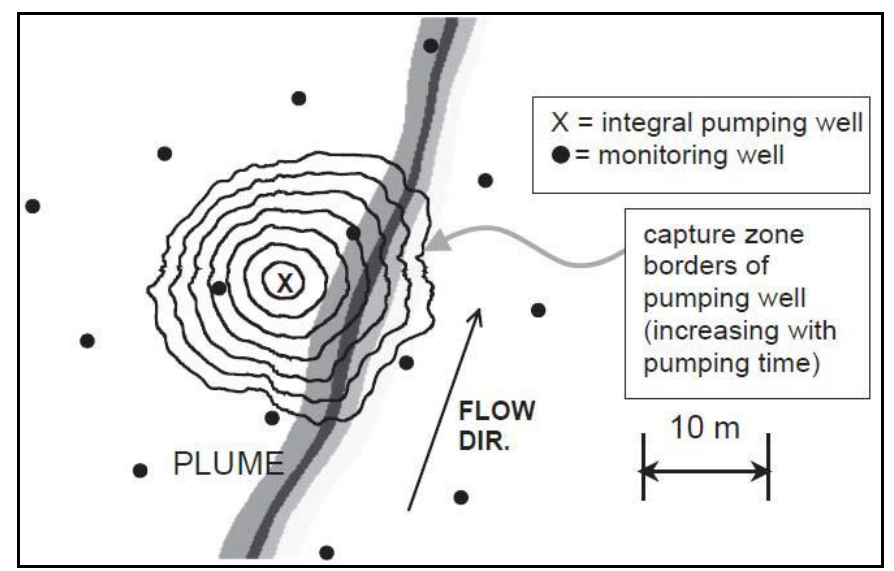

Fig. 2.1-3: Point scale measurements (black dots) and integral pumping test (IPT) in comparison. (Jarsjö et al., 2005).

The use of (ii) integral methods could reduce the amount of monitoring wells and indirectly decrease the exploration costs needed to obtain an accurate flux measurement using point methods. Integral methods used pumping wells along a control plane downgradient of a supposed and possible pollutant source zone. This way is done in order to investigate large volumes of the contaminant plume originating from the source (Goltz et al., 2007), by use of two possible approaches: (a) Integral Pumping Test (IPT) and (b) Tandem Recirculating Wells (TRW).

The basic idea of the Integral Pumping test (IPT method) (Fig. 2.1-4, Fig. 2.1-5) was established by Holder et al. (1998), Schwarz et al. (1998), Teutsch et al. (2000), Ptak et al. (2000) and Schwarz (2002). It is primarily based on multiple pumping wells aligned perpendicular to the prevailing direction of groundwater flow. It estimates an averaged contaminant mass flux over a large subsurface volume and across control planes (Fig. 2.1-4).

The total mass discharge from a possible contaminant source zone will be defined by covering a whole cross-section of a contaminant plume downstream of a pollutant source and employing pumping tests. The definition of pollutant concentrations as a function of time (CT-series) is possible with multiple CT-series measurements at the pumping wells. The placement of the wells as well as the pumping volume is fundamental to capturing the entire contaminant plume originating from the source. After Goltz et al. (2007), the IPT method avoids the point scale data analysis complexities, which requires multiple concentration measurements over time and does not require separate measurements of hydraulic conductivity and hydraulic gradient. 


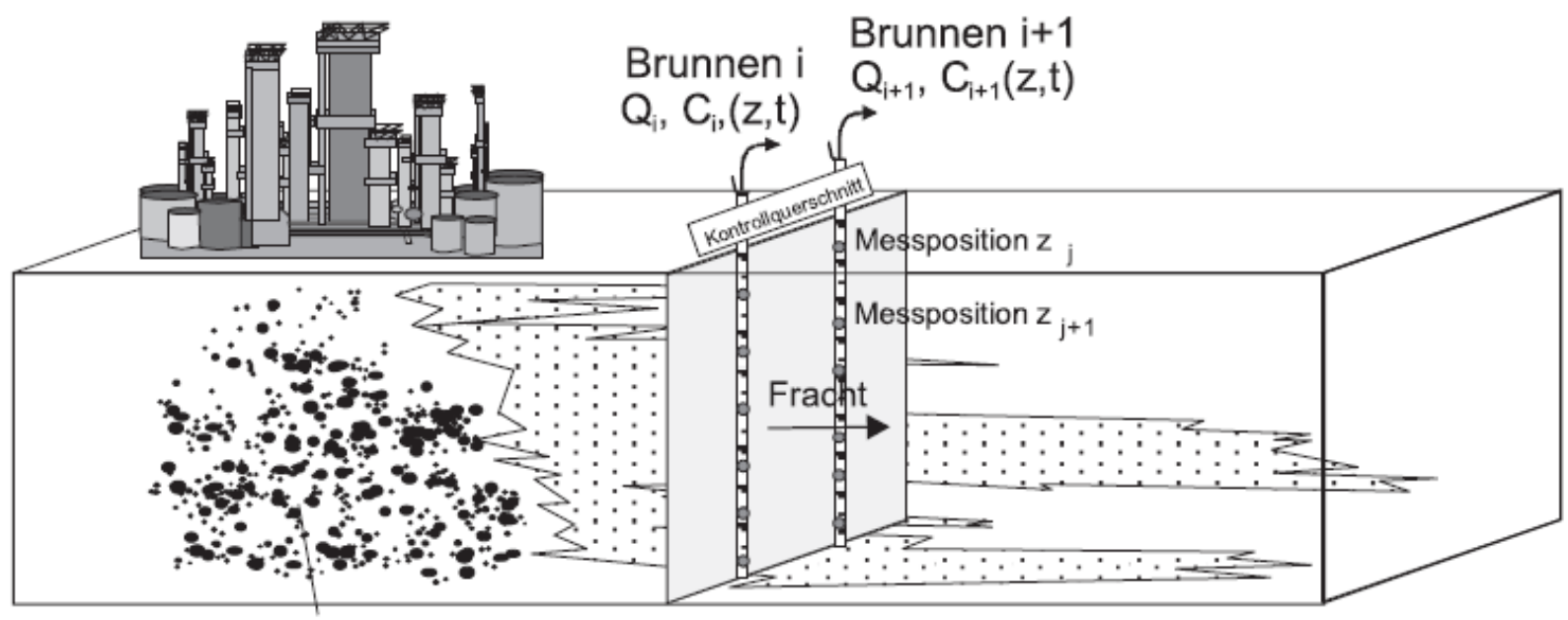

Fig. 2.1-4: Determination of total pollutant loads (Fracht) by monitoring $C(t)$ across multiple levels (Messposition) $\left(z_{j}, z_{j+1}\right)$ of control plane (Kontrollquerschnitt). The pumping rate $(Q)$, specific contaminant concentration $\left(\mathrm{c}_{\mathrm{i}}\right)$, a related pumping time $(\mathrm{T})$ in different multilevel monitoring wells (Brunnen). (Herford et al., 2000, in: Ptak et al., 2004).

Bockelmann et al. (2003) and advanced work by Bauer et al. (2004) described the integral approach as a pioneer of integral investigation strategies.

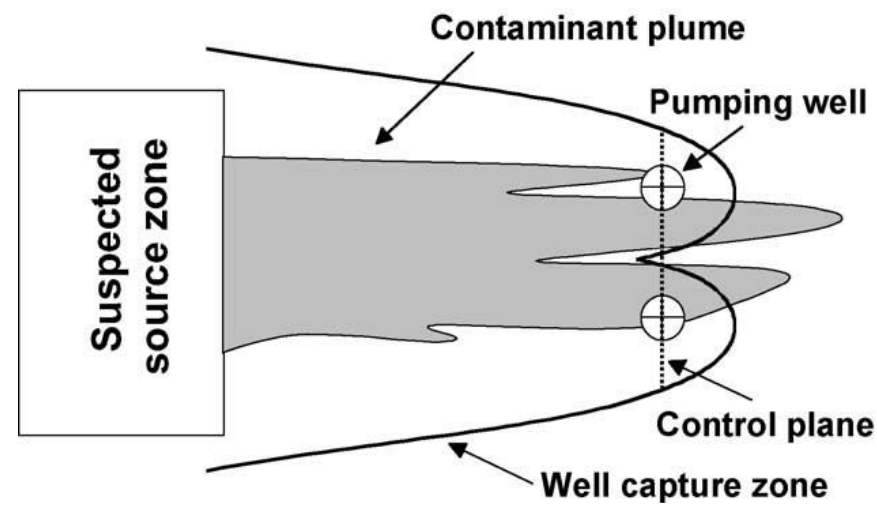

Fig. 2.1-5: Principle of integral approach by capturing the total groundwater discharge using one or multiple pumping wells downgradient from a possible source zone at defined control planes to define the total mass discharge. The contaminant concentrations are given as a function of time in the discharge of the wells during pumping (CT-series). (Bockelmann et al., 2003).

The mass discharge can be calculated through a simplified analytical solution or a numerical algorithm based on a numerical flow and transport model:

$$
M_{d}=2 \sum_{i=1}^{D} Q_{i} C_{x i}
$$

With: $M_{d}$ as mass discharge in $\left[M T^{1}\right], D$ [-] as number of sampling events in the CT series, $Q_{i}\left[L^{3} T^{1}\right]$ as the groundwater flow rate within the $i_{t h}$ as stream tube, $C_{x i}\left[\mathrm{ML}^{-3}\right]$ as theoretical concentration, which is the average of the concentrations of the two intercepted streamtubes at pumping time $t_{i}[T]$.

The mass discharge could also be estimated for a heterogeneous aquifer, by inverting CT data numerically with detailed hydraulic conductivity distribution measurements (Bockelmann et al., 2003). 
To apply the IPT method, one or more pumping wells are placed along a control plane (control cross-section, transaction, perpendicular to the groundwater flow direction) and operated simultaneously, or in subsequent pumping campaigns, downstream of a suspected pollutant source zone, Fig. 2.1-6. The position of the pumping wells, their pumping rates and pumping duration are adjusted to cover the total width of the potential polluted area in the well capture zones. During pumping, the groundwater capture zones increase. The contaminant concentration is measured as a function of time at each of the pumping wells and is representative for a distinct aquifer zone. The transport and mass flux rate can also be obtained from IPTs by measuring and interpreting the concentration time series from a pumping campaign at a well. This can be done in order to find the natural groundwater flow conditions before pumping and in addition to the mean concentration and the total mass flux rate. The installation of multilevel observation wells was realised by Direct-Push technologies after McCall (2002). The approach of CT-series itself was already investigated by Yare (1975), Bear and Sun (1998) and Keely and Wolf (1983).

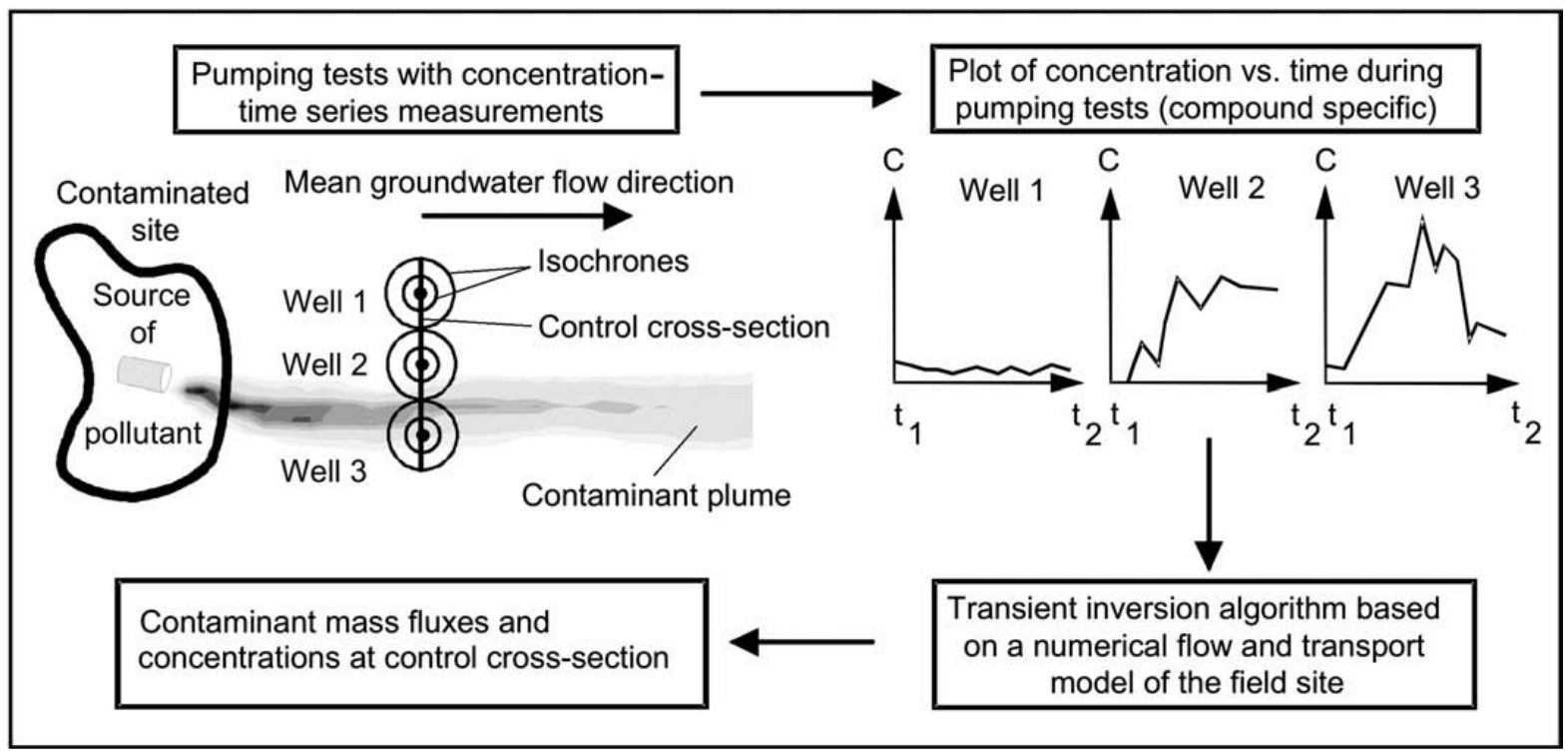

Fig. 2.1-6: Basic principle of integral pumping tests. (Ptak and Teutsch, 2000).

Due to the spatial integration of a pumping test, and due to the increasing capture zone with pumping time, both the spatial distribution of the contaminants as well as the total mass flow rate within a contaminant plume can be estimated.

Schwarz (2002) developed a mathematical solution for the mass flow rates across a control plane as a sum of contaminant concentration based on the pumping rate and spatial dist 
ance of groundwater stream tubes (Eq. 2.1-7).

$$
M_{C P}=2 \sum_{i=1}^{n} \hat{c_{i}} Q_{i} \quad \text { with } \hat{c_{i}}=\frac{c_{i} \frac{\pi}{2}-\sum_{k=1}^{i-1} \hat{c_{k}}\left(\arccos \frac{r_{k}-1}{r_{i}}-\arccos \frac{r_{k}}{r_{i}}\right)}{\arccos \left(\frac{r_{i-1}}{r_{i}}\right)}
$$

With: $M_{C P}\left[M T^{-1}\right]$ as mass flow rate perpendicular to the control plane, $c_{i}\left[M L^{-3}\right]$ as measured concentration at the pumping well at time $t_{i} \hat{c}_{i}$ as average concentrations of the two streamtubes of the natural groundwater flow field positioned left and right from the pumping well at a distance $r[L]$ (with $\left.r_{i}^{-1} b_{r} b_{r i}\right), Q_{i}=K / \nabla h / b\left(r_{i}^{-1}-r_{i}\right)$ $\left[L^{3} T^{-1}\right]$ as discharge under natural, undisturbed conditions perpendicular to the control plane at both the left and right streamtubes, $K\left[L^{3} T^{-1}\right] a s$ hydraulic conductivity and $|\nabla h|$ as hydraulic gradient of the undisturbed aquifer.

The use of this integral method is limited to a groundwater aquifer with high transmissivity and a stable contaminant concentration (Goltz et al., 2007). According to Bockelmann (2003), the existing problems using this method could be related to the pumping volume, the capture of the total groundwater discharge and the potential costs. Even a small variation in capturing discharge can cause an irregular mass discharge result: An incomplete discharge capture could lead to an undervaluation of the mass discharge or a value that is too large, which may be generated when mixing uncontaminated water with contaminant from the plume. The use of an average groundwater flux at the field scale could cause over-/ underestimations of flow paths across the control plane. The lower the dispersivity values and the shorter the transport times are, the more overestimated the mass flux will be (Zeru and Schäfer, 2005). Separate measurements of hydraulic conductivity and hydraulic gradient are reasoned.

Under various aquifer conditions and different frameworks of the monitoring network, further work is needed to evaluate the applicability of different field techniques for different contaminant plume geometries. The quantification of uncertainties with respect to contaminant mass flux and average concentration at field scale was originally figured out by Jarsjö et al. (2005). A three dimensional IPT approach was provided by Ptak et al. (2005), allowing a depth-oriented quantification of contaminant concentrations and mass fluxes. The integral approach of a pumping test is an effective method and has versatile applications, e.g. in Ptak et al. (2000), Ptak and Teutsch (2000), Schwarz (2002), Jarsjö et al. (2002), Peter et al. (2003), Bayer-Raich et al. (2003a), Bayer-Raich et al. (2003b), Bayer-Raich et al. (2004), Bauer et al. (2004), Weiß et al. (2004), Jarsjö et al. (2005), Kalbus et al. (2007), Herold et al. (2007), Her- 
old et al. (2008), Herold et al. (2009), Leschink (2010), Alberti (2011), Béland-Pelletier et al. (2011), Luciano et al. (2012).

For the interpretation of a concentration time series in ITP, the inversion technique CSTREAM was developed by Bayer-Raich et al., 2003a, Bayer-Raich et al., 2003b, Bayer-Raich et al., 2004 according to Schwarz (2002) for analytical and numerical inversion solutions in homogenous or heterogeneous porous aquifer systems. The inversion approach generally uses backward particle tracking in a calibrated groundwater flow system created in MODFLOW (Harbaugh and McDonald, 1996) and an advective transport model, generated in MODPATH (Pollock, 1994), of the investigation area that determines the isochrones and streamlines around a well. The mass flow rate is obtained is obtained with the following equation:

$$
M_{C P}(t)=\int_{l_{C P}(t)} C_{0}(x, 0) q_{0 y}(x, 0) b(x, 0) d x
$$

With: $M_{C P}(t)\left[M T^{-1}\right]$ as mass flux along control plane $(C P)$ at time $t, C_{0}(x, 0)$ as depth-averaged initial concentration in $x$-direction $\left[M L^{-3}\right], q_{0 y}(x, 0)$ as initial Darcy velocity in $y$-direction $\left[L T^{-1}\right], \ell_{C P}(t)$ as length of control plane at time $t[L], b(x, 0)$ as aquifer thickness $[L]$.

The Tandem Recirculating Wells method (b) is described by two interacting wells in downand up-flow mode, both containing an extraction and injection screen to measure mass flux (Kim, 2005 and Huang et al., 2004), connecting separately measurements of hydraulic conductivity, hydraulic gradient, and contaminant, see Eq.2.1-9.

$$
M_{f}=K * i * C
$$

With: $M_{f}$ as contaminant mass flux [M], $K$ as hydraulic conductivity $\left[L T^{-1}\right], i$ as hydraulic gradient [-] and $C$ as contaminant concentration $\left[\mathrm{ML}^{-3}\right]$.

Every parameter needed to calculate the mass flux can be measured in situ. After Kim (2005) the hydraulic gradient can be measured as the piezometrical surface at the two TRWs. The measurement of hydraulic conductivity is based on a special tracer test to measure the interconnection of groundwater flow between the TRWs. Knowing the four interflows for given TRW pumping rates, inverse modelling can be applied to obtain hydraulic conductivity. The method can be applied assuming isotropic or anisotropic conductivities, Goltz et al., (2007). 
Passive methods (iii) were developed for direct in situ measurements of contaminants and water fluxes in porous media. The Flux Meter (EnviroFlux, Gainsville, Florida) is "a selfcontained permeable component" to measure the mass flux directly in the aquifer (Hatfield et al., 2002, Hatfield et al., 2004). It is equipped with a permeable sorbent and is saturated with a certain volume of water soluble tracers. The component size is normed and suitable for every normed screened well or a borehole. Dissolved contaminants in the groundwater, like hydrophobic and / or hydrophilic permeable contaminants, can be preserved by the component. Removed from the well or boring, the sorbent can be extracted to quantify both the mass of all captured contaminants and the residual masses of every resident tracer. The groundwater flux can be estimated with residual resident tracer masses (Eq. 2.1-10). The time-averaged contaminant fluxes can be calculated by contaminant masses:

$$
J_{c}=\frac{q M_{c}}{\pi r^{2} L\left(1-M_{R C}\right) \theta R_{d c}}
$$

With: $J_{c}\left[M L^{-1}\right]$ as contaminant mass flux, $M_{c}[M]$ as the mass of contaminant sorbed, $L[L]$, as the length of the sorbent matrix or the vertical thickness of aquifer interval sampled $R_{d c}[-]$ as the retardation of contaminant on the sorbent, and $M_{R C}$ as the relative mass of a resident tracer retained after time period $t$ where that tracer has the same retardation as $R_{d c}$.

A Multilevel-Sampler enables orientated groundwater sampling in different aquifer levels at the same time. A direct calculation of mass flux is not possible, but the multilevel groundwater samples are useful for the determination of any degree of contamination in different aquifer levels. Ronen et al. (1987) first constructed a modular multilevel sampler for sampling ground water contaminants in the saturated and the unsaturated zone. As shown in the technical construction drawing in Fig. 2.1-7, the sampler is divided into (A) 38 vertical crisscrossed holes, (B) dialysis cells, (C) flexible rubber seals separations, (D) PVC rings, (E) nylon screws, (F) PVC coated weight, (G) an upper holding segment, (H) rod segments, (I) double screw, $(\mathrm{J})$ stainless steel screw and $(\mathrm{K})$ stainless steel wire.

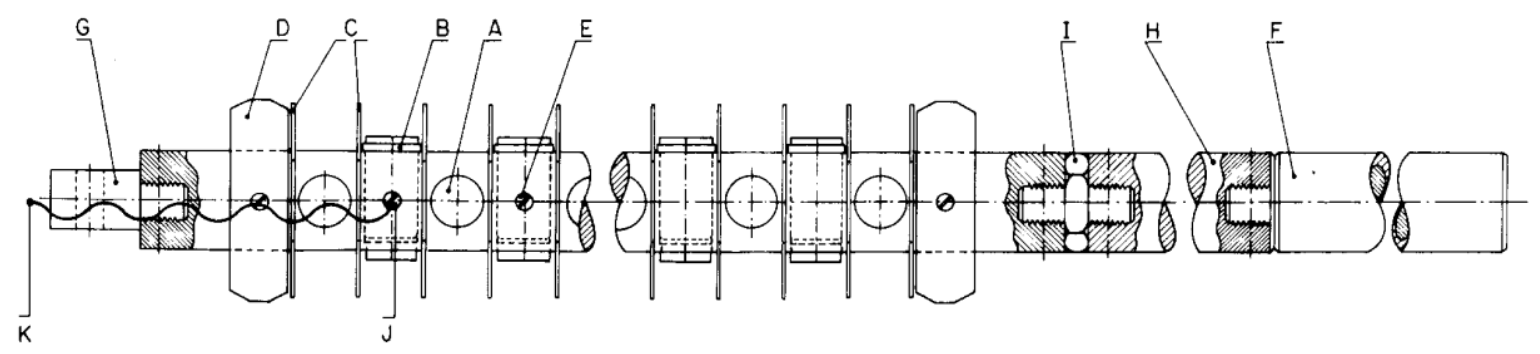

Fig. 2.1-7: Technical drawing of a multilevel Sampler with different packers and membranes. (Ronen et al. 1987). 
An application of the multilevel sampler is given in, e.g. Béland-Pelletier et al. (2011) and Kurtzman et al. (2012).

Farhat et al. (2006) have established a Microsoft Excel software tool, the Mass Flux Toolkit (GSI, Environmental). This tool can generate and manage field data of mass discharge and mass flux, calculate the resulting mass flux, and identify information to reduce uncertainties in mass flux estimations.

In summary, these integral methods are able to provide the most use within the test site. The IPT method in particular can provide further development if the aquifer fulfils the relevant prerequisites, such as the ability to carry enough water or to allow for a sufficient number of wells. The combination of CSTREAM with the IPT method (e.g. Teutsch et al., 2000, Ptak et al., 2000) makes for an interesting and well-established method for the determination of contaminants within an aquifer. In the event that the aquifer is built up on several groundwater levels, passive methods, such as the multi-level sampler, can be used to sample at each level separately. However, an exact assessment of the possible source zone position of contaminants is not possible by using only these methods. Following necessary assessments of the contaminant plume length and the final evaluation will be considered in the next chapters. 


\subsection{Plume length estimations}

The degree of groundwater contamination and its origin is often apparent by the determination of the contaminant plume and the specific plume length, detected in the direction of groundwater flow by mass flux methods. Subsequent to the effective approximation of the mass flux and mass discharge, a limitation of the contaminants spreading is needed for the evaluation of the possible transport of contamination. Since the middle 1980's, an extensive research field has been the analytical analysis of contaminant plumes by exponential and error functions.

Generating a definition of the contaminant plume length is a complex approach. A process oriented flow and transport model of the investigated site is needed, based on numerous hydro-geochemical parameters that can be difficult to obtain. In general, such models are too costly to employ under typical practice budgets. In this context, Teutsch and Rügner (1999) claim that the spread of a contaminant plume depends on several physical transport processes (sorption, diffusion, advection, dispersion, retardation and volatilisation), on geo-

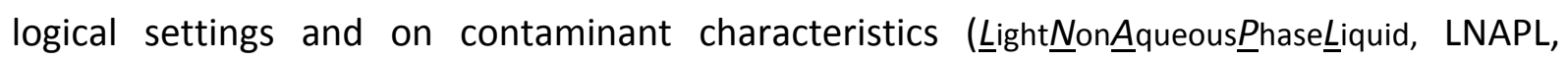
$\underline{D}$ ense $\underline{N}$ on $\underline{A}$ queous $\underline{P}$ hase $\underline{L}$ iquid, DNAPL), see Fig. 2.2-1.

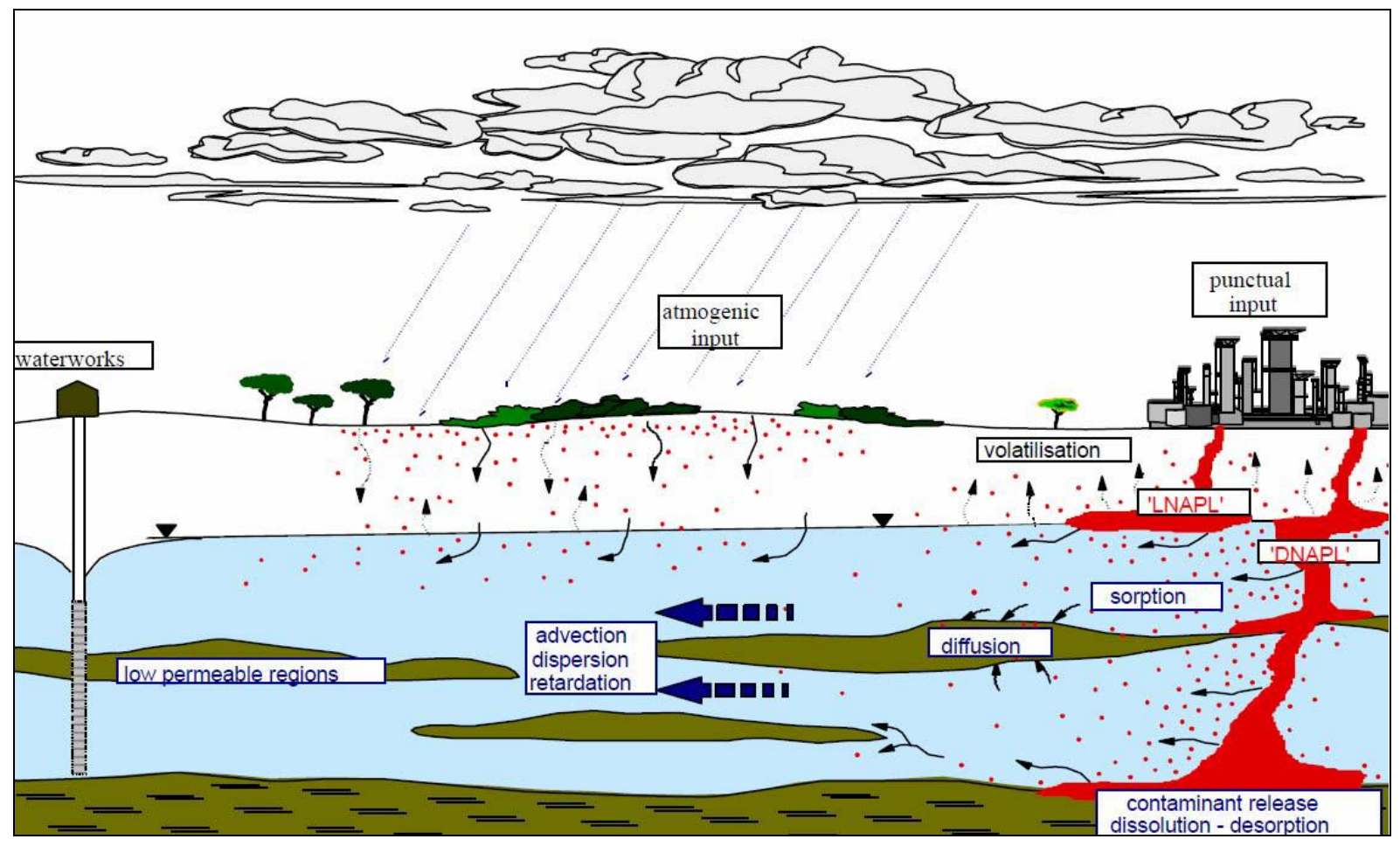

Fig. 2.2-1: Transport of different contaminants (LNAPLs and DNAPLs) in groundwater, according to transport processes in the aquifer. (Schüth, 1994). 
Taking these processes into account, as a continuous spread of the contaminant plume occurs, dissolution from the residual phase will result in a depleted source zone.

How to define the real plume length of a contaminant in porous aquifers, as well as the geometry of contaminant spreading, has been a problem that is difficult to solve over the years.

The realisation of plume geometry succeeded Domenico and Robbins (1986). This knowledge must be regarded as an authoritative method. The approach demonstrated a difference in geometric distribution of a plume in $x, y$, and $z$ direction, depending on the transport media. As schematically illustrated in Fig. 2.2-2, they figured out that (a) the transverse spreading of a contamination is bounded at the tops by a zero flux boundary, (b) the conduct of the contaminant on the upper surface in y-direction is corresponding to the water table and (c) the plume spreading in z-direction is calculated based on numerical approaches.
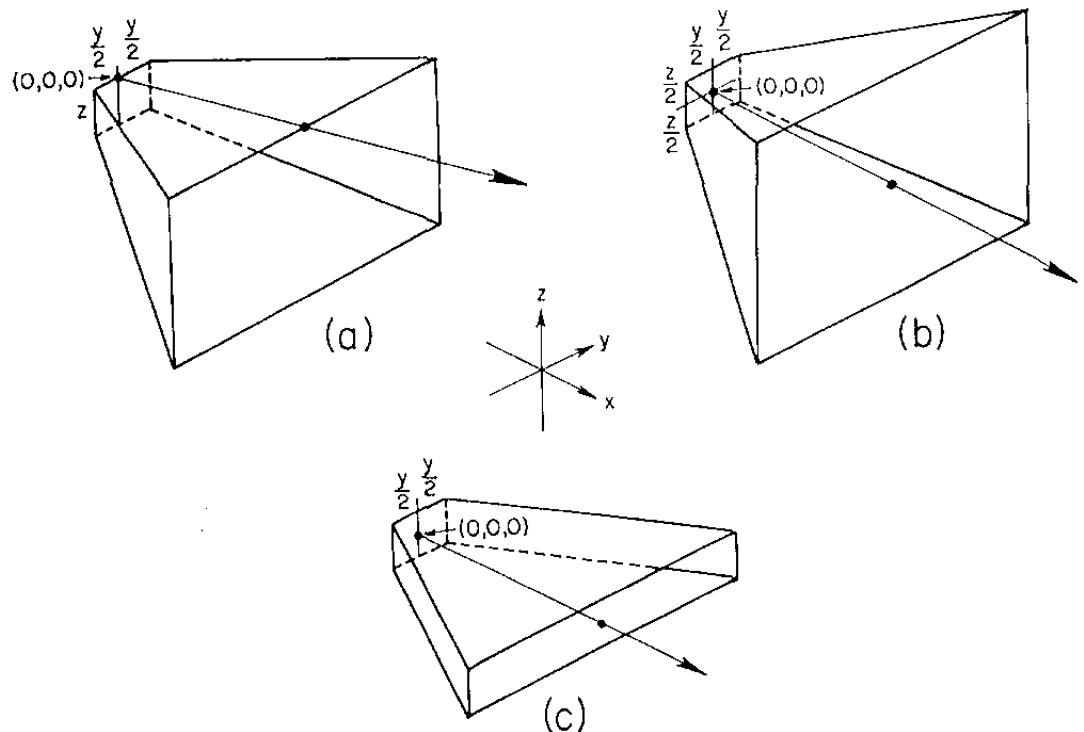

Fig. 2.2-2: Contaminant movement geometries in $x_{-}, y^{-}, \mathrm{z}-$ direction. (Domenico and Robbins, 1986).

As a result, Domenico and Robbins (1986) generated an extended pulse calculation to a continuous finite source problem, based on the movement of a semi-infinite contaminant within parcels, given in Eq. 2.2-1, moving with 1D velocity in $\mathrm{x}$-direction:

$$
\begin{aligned}
& C(x, y, z, t)=\left(C_{o} / 8\right) \operatorname{erfc}\left[(x-v t) / 2\left(D_{x} t\right)^{1 / 2}\right] \\
& \left\{\operatorname{erf}\left[(y+Y / 2) / 2\left(D_{y} x / v\right)^{1 / 2}\right]-\operatorname{erf}\left[(y-Y / 2) / 2\left(D_{y} x / v\right)^{1 / 2}\right]\right\} \\
& \left\{\operatorname{erf}\left[(z+Z / 2) / 2\left(D_{z} x / v\right)^{1 / 2}\right]-\operatorname{erf}\left[(z-Z / 2) / 2\left(D_{z} x / v\right)^{1 / 2}\right]\right\}
\end{aligned}
$$


But their advection-dispersion equation (see Eq. 2-7) is the further governing development intended for definition of the 2D contaminant transport from a finite point source in an aquifer.

Even the change of plume parameters can occur because of changing groundwater levels, groundwater gradient and flow velocities, and groundwater flow directions (Leven and Dietrich 2004). So, because of these potential changes in groundwater, the measured contaminant concentrations could indicate a temporal variety. The determination of realistic plume lengths is analytically limited (e.g. Schiedeck et al., 1997, Rügner et al., 2001, Ham et al., 2004, Liedl et al., 2005, Cirpka et al., 2006, Liedl et al., 2011, Yadav et al., 2013).

The innovative idea for the explanation of plume lengths in temporal behaviour was developed by Teutsch and Rügner (1999). In their opinion, the plume extent depends on groundwater flow direction and conservative transport processes, like advection and hydrodynamic dispersion with simultaneous consideration of reactive processes, such as dilution, sorption, biodegradation or volatilization. As a result of the influence of these processes, contaminant plumes are not stationary, but temporal and transient in four steps of spreading rate, see Fig. 2.2-3.

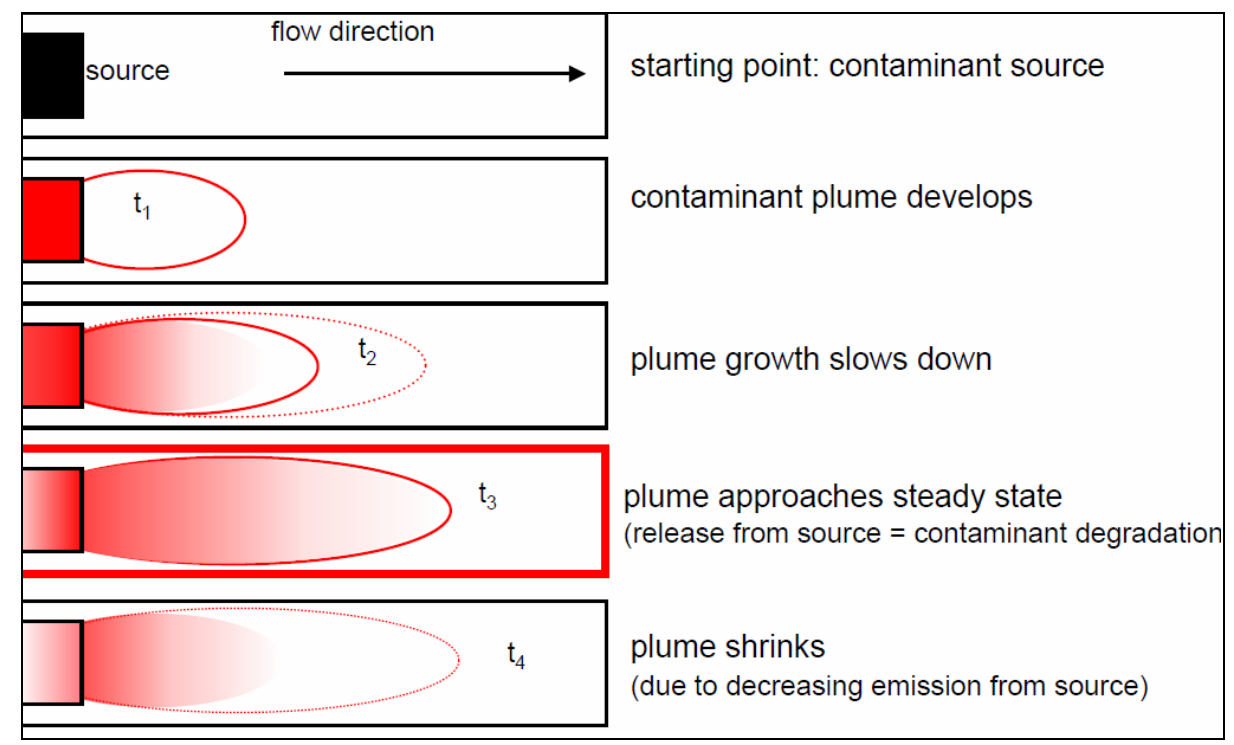

Fig. 2.2-3: Temporal behaviour of a contaminant plume (2D view). (Teutsch and Rügner, 1999).

Thus, a contaminant plume grows, if the transport conservative processes dominate over reactive processes (t1-t2, Fig. 2.2-3). Once the reactive processes are dominating, the plume is shrinking (t4, Fig. 2.2-3) and the length is also controlled by biotic decay or Monod kinetic 
reactions such as transverse dispersion. Chu et al. (2005) and Cirpka and Valocchi (2007) described in Eq. 2.2-2 this stage of plume length analysis as follows:

$$
L=\frac{\pi W^{2}}{16 n \alpha_{T h}}\left(\frac{n_{A} / n_{D} \beta_{D}^{0}}{\beta_{A}^{0}-\beta_{\varepsilon}^{0}}\right)^{2}
$$

With: $L$ as plume length $[L], \beta_{D}^{0}$ as concentration of electron donor $\left[\mathrm{ML}^{-3}\right], \beta_{A}^{0}$ as concentration of electron acceptor $\left[\mathrm{ML}^{-3}\right], n_{A} / n_{D}$ as stoichiometric ratio of el. acceptor and el. donor [-], $\alpha_{T h}$ as transversal dispersivity in horizontal direction [L].

If the release rate of the pollutant is equivalent to the degradation rate and the reactive and conservative processes are balanced, the plume has achieved a steady state situation along with its maximum length (Fig. 2.2-3, red box, t3).

Based on the knowledge of plume degradation by Teutsch and Rügner (1999) as well as the geometrical spreading by Domenico and Robbins (1986), Ham et al. (2004) described plume length $L$ (Eq. 2.2-3) as the measured plume length along the $x$-axis from the contamination source to a certain concentration contour. They defined the length as the contour line where all of the species $B$ is degraded.

$$
L=\frac{n^{2} C_{B}^{0^{2}} Q^{2}}{4 \pi C_{0}^{2} q_{0}^{2}} * \frac{1}{\alpha_{t}}
$$

With: $L$ as plume length $[\mathrm{m}], C_{0}$ as concentration of the species $B\left[M L^{-3}\right], Q$ as injection flow rate $\left[L^{2} T^{-1}\right]$ and $C_{B}{ }^{o}\left[M L^{-3}\right]$ as concentration of injected solute $B . q=\left(q_{x} ; 0\right)$, where $q_{x}\left[L T^{-1}\right]$ as specific discharge in positive $x$ direction $[L], \alpha_{t}$ as transverse dispersivity, $C_{B}(x ; y ; \infty)=0$.

Liedl et al. (2005) used the understanding obtained from Ham et al. (2004) and considered the maximum plume length in a homogenous aquifer, in view of chemical interactions. (Fig. 2.2-4).

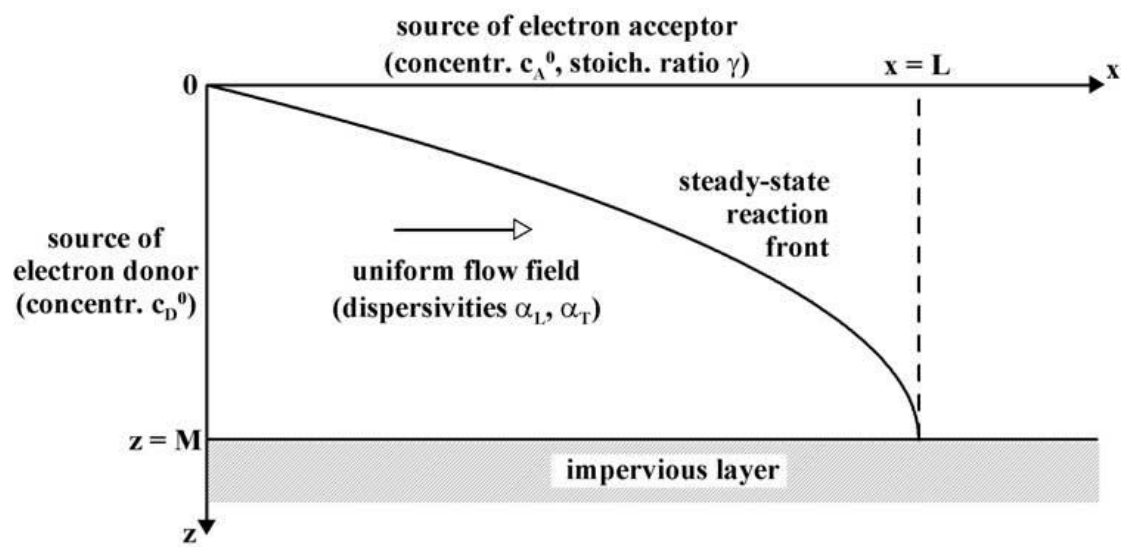

Fig. 2.2-4: Binary reaction between the electron donor and an electron acceptor in a homogenous aquifer. (Liedl et al., 2005). 
The interactions are found between electron donor and acceptor, based on advection, longitudinal and transverse dispersion, as well as linear groundwater flow velocity.

The steady plume is regarded as an electron donor. Chemical redox reactions create an area of electron donor and electron acceptor separation, with two regions made up of a steady state reaction part and a constant flow field part. Along the frontier line between electron donor and electron acceptor, the concentrations of the electron donor and acceptor are constant and zero $\left(C_{D}=C_{A}=0\right)$. The redox boundary intersects the aquifer bottom. The position of connection is equal to the maximum length of a steady state plume (Eq. 2.2-4).

$$
L_{1}^{*}=\frac{4 M^{2}}{\pi^{2} \alpha_{T}} \ln \left(\frac{4}{\pi} \frac{\gamma C_{D}^{0}+C_{A}^{0}}{C_{A}^{0}}\right)
$$

With: $L^{*}{ }_{1}$ as plume length [L], $M$ as source thickness [ $\left.L\right], \alpha_{T}$ as vertical transverse dispersivity $[L], \gamma$ as stoichiometric ratio [-] (number of moles of acceptor needed to annihilate 1 mole of donor), $C_{D}{ }^{0}$ as concentration of electron donor $\left[\mathrm{ML}^{-3}\right], \mathrm{C}_{A}{ }^{0}$ as concentration of electron acceptor $\left[\mathrm{ML}^{-3}\right]$.

Cirpka et al. (2006) extended previous knowledge and defined the steady state plume length to the related transverse dispersion (Eq. 2.2-5). The process of mixing, substituted diagonally to the direction of flow, is dispersion across a control plane:

$$
L=\frac{v h^{2}}{16 D_{z}(\operatorname{inverf}(X))^{2}}
$$

With: $L$ as plume length $[L], h$ as injection height $[L], v$ as seepage velocity $\left[L T^{1}\right], X$ as mixing ratio along the centreline $[-], D_{z}$ as specified transverse dispersion coefficient $\left[L^{2} T^{-1}\right]$, inverf( $)$ as inverse error function [-].

Modern analytical methodologies to characterise the maximum plume length under steady state conditions are done by Yadav et al. (2013). They used a straightforward calculation to approximate the plume length by natural attenuation within a MS-Excel ${ }^{\circledR}$ tool called NAFLA.

The outward release rate of a contaminant source, according to its solubility and kinetics, defined the contaminated mass in a plume (Schiedeck, 1997 and Grathwohl, 1997). A comprehensive, statistical approach of plume length evaluation for diverse organic pollutants is given by Schiedeck et al. (1997) and extended by Rügner and Teutsch (2001). They handled numerous cases of damage based on statistical quartiles. A brief selection by Schiedeck et al. (1997) is given in Tab. 2.2-1 for aliphatic CHCs, Phenol, BTEX, Benzene and others, like PAH. Teutsch and Rügner (1999) do not consider specific transport processes or natural attenuation. Their focus is on empirical mass flux estimations using statistical quartile (Q25 and 
Q75) calculations in relation to a subjectively set confidence level.

Table 2.2-1: Statistical approach of plume length estimations after Schiedeck et al. (1997) for five groups of organic substances: CHCs, Phenol, BTEX, Benzene and others.

\begin{tabular}{|c|c|c|c|c|}
\hline $\begin{array}{l}\text { Contaminant } \\
\text { (No. of cases) }\end{array}$ & $\begin{array}{l}\varnothing \text { Transport } \\
\text { length }[\mathrm{m}] \text { in GW }\end{array}$ & $\begin{array}{l}\varnothing \text { Transport } \\
\text { length }[\mathrm{m}] \text { in } \mathrm{GW} \text { in } \\
75 \% \text { of cases }\end{array}$ & $\begin{array}{l}\varnothing \text { Transport } \\
\text { length }[\mathrm{m}] \text { in } \mathrm{GW} \\
25 \% \text { of cases }\end{array}$ & $\begin{array}{l}\text { Max. Transport } \\
\text { length }[\mathrm{m}] \text { in } \mathrm{GW}\end{array}$ \\
\hline Aliphatic CHCs & 1543 (107) & $654(80)$ & $<2100$ (107) & 1000 (107) \\
\hline Phenol & $416(18)$ & $190(12)$ & $<600$ (18) & $1600(18)$ \\
\hline BTEX & 209 (18) & $143(73)$ & $<300(27)$ & 700 (27) \\
\hline Benzene & $277(14)$ & $200(10)$ & $<300$ (14) & 800 (14) \\
\hline $\begin{array}{l}\text { Other organic con- } \\
\text { taminants }\end{array}$ & $892(30)$ & 390 (19) & $<1300(30)$ & 3000 (30) \\
\hline
\end{tabular}

A complete consideration of the maximum plume length is probably based on the combination of analytical and statistical approaches. Depending on the database, calculations of the plume length or the statistical approach have to be considered. In connection to integral mass flux methods, an application of Liedl et al. (2005) would be possible to achieve detailed results. The statistical approach of Schiedeck et al. (1997) can also be helpful to get a generalised overview of the extreme maximum and minimum plume length. A slightly detailed statement of the statistical results is given in Teutsch (1999).

Plume length estimations enable an assessment possible limitation of the spread of pollutants in aquifers. However, even if an estimation of the direction of origin is possible, a statement of the possible contaminant source zone presence or absence is not. Further investigations are needed for a two-dimensional area calculation of contaminant origins. 


\subsection{Contaminant source zone characterisation}

Contaminants in groundwater are often first noticed when they are detected in groundwater samples. It is often that the source is not known and the only available information is the contaminant concentration at distributed monitoring wells. As an important task for remediation, the question for the pollution origin arises. Initial assessments can be counted to a contamination register. Nevertheless, hereby, the delineation of a source zone is only possible if known sources directly indicate the pollutant. Examples, such as agricultural fields for pesticides, coal mines for PAK, or oil and gas wells for CKW and Benzene are demonstrated in Fig. 2.3-1.

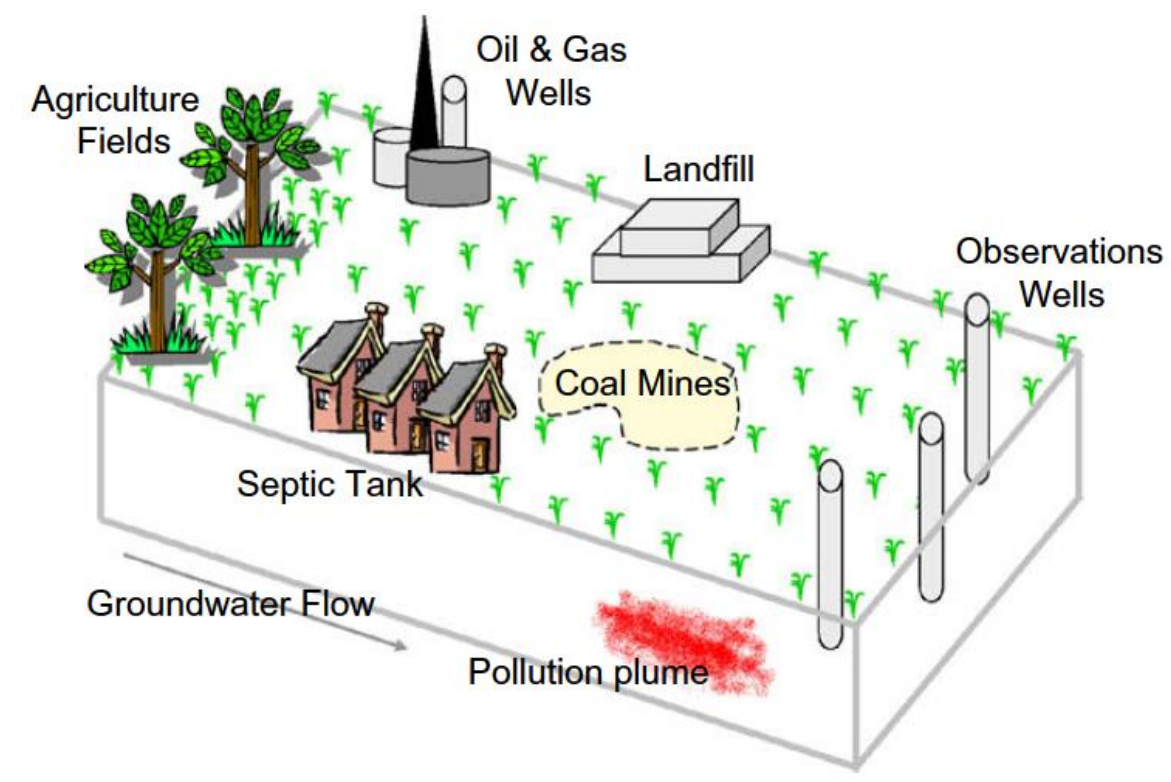

Fig. 2.3-1: Theoretical model of possible source zones of a contaminant plume. (Mirghani et al., 2009).

If multiple contamination sources are contemplable or if the contaminant is distributed uncertainly, source zone identification only by the use of substance register is impossible. Researchers dealt with this exact problem for almost 30 years. A detailed outline of developed approaches since the middle 1980's are represented in Atmadja and Bagtzoglou (2001), Michalak and Kitandis (2004), and Sun et al. (2006). A common answer for the contaminant plume extent as well as a delineation of unknown pollution source zones is the consideration of pollution concentrations (observed, estimated or assumed) by means of known groundwater flow and transport processes.

A consideration of mass flux and plume length was necessary to get a common overview of 
the contaminant spreading. The contaminant transport was often realised by using the ADE backward in time (Ababou et al., 2010), including optimisation methods in forward model inversion (Gorelick et al., 1983, Wagner, 1992). It was then developed further with stochastically estimations backward in time by Wilson and Liu (1994) and Liu and Wilson (1995) and then with geostatistical contemplation (Michalak and Kitanidis, 2004). Classical methods of mass discharge data evaluation is employed by Brusseau et al. (2011) in long term.

Modern approaches to delineate contamination source presence and absence zones varied between (i) tomography or seismic/remote sensing data, (ii) tracers and isotopes, (iii) simulated inversion groundwater flow and transport models and backward models, (iv) GIS Systems and (v) combination scheme:

Bagtzoglou et al. (1991) identified sources of contamination in groundwater systems by monitoring pollution data of sampling network. To increase the quantity of wells, they proposed the use of (i) tomography or seismic/remote sensing data. Liu and Kitanidis (2011) described hydraulic tomography and electric resistivity tomography in a sandbox experiment to estimate large-scale inverse modelling methods. The effect created efficient inverse methods, with assimilation of measurement volume for the collection of more indirect measurements. Aghasi et al. (2012) used electrical resistance tomography at the test site. They jointed an inversion of hydrological and geophysical data to simulate an interaction of groundwater with the contaminant source zone, based on a 3D groundwater flow and downstream transport model, Fig. 2.3-2.

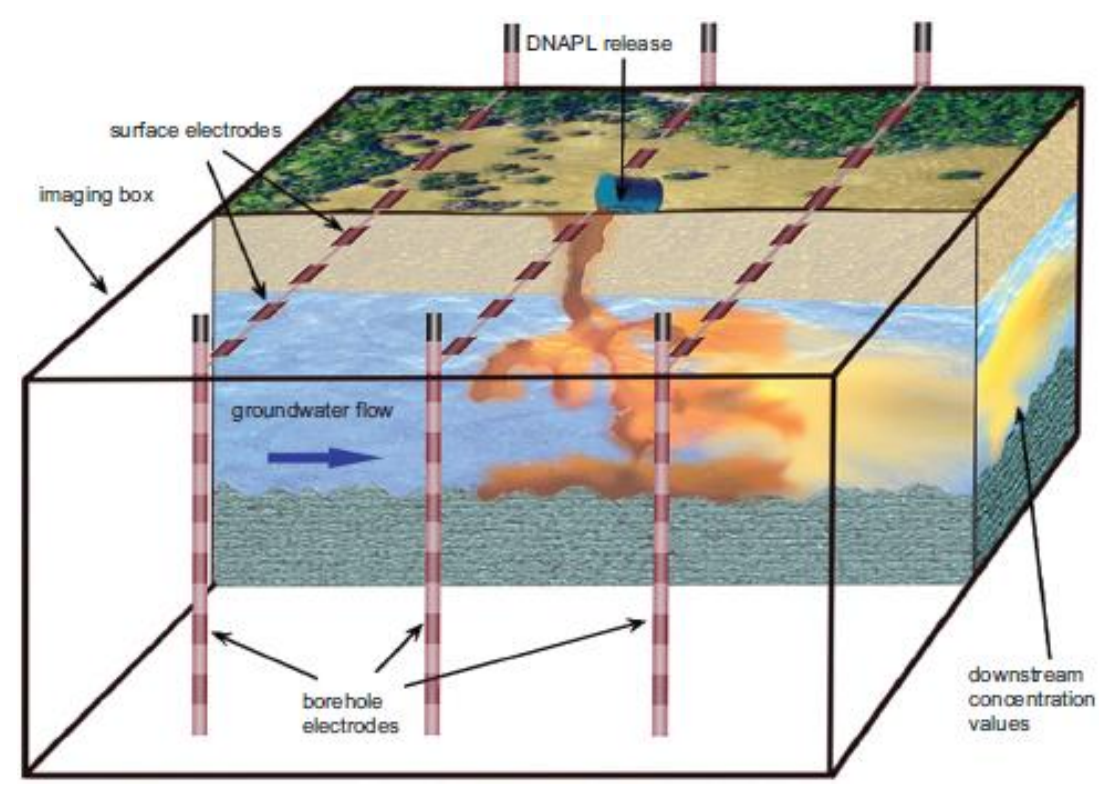

Fig. 2.3-2: Identification of contamination source with electrical resistance tomography. (Aghasi et al., 2012). 
The electric potential quantities are related to the electrical properties of the medium and are obtained at a cross gradient to the water flow direction. The inversion technique of (electrical potential quantities) is based on the parametric level set method, which provides for the recovery of the geometric profiles of the low and high saturation regions and low order characterisations of the spatial variability within each region.

The surface electrical resistivity tomography monitoring approach is also potentially useful for examining subsurface plume responses to recharge over field-relevant scales (Gasperikova et al., 2012). Even an application to soil pollution is feasible (Serefou et al., 2012). A more efficient method was to combine seismic techniques to image the geological structure's seismic reflection, P-wave tomography and spectral analysis of surface waves by Grandjean (2006). Orozco et al. (2012) used broadband spectral induced polarisation (SIP) measurements to delineate contaminated areas, based on different spectral response anomalies. Low phase response values defined locations with high contaminant concentrations, with higher phase values describing lower concentrations.

To determine the behaviour of contaminants and their spreading in regard to source estimations, the use of (ii) tracers and isotopes analysis can be helpful. Illman et al. (2010) uses a combination of hydraulic and partitioning tracer tomography to demonstrate the effectiveness of the Sequential Successive Linear Estimator algorithm to define DNAPL source zones in sandbox experiments. Yang and Lee (2012) investigated an influence of seasonal rainfall impact events and temporal groundwater recharge for sources of small contaminant plumes, covered by major contaminant plumes, and identified sources are employing compoundspecific stable isotope analyses. The clarification of conductivity heterogeneity can have a large impact on calculated saturation distributions, underlining the importance of accurate delineation of hydraulic heterogeneity. In situ Su et al. (2012) monitored and evaluated the behaviour of chlorinated volatile organic compound's source zone and its chlorinated daughter products with emulsified zero valent iron nanoparticles. Breukelen and Rolle (2012) observed isotope analysis signals in contamination plumes to show an effect of transverse hydrodynamic dispersion. They used reactive transport modelling and implemented diffusioninduced isotope fractionation, different parameters of local transverse dispersion, field data and evolution of isotope ratios. The longer the distance from the source, the higher the degradation rate, and the more transformation of induced positive isotope signals takes place. 
The effect of diffusion-induced isotope fractionation on the total isotope signal reduction was highest near the source and low for values of groundwater flow velocity, transverse dispersion coefficient, molecular weight, rate constant, and for the isotope fractionation factor of the degradation reaction (Fig. 2.3-3).

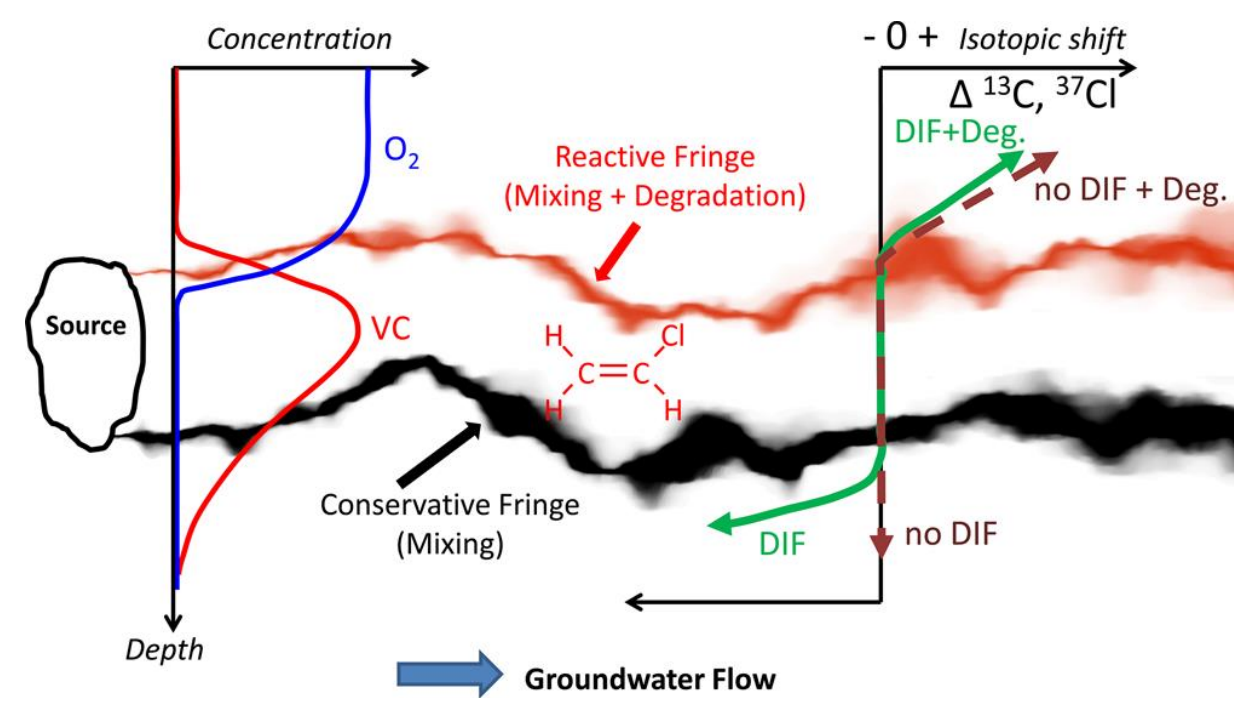

Fig. 2.3-3: Transverse Hydrodynamic Dispersion Effects on Isotope Signals in Plumes (Breukelen and Rolle, 2012).

A 2D compound specific isotope analysis by Wiegert et al. (2012) allowed monitoring in-situ biodegradation of PCE and TCE by combined stable carbon and chlorine. The interpretation is carried out by the use of isotopes integrated with mass load in a numerical reactive transport model along flow paths.

The implementation of tomography or seismic/remote sensing, tracers and isotope methods is quite expensive and is mainly dependent on the availability of expensive equipment. For ordinary engineering is not practical in most cases. Similarly, the required time is not comparable to the technique of drilling exploratory wells. In such circumstances, (iii) the use of simulated inversion groundwater flow and transport models and backward models are more typical.

Contaminant transport control algorithms are feasible as differential equations backwards in time, including adjoint methods (Vesselinov and Harp, 2010). Ayvaz (2010) used MODFLOW (Harbaugh and McDonald, 1996) and MT3DMS packages to demonstrate the groundwater flow and transport processes. The processes were then interconnected with a heuristic harmony search algorithm simulation-optimization model, regarding the pollution sources as 
explicit decision variables, determined by the optimization model. Mirghani et al. (2009) optimised a numerical flow and transport model with search algorithms in terms of solution quality and computational performance by cluster analyses. Groundwater modelling is associated to many uncertainties (Franssen et al., 2009), summarized in boundary conditions, geological heterogeneity and unknown hydrogeological parameters. Alberti et al. (2011) used the knowledge of numerical flow modelling and identified a contaminant plume with the help of IPT results in Italy by estimation of the mass fluxes and then prepared a classified list of the main contamination sources. A delineation of an exact contaminant source position was not possible, but with the help of historical studies, the number of probable sources could be limited.

Advanced general methods in backward modelling for single point pollution sources in homogenous aquifers are specified by numerous approaches. This includes: (i) random walk particle method (Bagtzoglou et al., 1991), (ii) adjoint methods after Neupauer and Wilson (1999), (iii) Tikhonov regularisation, minimal relative entropy in 1D for hypothetical release history functions, and contaminant plumes (Neupauer et al., 2000, Skaggs and Kabala, 1994), and (iv) backtracking models subjected to sorption and decay (Neupauer et al., 2007, Dokou and Pinder, 2009). Milnes and Perrochet (2007) expanded the knowledge for 2D heterogeneous models. The position of the pollution source is identified by transfer function theory of target concentrations and backwards simulation of the pollution plume depending on the dispersion-based shrinkage of the concentration contour. The backward flow time specifies the time since the beginning of the contamination. Refining methods of inverse approaches are sought by various research groups. Mahar and Datta (1997) upgraded the knowledge of backtracking with a gradient- based optimisation technique to implement flow and transport calculations as binding constraints. Vesselinov and Harp (2010) developed an adaptive hybrid optimisation method by integration of three optimisation strategies: Levenberg-Marquardt-, Particle Swarm- and Adaptive Particle Swarm Optimisation. Foddis (2010) tried to locate a source by using special software for flux and transport models in porous media called "TRACES". Modelling of the cause and effect relationships in groundwater contamination was realised with Artificial Neural Networks (ANN) technology.

Numerical and Backtracking methods are mostly used above as singular, mathematical strategies. A unified method for determining the source of the contamination is not given. Also, a graphical representation of the results is unfortunately rather the exception. This result is 
often necessary when performing engineering consultancies.

The graphical demonstration of contamination sources is enabled by the use of GIS systems, (iv). Flügel and Michl (1995) analysed hydraulic conductivity and transmissivity raster data in a GIS system and combined them with a numerical groundwater and transport model in Processing MODFLOW (Harbaugh and McDonald, 1996) and MODPATH (Pollock, 1994). Facchinelli et al. (2001) transferred the knowledge of regional variability and multivariate statistical GIS tools to identify non-point contamination sources in soils. Based up this, Hossein and Piantanakulchai (2013) achieved a Monte Carlo type inverse and gradient-based optimisation modelling methodology for the characterisation of structural parameter uncertainty, with adjustment of their approximation to the definition of source geometry and hydraulic conductivity field. The results show greater uncertainty in the estimated dissolution rate than a reasonable positive correlation between the two parameters.

To evaluate the usefulness or functionality of a test site as well as to ensure lower cost and handling time, the approach pursued and highlighted in this dissertation is the spatial limiting of contaminant sources, as well as their absence, by previous IPT methods and the calculation of pathlines backwards in time. Jarsjö et al. (2005) established a combination scheme, (v), using IPT, MODFLOW (Harbaugh and McDonald, 1996), the numerical IPT inversion algorithm CSTREAM and analytical plume length statistics in order to delimit possible contamination source zone presences and /or contamination source zone absences. The estimations are fraught with uncertainties. In concurrence with Franssen (2009), these uncertainties can be attributed for many reasons. This includes mass flow and average contaminants concentrations, boundary conditions in numerical groundwater modelling and the local water balance as well as to heterogeneous in hydraulic conditions and in reactive transport parameters for delimiting of both contaminant source zones and zones absent of source.

To restrict the boundary and subsequent streamline uncertainty, two numerical model scenarios (Fig. 2.3-4 a, M1, solid black line, and M2, dashed grey line) and inversely calculated streamlines in CSTREAM were set up. The total amount of streamlines obtained from particle tracking, as shown in Fig. 2.3-4 is used as reference for the source zone definition for inert (Fig. 2.3-4 b) and for reactive compounds (Fig. 2.3-4 c). For non-reactive compounds, the delineation of a contamination source can be set as a total zone covered by any streamlines 
from both scenario models (see solid black line, Fig. 2.3-4 b). If there is no contaminant detected in either of the two models, the source zone absence can be defined as an intersecting set of those streamlines (see grey line, Fig. 2.3-4 b). The source zone definition for reactive compounds is coupled with plume length statistics and the determination of minimum and maximum plume lengths at a predefined confidence level (seeFig. 2.3-4 c).

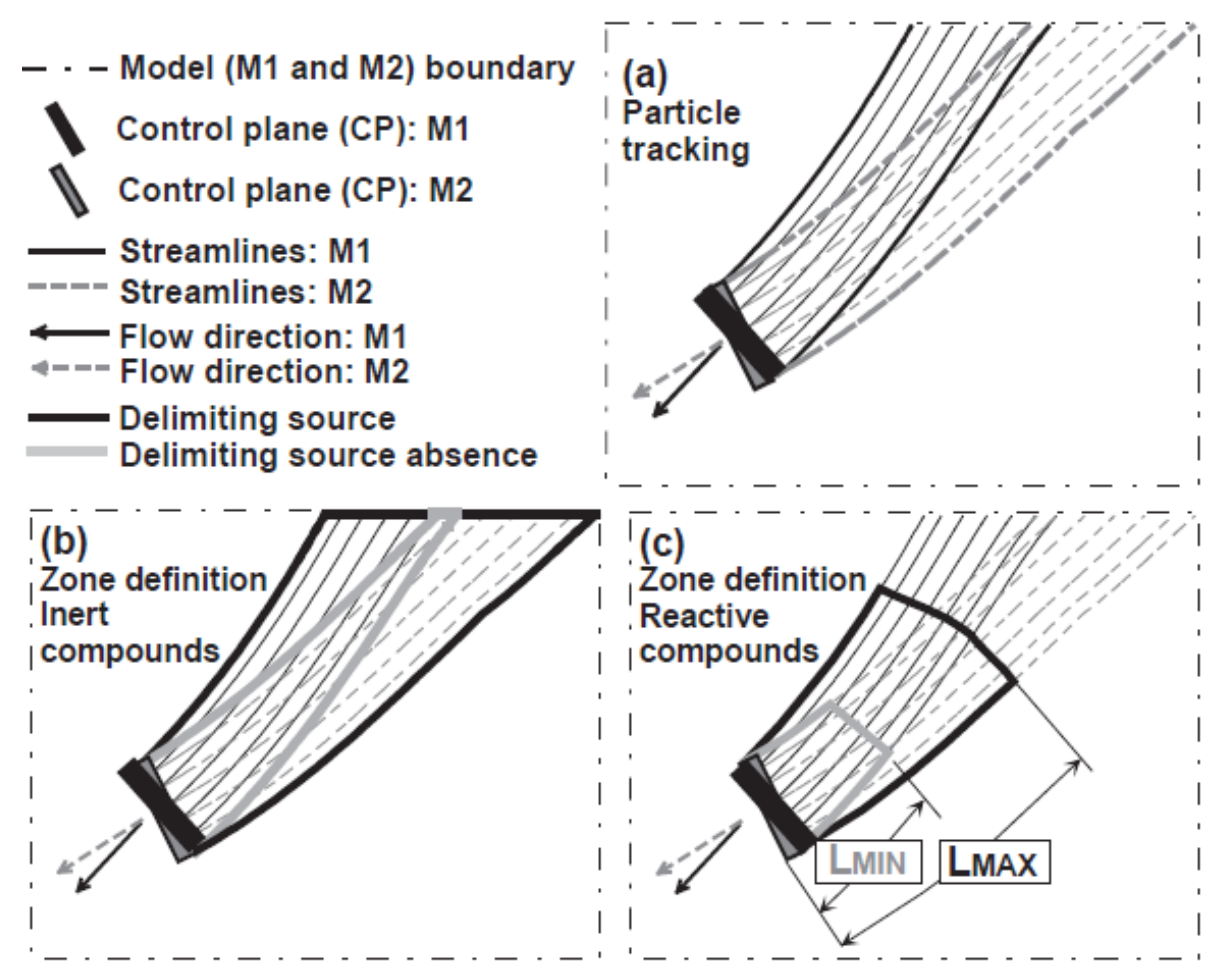

Fig. 2.3-4: Delineation of source zone and source zone absence, after Jarsjö et al. (2005). With (a) particle tracking streamlines, (b) for inert compounds, (c) for reactive compounds, with: LMin as minimum plume length, LMax as maximum plume length. (Jarsjö et al., 2005).

The possible source zone (Fig. 2.3-4 c, black lines) $\mathrm{Z}_{\mathrm{In}, \mathrm{R}}$ (Eq. 2.3-1) is defined as total area covered by streamlines from both models up to the maximum plume length. The source zone absence area (Fig. 2.3-4 c, grey lines) $\mathrm{Z}_{\mathrm{EX}, \mathrm{R}}$ can be determined as the area covered by the intersecting set of streamlines up to the minimum plume length, according to Eq. 2.3-2.

$$
\begin{aligned}
& Z_{I N, R}=\bigcup_{i=1}^{n} A_{M A X}(\alpha ; \underline{\varepsilon})_{i} \\
& Z_{E X, R}=\bigcap_{i=1}^{n} A_{M I N}(\alpha ; \underline{\varepsilon})_{i^{\prime}}
\end{aligned}
$$

Eq. (2.3-1) and Eq. (2.3-2) with: $\alpha$ as confidence level, $\underline{\varepsilon}$ as parameter set for quantification of contaminant and aquifer type with physical and chemical conditions, $i$ as model, $A_{M A X}$ as area of streamlines $L_{M a x}(\alpha \underline{\varepsilon}), A_{M i n}$ as area of streamlines $L_{\text {Min }}(\alpha, \underline{\mathcal{E}})$. 
A calculation within CSTREAM also enables a different breakdown of impurities in the light stream of individual tubes, which allows a selection of the contaminated areas in prior to this zone evaluation.

Herold et al. (2007), Herold et al. (2008), Herold et al. (2009) applied the scheme of numerical groundwater modelling in combination to CSTREAM analysis on a region in Southern Germany and thus confirmed the thesis by Jarsjö et al. (2005). Rooij et al. (2012) extended the knowledge and defined a particle-tracking system for simulating pathlines in coupled surface-subsurface flow systems for simulation of advective transport. They undertook a 3D groundwater flow field model, simulated in a cell centred finite difference method in MODFLOW (Harbaugh and McDonald, 1996). The pathlines are simulated by classical particle tracking methods with PMPath.

The approach by Jarsjö et al. (2005) is an easy to use and cost-effective engineering method to identify pollution sources. However, an automated application of the various tests, as well as immediate presentation of results, is also not provided in this case. 


\section{Chapter 3}

\section{ModBack Development}

ModBack development includes an overview of programming the software as well as its external appearance.

\subsection{About ModBack}

ModBack combines the existing modelling tools PMWin (WebTech 360, Processing Modflow Pro), CSTREAM (Bayer-Raich et al., 2003a, Bayer-Raich et al., 2003b, Bayer-Raich et al., 2004), NAS as well as ESRI ArcGIS $10.0^{\circ}$, Golden Software Surfer and Microsoft Excel. These are combined within a GIS-based GUI to delineate potential contaminant source zones in saturated aquifer systems in the subsurface. Its framework is given by the assumptions of Schiedeck et al. (1997), Bayer-Raich et al. (2003), Jarsjö et al. (2005), Liedl et al. (2005) and Rothschink (2007), and is advanced by analysis tools. With ModBack, a tool is available, that helps to reduce the costs of contaminated site management significantly.

The software is written as an object orientated program in Visual Basic .NET 3.5 and contains advanced analysis tools, integrates already existing tools, and predefines standard GIS functions by demand of ArcObjects libraries.

The structure of ModBack is separated into four blocks of procedures: (i) geographical data input, (ii) groundwater and transport modelling, (iii) backtracking and (iv) source zone considerations. The basic work flow chart of ModBack is sketched in Fig. 3.1-1. The input of geographical data (i) integrates all coordinate-based information pertaining to the study site. Information on groundwater contamination is acquired either by conventional sampling from monitoring wells or through IPT at control planes with a specific sampling scheme. Combinations of the data with available subsurface information are then used to set up a groundwater flow model (PMWin, directly controlled by ModBack) (ii) of the study site, resulting in a simulated groundwater flow field for transport simulations. Backtracking methods (iii) will be considered numerically with the software CSTREAM (Bayer-Raich et al., 2003a, Bayer-Raich et al., 2003b, Bayer-Raich et al., 2004) at defined cross sections (control planes). Also an analytical tool by Rothschink (2007) is included. The contamination source analysis (iv) is based 
on backtracking within ModBack. The potential areas of contamination source presence or absence can be determined with the help of plume length estimations using plume length statistics (Schiedeck et al., 1997), first order rate degradation equations or/and calculations based on site specific hydraulic and chemical parameters after Liedl et al. (2005). Any relevant output results can be graphically displayed, analysed and saved as vector data and are compatible to other GIS software tools. The possibility of subsequent editing or drawing any geometric shapes is provided.

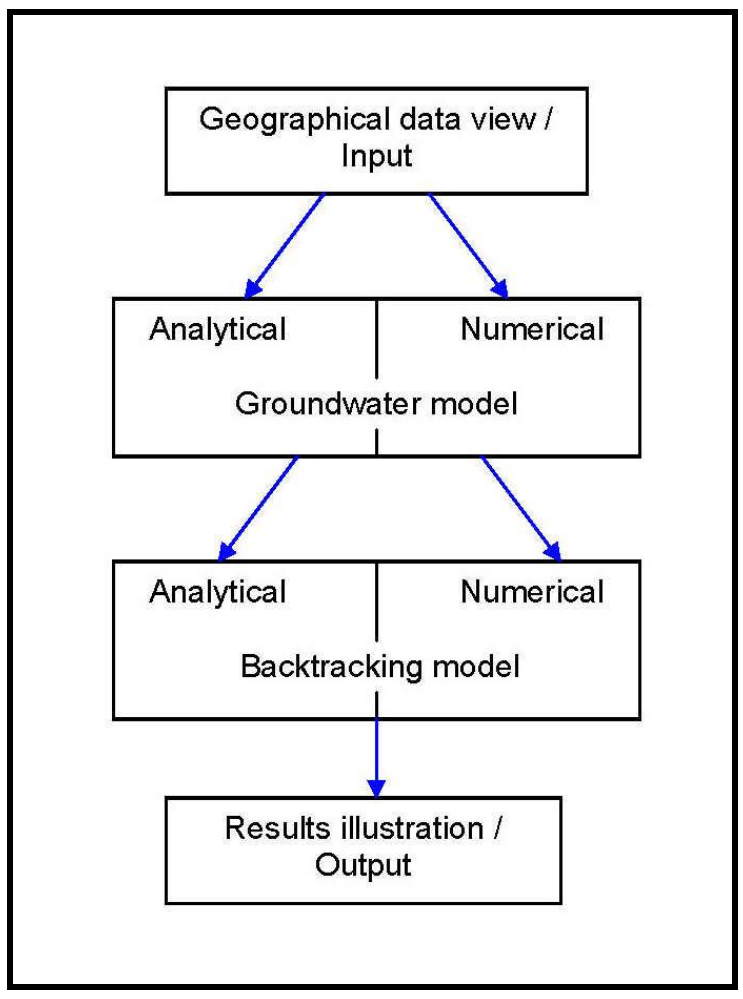

i. Input of geographical data in data view

ii. Groundwater Model: Analytical control plane calculations, numerical groundwater modelling in PMWin (WebTech 360, Processing Modflow Pro).

iii. Backtracking model: analytical calculations and numerical modelling in CSTREAM (Bayer-Raich et al., 2003a, Bayer-Raich et al., 2003b, BayerRaich et al., 2004).

iv. Output data and illustration of results in data view.

Fig. 3.1-1: Flow chart of ModBack with explanation on right side from i-iv: Input data, Groundwater model, Backtracking model and result illustration.

\subsection{System Requirements}

The precondition for using ModBack contains computer software terms, such as a Microsoft Windows operating system, with of 2 GB internal memory, at least 256 MB RAM of graphic board and Microsoft .NET Framework 3.1 SP1 as a substructure. Additional software is indispensable for a system run: ESRI ArcGIS 10.0 ${ }^{\circ}$, Processing Modflow Pro 7.0 (PMWin, WebTech 360, Processing Modflow Pro, PMPath, Wen-Hsing Chiang, 2005), NAS (VirginiaTech, USGS and NAVFAC cooperation), CSTREAM (Bayer-Raich et al., 2003a, Bayer-Raich et al., 2003b, Bayer-Raich et al., 2004), Golden Software Surfer and Microsoft Excel. ModBack is provided as a data package, consisting of system folders for the individual processing steps, equal to those in Fig. 3.1-1. The software itself is available as an executable file. 


\subsection{Development}

The creation of an $\operatorname{ArcGIS}^{\circledR}$ - and Windows Forms based, object orientated software like ModBack is basically possible by the use of ArcObjects $^{\mathrm{TM}}$ and VisualBasicNET.

The ArcGIS ${ }^{\circledR}$ family is a platform for Geographical Information Systems. It is based on programmable software components of ArcObjects $^{\mathrm{TM}}$ (Cameron et al., 2004a) and embodies the interface between the $\operatorname{ArcGIS}^{\circledR}$ components (Developer Kits) and the Application Server (ArcSDE) to gain access to the fundamental database for management and sharing in spatial data as tables. According to Cameron et al. (2004a) $\operatorname{ArcGIS}^{\circledR}$ affords a set of software products to create, use or export spatial data and is built-up by four blocks of GIS types (Fig. 3.3-1, i-iv):

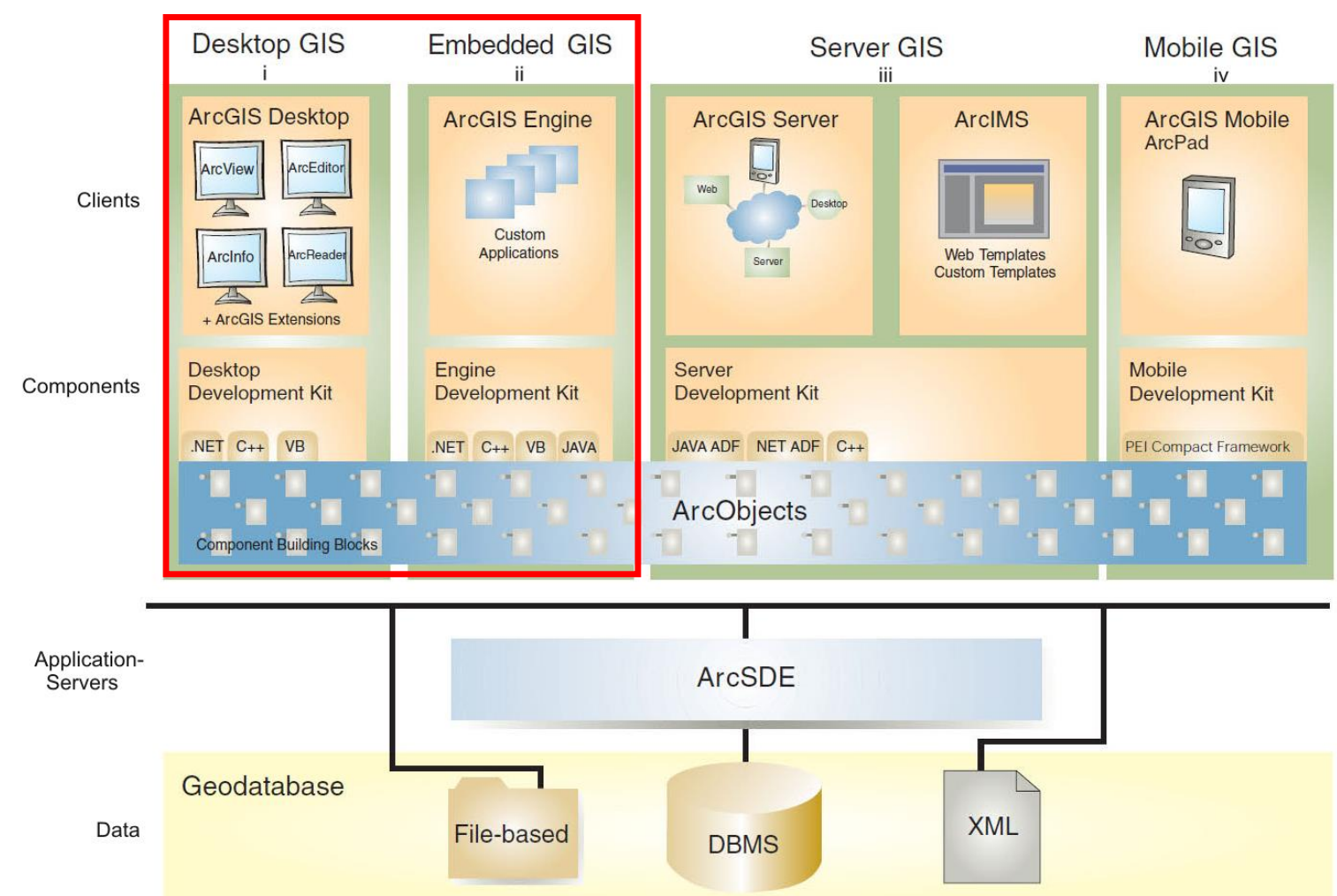

Fig. 3.3-1: ArcGIS structure of the individual products (i-iv), the red box indicates the used products. (Modified after Cameron et al., 2004a).

(i) Desktop GIS is composed of $\operatorname{ArcGIS}^{\circledR}$ Desktop, including a series of Windows ${ }^{\circledR}$ desktop application frameworks, such as $\operatorname{ArcMap}^{\circledR}, \operatorname{ArcCatalog}^{\circledR}, \operatorname{ArcToolbox}^{\mathrm{TM}}$, integrated functional levels, clients $\left(\operatorname{ArcView}^{\circledR}, \operatorname{ArcEditor}^{\circledR}, \operatorname{Arcinfo}^{\circledR}, \operatorname{ArcReader}^{\circledR}\right.$, ArcGIS $^{\circledR}$ Extensions $^{\mathrm{TM}}$ ) and the component Desktop Development Kit, available for coding languages as .NET, C++ and VisualBasic. 
(ii) Embedded GIS collectively consists of the clients ArcGIS ${ }^{\circledR}$ Engine, comprising Custom Applications, and the Engine Development Kit component to build user specific software applications. Additional to Desktop GIS, Java API is suitable.

(iii) Server GIS is constructed by $\operatorname{ArcGIS}^{\circledR}$ Server and $\operatorname{Arc}^{\top M} I M S$, comprising Web and Custom Templates as well as clients for Web, Desktop and Server. It is equipped with Server Development Kit, selectable by Java, .NET, and C++ ADF, to implement enterprise GIS applications.

(iv) Mobile GIS is build-up by $\operatorname{ArcGIS}^{\circledR}$ Mobile and ArcPad clients, inclusive of the Mobile Development component and recallable by PEI Compact Framework.

For coding ModBack as a standalone application, ArcGIS ${ }^{\circledR}$ Desktop and ArcGIS ${ }^{\circledR}$ Engine Development Kits have been used (red box, Fig. 3.3-1). The ArcGIS ${ }^{\circledR}$ Desktop Developer Kit enables an extension or customisation of desktop application frameworks and supports the COM and .NET API, to develop new GIS tools, user interfaces, improved functions and full extensions for upgrading productivity of GIS (Cameron et al., 2004a). According to Cameron et al. (2004b) ArcGIS ${ }^{\circledR}$ Engine is embedded specifically for software development, having several GIS components to code component-based software or to develop custom GIS and mapping applications.

The main sections can be summarised as a collection of libraries with GIS components base service, data access, map presentation and extensions (ArcObjects ${ }^{\mathrm{TM}}$ ). The components are split into so called "coarse-grained" objects, like map objects, or "fine-grained" objects, such as individual geometry objects. Value-added developer controls, like SDK, are managed with application development and top off the spectrum of controls.

ModBack is explained in detail in the subchapters 3.3.1, 3.3.2 and 3.3.3, focusing on ArcObjects $^{T M}$ components (ObjectLibraries), the already existing integrated tools, and self-coded advanced tools. For privacy reasons, the source code will not be explained and the tools will be explained only with respect to their function.

The ModBack handling is either found in User Manual of ModBack (Thomas-Thielsch et al., 2012) or affiliated at the level of the program code. 


\subsubsection{Libraries and Controls}

ArcGIS ${ }^{\circledR}$ Objects can be built and extended in a broadest sense by using Developer Kits. ArcGIS ${ }^{\circledR}$ Desktop Developer Kit offers 59 libraries, all split into main libraries. The libraries are specialised for User Interface design (UI libraries) and integrate standard commands and tools contributed to the framing. ArcGIS ${ }^{\circledR}$ Engine provides extensions for ObjectLibaries. ObjectLibraries, with standard programming, represent the framework to build the cornerstone of coding a GIS standalone application. "Coarse-grained" objects, such as map objects that interact with existing ArcMap ${ }^{\circledR}$ documents e.g. (open, save, close) or "fine- grained" objects, as individual geometry objects, including comprehensive GIS functionality and object libraries (developer components) in a structured design (Fig. 3.3.1-1, Fig. 3.3.1-2, Cameron et al., 2004a, , Cameron et al., 2004b, Bader et al., 2004) can be selected. Within ModBack there are 17 main libraries from ArcGIS ${ }^{\circledR}$ Desktop Developer Kit, 12 ArcGIS $^{\circledR}$ Engine Developer Kit UI libraries and 7 "fine grained" libraries have been made accessible. The following Tab. 3.3.1-1 shows a listing of all libraries.

Table 3.3.1-1: Integrated ArcObjects Libraries separated main libraries, UI libraries and "finegrained" libraries according to $\operatorname{ArcGIS}^{\circledR}$ Desktop and $\operatorname{ArcGIS}^{\circledR}$ Engine Developer Kit.

Desktop Dev. Kit Main Libraries
Esri.ArcGIS.ArcGIS
Esri.ArcGIS.Carto
Esri.ArcGIS.Controls
Esri.ArcGIS.DataSourceGDB
Esri.ArcGIS.DataSourceFiles
Esri.ArcGIS.DataSourcesNetCDF
Esri.ArcGIS.DataSourceOleDB
Esri.ArcGIS.Display
Esri.ArcGIS.Geodatabase
Esri.ArcGIS.GeoDatabseDistributed
Esri.ArcGIS.GeoDatabaseExtensions
Esri.ArcGIS.Geoprocessor
Esri.ArcGIS.Geometry
Esri.ArcGIS.GISClient
Esri.ArcGIS.GlobeCore
Esri.ArcGIS.Output
Esri.ArcGIS.System

\begin{tabular}{l} 
Engine Dev. Kit UI Libraries \\
\hline Esri.ArcGIS.ArcMapUI \\
Esri.ArcGIS.CartoUI \\
Esri.ArcGIS.Catalog \\
Esri.ArcGIS.CatalogUI \\
Esri.ArcGIS.DisplayUI \\
ESRI.ARcGIS.Editor \\
Esri.ArcGIS.Framework \\
Esri.ArcGIS.GeoDatabaseUI \\
Esri.ArcGIS.Geoprocessing \\
Esri.ArcGIS.GeoReferenceUI \\
Esri.ArcGIS.LocationUI \\
Esri.ArcGIS.SystemUI \\
Engine Dev. Kit Libraries "fine-grained" \\
Esri.ArcGIS.ADF \\
Esri.ArcGIS.3DAnalyst \\
Esri.ArcGIS.Animation \\
Esri.ArcGIS.AxControls \\
Esri.ArcGIS.AnalysisTools \\
Esri.ArcGIS.esriSystem \\
Esri.ArcGIS.Version
\end{tabular}

The block diagrams in Fig. 3.3.1-1 and Fig. 3.3.1-2 visualise the branched network of Object Libraries. In both figures, the used libraries are highlighted; omitted ones are shaded in grey. The library dependency order is more conspicuous. ArcGIS.System represents the base of the $\operatorname{ArcGIS}^{\circledR}$ main library structure (Fig. 3.3.1-1). ArcGIS.Framework is the gateway for subsequent UI libraries (Fig. 3.3.1-2). According to that, the use of contiguous libraries needs to be followed stringently to succeed within the network of linked logical operations. 


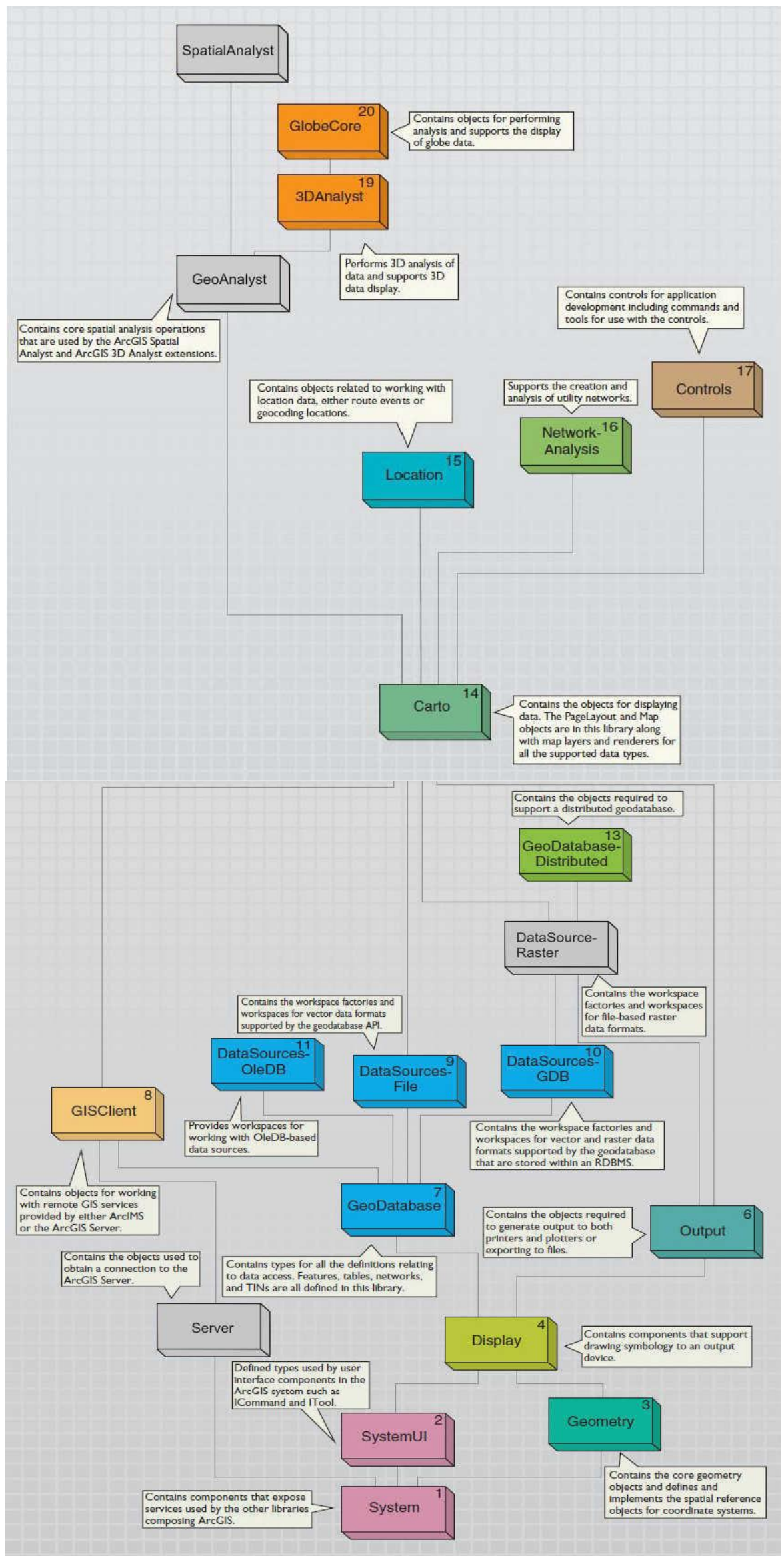

Fig. 3.3.1-1: Structure tree of $\operatorname{ArcGIS}^{\circledR}$ Desktop Developer Kit main libraries, used are highlighted in colour, unused are shaded in grey, speech bubbles comprise the purpose of libraries. (Modified after Cameron et al., 2004a). 


\subsubsection{Libraries and Controls}

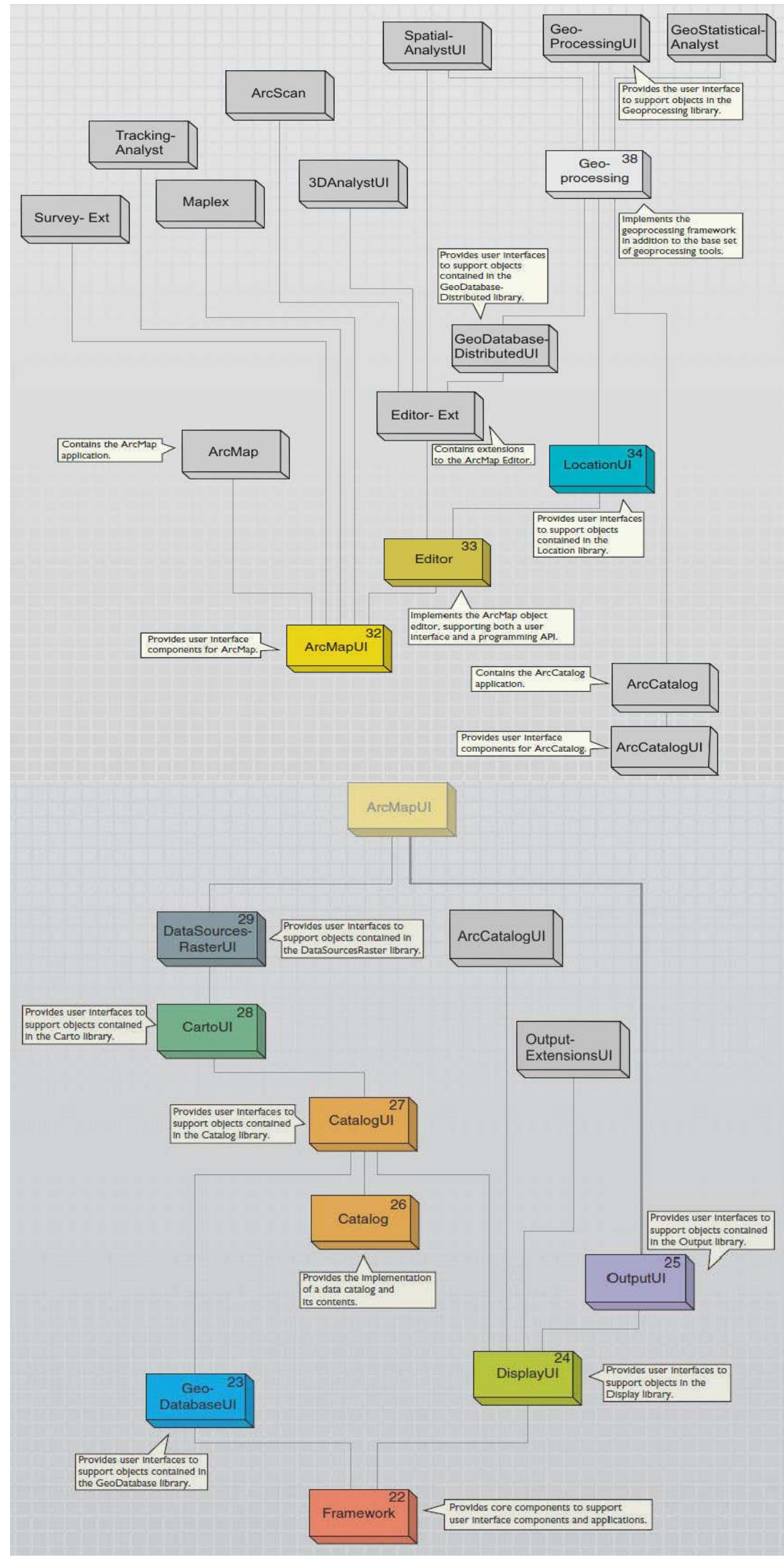

Fig. 3.3.1-2: Specification tree of ArcGIS ${ }^{\oplus}$ Desktop Developer Kit UI Libraries, used are highlighted in colour, unused are shaded in grey, speech bubbles contain the function of libraries. (Modified after Cameron et al., 2004b). 
Besides the libraries mentioned above, Microsoft.System libraries and Window-based libraries have been used, which are necessary for object orientated programming within Visual Basic.NET, for which further detailed information can be found in Kofler (2008).

Each ObjectLibrary contains developer components, so called Controls, with $\operatorname{ArcGIS}^{\circledR}$ functionality and supply a graphical user interface, among others available as a .NET Windows control (Cameron et al. 2004b). Inherent parts of ModBack are "coarse-grained" controls, like (i) LicenseControl, (ii) BuddyControl, (iii) MapControl, (iv) TOCControl, (v) ToolbarControl as well as (vi) ReaderControl, all providing a visual design environment ("fine-grained" controls), as shortly explained in the following after Cameron et al. (2004b), according to the implementation within ModBack:

(i) LicenseControl: Initialises an application with a convenient $\operatorname{ArcGIS}^{\circledR}$ licence.

(ii) BuddyControl: Generates a conjunctional work between the controls MapControl, ToolbarControl and TOCControl.

(iii) MapControl: Corresponds to the data view of $\operatorname{ArcMap}^{\circledR}$ Desktop application and enables to read and write map documents (open map, save map, close map).

(iv) TocControl: Displays map document layers and their symbology in a tree structure.

(v) ToolbarControl: Includes a series of commands and tools for modifying the map view (zooming, panning, document extend), shortcut buttons of the main menu (open map, save map, add vector data) and submenus to edit existing data.

(vi) ReaderControl: Corresponds to the data views of the ArcReader ${ }^{\mathrm{TM}}$ Desktop application and allocates the internal windows and tools Find window and the Identify tool.

Beyond the available standard commands, there are other integrated user functions. This includes extensions of the File Menu, with commands to export a map or exit the software, save a layer file, program settings, and a TOC Toolbar Menu that includes tools and commands for changing layer symbology, removing layer and zooming to selected layer have been added and coded by hand. A direct link to the included software PMWin (WebTech 360, Processing Modflow Pro), CSTREAM (Bayer-Raich et al., 2003a, Bayer-Raich et al.,

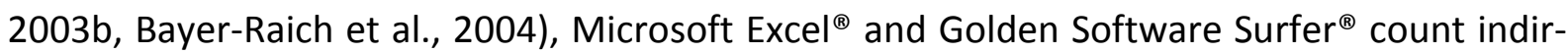
ectly to the additional and indispensible functions within ModBack, established for independent use and for further semi-automated work. 


\subsubsection{Advanced Tools}

The exclusive use of available encoded commands in ObjectLibraries is not sufficient in order to create such an extensive tool as ModBack and it fails to answer the question of delimiting the contamination source in groundwater. Consequently, advanced tools have been established to simplify the handling of numerically determined data and their analysis. The results of analytical and numerical approaches are essential for further investigation tools. Evaluation and processing of pathlines is set as central task, with the aim to determine the spread of pollution by plume length calculations or plume length statistics to delimit potential contamination source or absence zones, according to Jarsjö et al. (2005).

The fundamental method for the realisation of innovative features within ModBack can be attributed to a direct transaction with an embedded temporary database. Acting as a clipboard in the background, it is automatically activated and intercepts any interaction with ModBack's functionality. Various integrated security levels ensure a smooth operation by a reset of potential buggy data input or by showing a warning message.

The prerequisite of functional ModBack software requires a path definition to the respective storage locations of specified software programs (ModBack, ESRI ArcGIS $10.0^{\odot}$, PMWin, WebTech 360, Processing Modflow Pro, Golden Software Surfer and NAS), (Fig. 3.3.2-1).

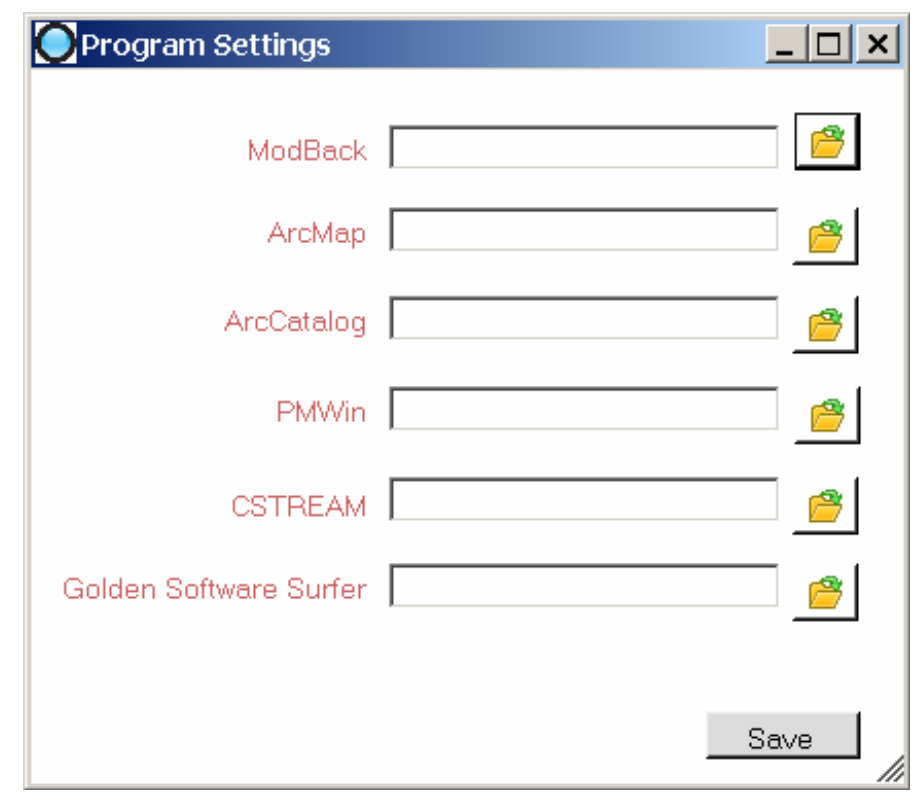

Fig. 3.3.2-1: Program Settings. 
By navigating through the Explorer's structure tree and selecting the according main folder, the acquisition is done. After saving, a new input is normally not necessary for further work sessions on the same computer.

This section will explain any advanced tools (subchapter 3.3.2.2) in their development and coded structure, as well as integrated computer software in subchapter 3.3.2.1. The underlying code will find no detailed attention.

\subsubsection{Integrated Features}

To acquire pathline information and backtracking results, a wide network of previous investigations are needed.

The hydrogeological approach is split into two application packages encompassing groundwater and backtracking modelling (Fig. 3.1-1). Groundwater modelling provides flow and transport model results needed for any other considerations within ModBack. Thus speaking, the more realistic the groundwater model set up, the more the results will be presentable. The quantities of the backtracking elevations mentioned above use IPT data explicitly. If no IPTs were performed or no information on older data records is available, the analytical approach Control Plane (Fig. 3.3.2.1-1) is implemented to generate an imaginary IPT, by defining the maximum radius of contribution (radius of capture zone) of a single well at a certain pumping time point. The position of a Control Plane can be determined graphically at half distance between two adjacent wells in meters. To perform a simulated IPT, different time steps can be set by defining different radii of contribution (capture zone). The calculation of the pumping time is carried out by a slightly modified cylinder formula inside a Microsoft Excel sheet with reference to hydrogeological parameters (drawdown $[\mathrm{m}]$, rate of discharge $[\mathrm{l} / \mathrm{s}]$, aquifer thickness $[\mathrm{m}]$ and the effective porosity [-]) as well as the determined maximum radius of contribution. The artificial inquiry of the IPT pumping time is calculated automatically. The calculation has to be performed for each well separately. The resulting pumping time can be used for numerical groundwater modelling and will be saved temporarily. Microsoft Excel, as standalone application, will be shown after calling within the GUI in the foreground and can be hidden manually. 


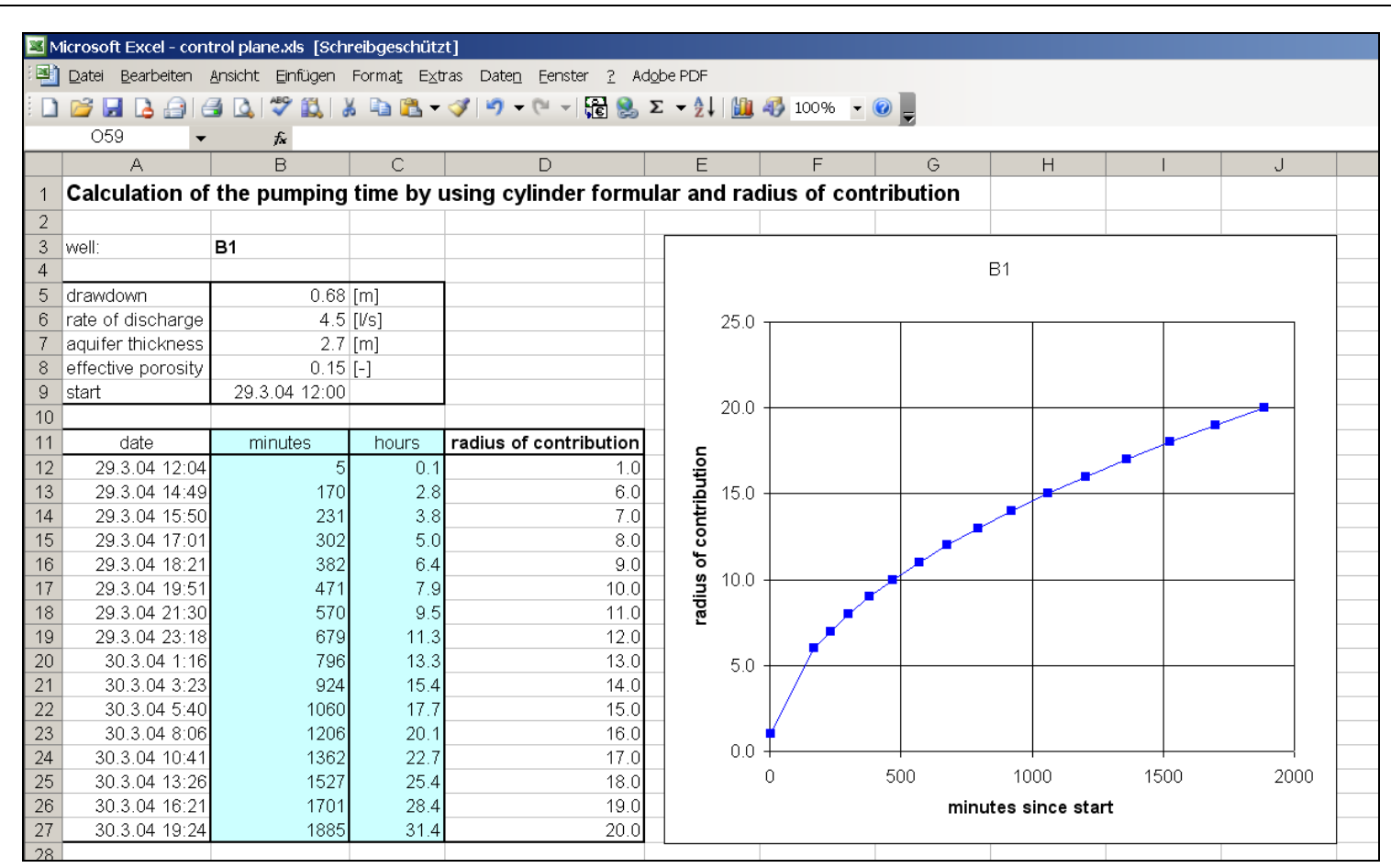

Fig. 3.3.2.1-1: Analytical integrated approach to calculate the pumping time using a modified cylinder formula. (Bear and Jacobs, 1978).

Numerical groundwater modelling mainly refers to the groundwater modelling software PMWin. It is integrated in ModBack by a shortcut to show the software independently in the front (Fig. 3.3.2.1-3). Independent software also implies independent use. It is possible to either use an already existing model or to set-up a new one. In case of the creation of a new model or a modification of an already existing model, the modelling time can be adjusted according to the calculations of the Control Plane.

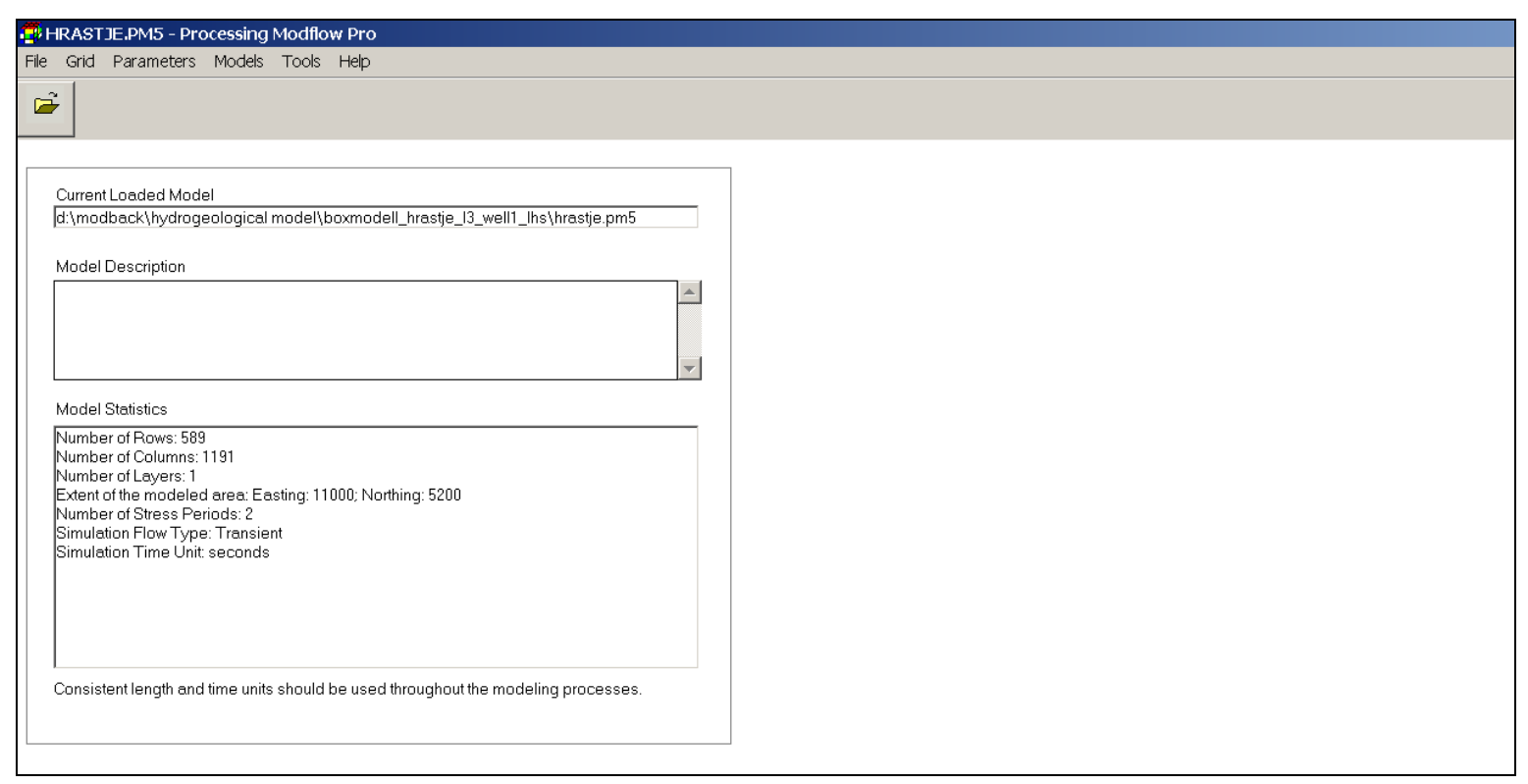

Fig. 3.3.2.1-2: Screenshot of PMPath GUI. (Wen-Hsing Chiang, 2005). 
All other necessary hydrogeological input parameters, with units are given in brackets, (horizontal hydraulic conductivity: $\left[\mathrm{LT}^{-1}\right]$, specific storage $\left[1 \mathrm{~L}^{-1}\right]$, transmissivity $\left[\mathrm{L}^{2} \mathrm{~T}^{-1}\right]$, storage coefficient $[-]$, effective porosity $[-]$, specific yield $[-]$, well with a pumping rate $\left[\mathrm{L}^{3} \mathrm{~T}^{-1}\right]$ ) have to be entered manually. The aim of creating pathlines is to achieve the knowledge of the backtracked advective distance of a contaminant over a certain period of time at a certain well. The idea behind this is to create two pathlines for one well, one at each end of the control plane. Starting points of the pathlines have to be added manually. The estimation of possible pathlines within PMPath (Wen-Hsing Chiang, 2005) is based on advective transport calculations. The resulting data format is a matrix. A specially coded copy command transfers the 17 PMWin resulting files (wel.dat, bas.dat, bcf.dat, budget.dat, ddown.dat, discret.dat, heads .dat, MAIN30.dat, MAIN.dat, mt3d.flo, oc.dat, output.dat, pcg2.dat, WATERBDG.dat, WBLZONE.dat, * .nam, rch.dat) into a predefined folder within the ModBack system for further numerical backtracking analyses in CSTREAM (Bayer-Raich et al., 2003a, Bayer-Raich et al., 2003b, Bayer-Raich et al., 2004).

The Backtracking approach itself is subdivided into two sections of analytical and numerical approaches. The analytical one is linked to an IPT tool after Rothschink (2007), shown within a Microsoft Excel sheet, as following (Fig. 3.3.2.1-3):

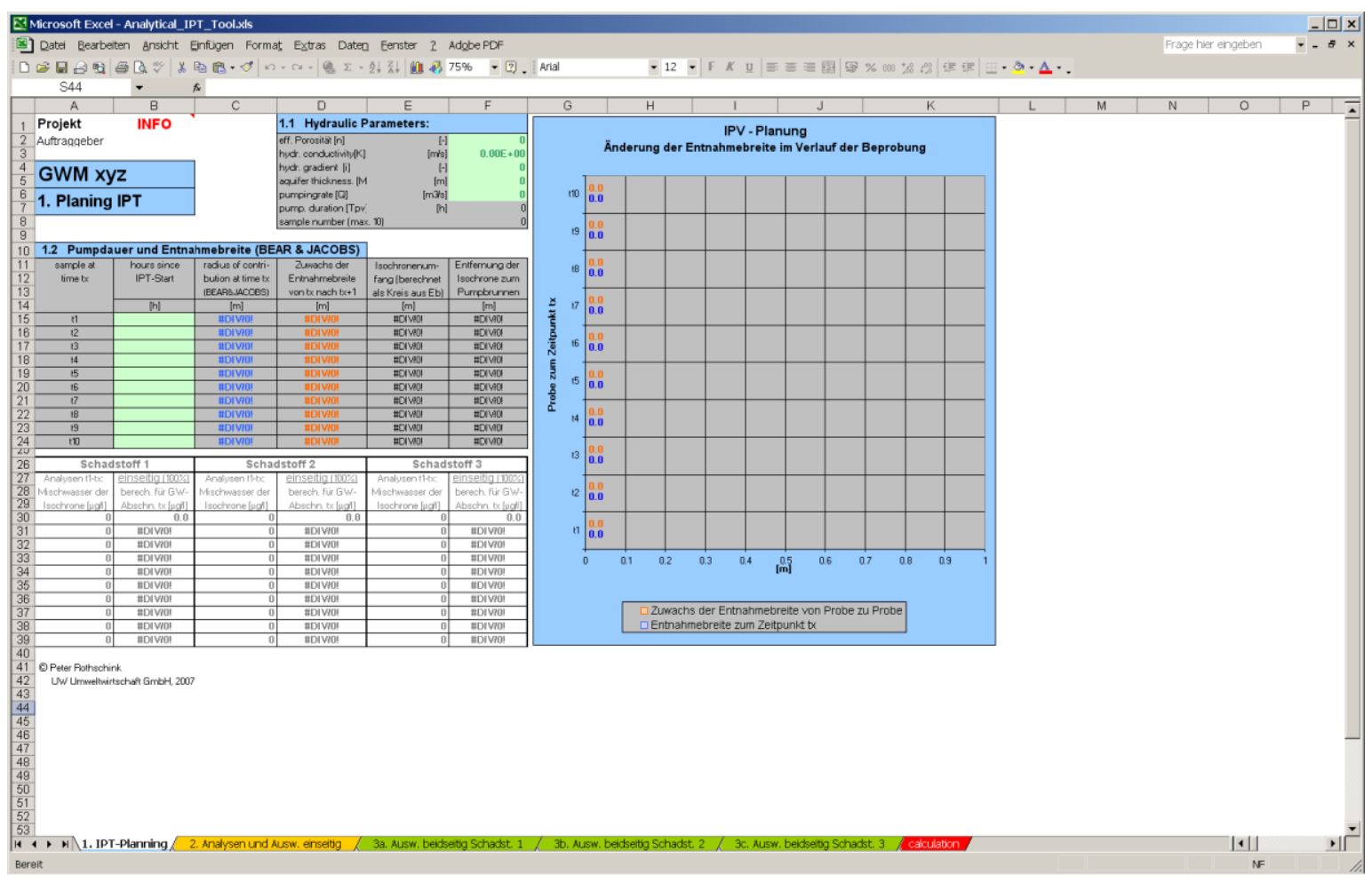

Fig. 3.3.2.1-3: GUI of the analytical backtracking tool. (Rothschink, 2007). 
The IPT tool is also an independent tool and serves as an additional approach to determine a possible source of contamination, regardless of numerical modelling, by the way of planning an IPT, an analysis and evaluation of contaminants is obtained (located on both sides or on one side of a well). This method is not needed beyond the previously generated data. It is solely attached for the completion of ModBack if insufficient information for a numerical approach is available. For further information, please take a look into the appropriate manual.

The numerical backtracking approach is colligated with the inversion tool CSTREAM after Bayer-Raich et al. (2003a), Bayer-Raich et al. (2003b) and Bayer-Raich et al. (2004) in console application, considering the site specific groundwater flow system and the analysed concentration time series of a contaminant.

CSTREAM allows an analytical and a numerical contemplation. Numerical Backtracking modelling is independent from analytical backtracking but based on numerical groundwater modelling results. To start the program CSTREAM, a shortcut command was coded. The required input data, resulting from the numerical groundwater modelling, were set as default. The handling is described in the ModBack User Manual (Thomas-Thielsch et al. 2012) and in the CSTREAM manual Bayer-Raich et al. (2003a), Bayer-Raich et al. (2003b) and Bayer-Raich et al. (2004). The results cannot be immediately transferred to a geographical data view. It requires a detour over Golden Software Surfer, executable by shortcut command in the front view, where the calculated flow lines, flow tubes and isochrones can be shown and exported as ESRI *.shp files or *.dxf data. Also via shortcut buttons, an access to the standalone NAS (Natural Attenuation software) computer software as well as to Plume length statistics after Schiedeck et al. (1997) was implemented. 


\subsubsection{Innovative Features}

The base process of innovative features can be attributed to a direct transaction with an embedded temporary database. Acting as a clipboard and temporary storage in the background, it automatically activates and intercepts an interaction with ModBacks functionality. Various integrated security levels ensure a smooth operation.

In total, ten advanced functions have been developed, mainly included in the sector of data analyses but also for initial data conversion and upload in ModBack. These essential functions include: (a) Add*.dxf-files, (b) Convert Table, (c) Add x/y Data, (d) Points To Line, (e) Calculate Plume length, (f) Estimations of $1^{\text {st }}$ order decay, (g) Cut Pathlines, (h) Create Polygon, (i) Delimit Source Zone with (i-i) Source zone presence and (i-ii) Source zone absence, (j) Change Symbology and are described on the following pages. Each tool stands for its own class within the program code. They are selectable as a command in the main form (GUI) and displayed separately in a detached input window. The data selection is possible within these windows by given links to explorer structure tree.

The structure tree in Fig. 3.3.2.2-1 shows the context of incorporated tools (highlighted in yellow). These are divided into three main branches of analysis and data conversion tools, relating to the result input of CSTREAM (Bayer-Raich et al., 2003a, Bayer-Raich et al., 2003b and Bayer-Raich et al., 2004) and PMPath (Wen-Hsing Chiang, 2005) and the MODBACK analysis tools as well. The analysis features include three main topics: Converting of resulting points to lines, plume length statistics and finally the delineation of the source zone and its absence. The tools are only linearly connected and act without interactive loops. Individual work steps are built on each other indicated by blue arrows. The general order of processing tools can be followed by continuous black lines; optional extensions are marked by dashed lines. Resulting data are coloured in green. The advanced tools also include analytical approaches (coloured in blue). 

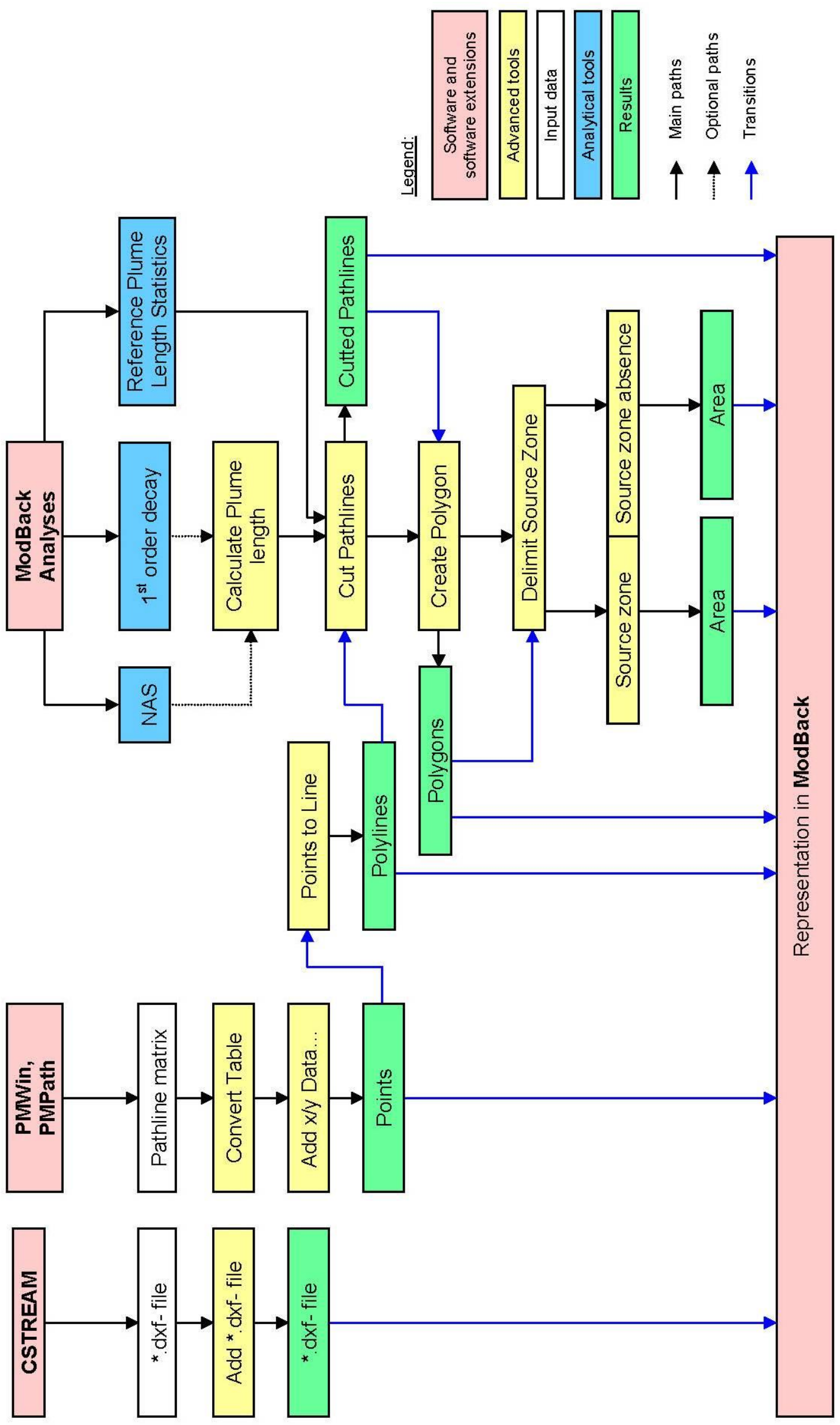

Fig. 3.3.2.2-1: Flow chart of advanced tools and results within ModBack. Legend is in the opposite site. 
The function (a) Add .dxf files (Fig. 3.3.2.2-1, Fig. 3.3.2.2-2) allows an upload and coordinate based display of CSTREAM *.dxf files only by file-selection within the input mask and an optional declaration of the coordinate system used. The data conversion is performed in the background, with reference to the temporary database. Any further interactive editing is not implemented.

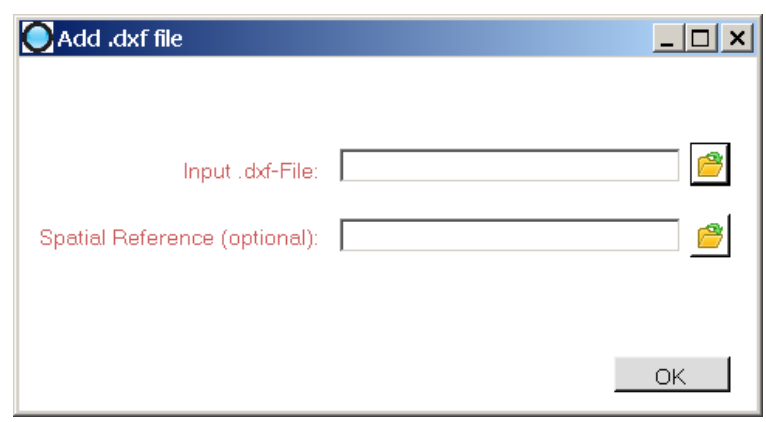

Fig. 3.3.2.2-2: Input window Add .dxf files.

$\operatorname{ArcGIS}^{\circledR}$ and consequently also ModBack do not allow any graphical representation of matrix data. To control PMPath (Wen-Hsing Chiang, 2005) pathline matrices results, a series of conversion tools have been developed to secure a coordinate based illustration of this information. This includes the conversion of matrices themselves, the uploading of the conversion file, as well as its further conversion into lines.

Any pathline matrix can be transferred to listed $x / y$ data using the (b) Convert Table command (Fig. 3.3.2.2-3, Fig. 3.3.2.2-1) by choosing a matrix within the input mask. The conversion is performed by transforming a matrix to a table, including three columns for $x$-coordinates, $y$-coordinates and an ID. According to the raw data, single line segments will be created as series of points (pathpointsets). In the case that more than one pathline is indicated in one matrix, they will be modified as self-acting points and stored as individual tables. The storage location of any table is not defined and freely selectable by the user (Save As... command, Fig. 3.3.2.2-12).

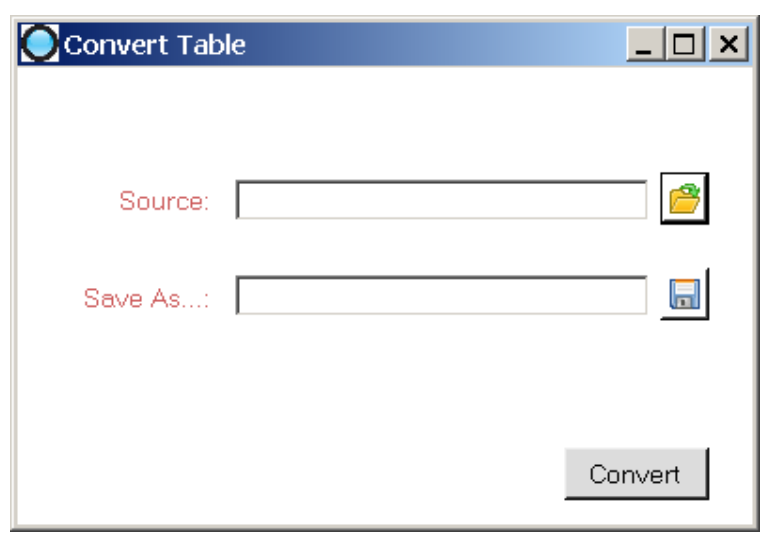

Fig. 3.3.2.2-3: Input mask of the Convert Table function. 
Add x/y Data... (c) (Fig. 3.3.2.2-1, Fig. 3.3.2.2-4) makes the addition of $x / y$ data to ModBack possible by adding as coordinate based pathpointset classes. The function requires a setting of the $x / y$ columns for each selected list, given in default. To maintain the versatility, a coordinate system is not predetermined and has to be set manually. The visual conception of $x / y$ data as pointset is code-controlled by default point size and their colour descriptions. The pathpointsets are saved temporarily in the internal storage.

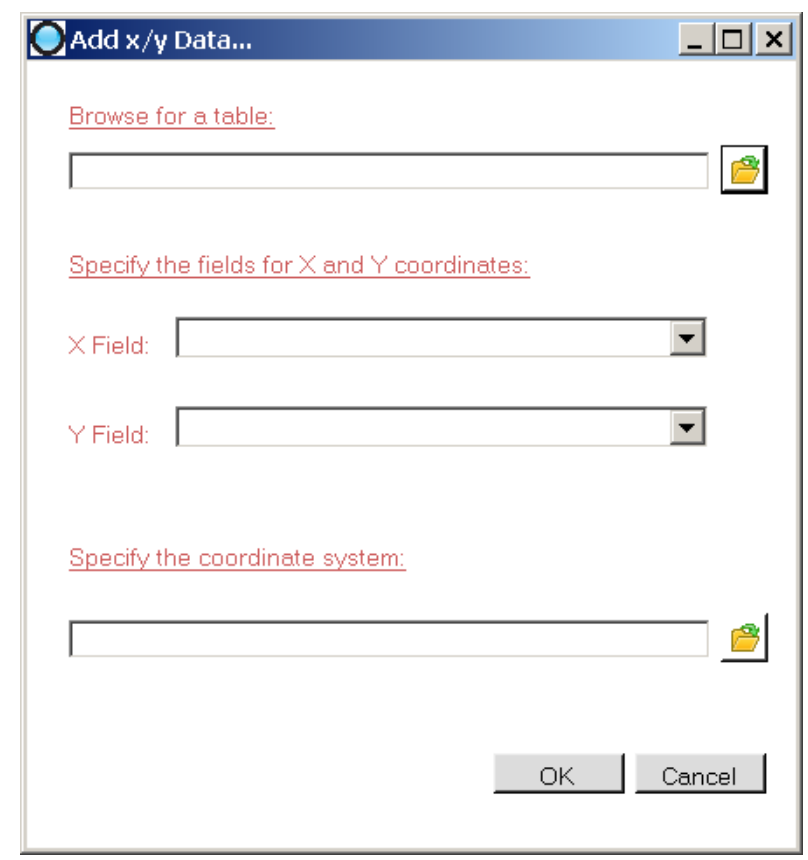

Fig. 3.3.2.2-4: Add x/y Data... functions.

Analysis tools within ModBack relate to the use of polylines. A transitional element between pathpointsets (added as $x / y$ table before) and polylines for completive analysis is the command (d) Points to Line (Fig. 3.3.2.2-5). The function connects individual points of a pathpointset as items in geographical order and forms a continuous polyline. The single items are invisible, but arithmetically present. Storage is momentary for the duration of application.

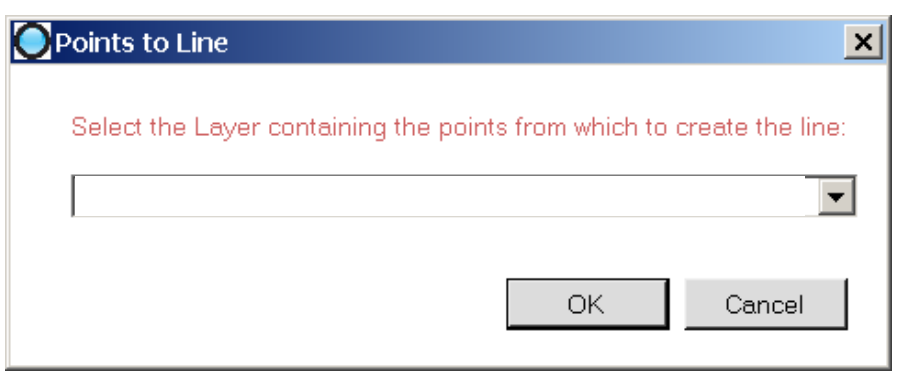

Fig. 3.3.2.2-5: Mask of function Points to Line.

The evaluation of the pathline lengths (plume length) is possible by a set of functions: Plume length statistics, plume length calculations based on hydrogeological parameters, 
natural attenuation as well as pollution degradation in $1^{\text {st }}$ order decay are possible. Whichever tool is used is up to the user and is not crucial for further processing, as long as the extension of a minimal or maximal plume length is known.

By means of the assumptions from Liedl et al. (2005), hydrogeological parameters are set in relation to each other and these affect the maximum length of a plume. Within the function (e) Calculate length (Fig. 3.3.2.2-6, Fig. 3.3.2.2-1), the parameters consist of: Aquifer thickness $(\mathrm{M})[\mathrm{L}]$, vertical transverse dispersivity $\left(\alpha_{T}\right)[\mathrm{L}]$, stoichiometric ratio $(\gamma)[-]$, concentration of electron donor $\left(C^{0}\right)\left[\mathrm{ML}^{-3}\right]$, and concentration of electron acceptor $\left(\mathrm{C}_{\mathrm{A}}^{0}\right)$ $\left[\mathrm{ML}^{-3}\right]$. The dimensions in the square brackets are flexibly set. The resulting plume length is given temporarily. The computation also runs in the background, in part depending on the temporary database.

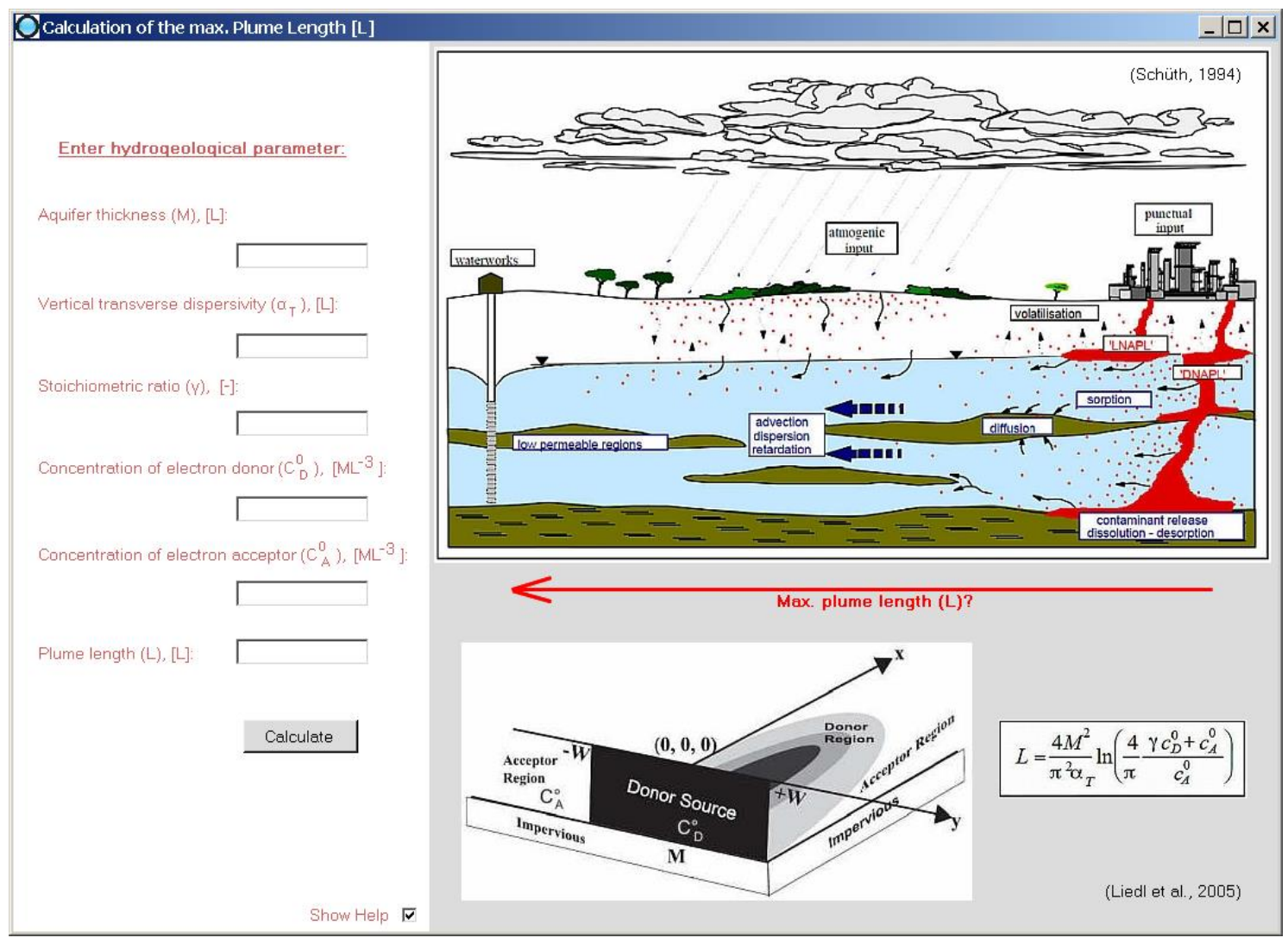

Fig. 3.3.2.2-6: GUI screenshot of advanced tool Calculate plume length, according to Liedl et al. (2005).

To calculate the natural attenuation of a pollutant according to the environmental influence, the Natural Attenuation command is created as a shortcut, accessing the homonymous software. The software is self-contained and opens in the foreground. The decomposition can be reckoned analytically in several steps. A result transfer for further computations is not given. 
The function (f) $1^{\text {st }}$ order decay (Fig. 3.3.2.2-7, Fig. 3.3.2.2-1) is coded as an advanced feature for the calculation of contaminant degradation as a $1^{\text {st }}$ order reaction for a pollutant concentration in dependence of the time and decay term. The initial concentration $\left(C_{0}\right)$ has to be used for the empirical definition of maximum plume length. The algorithm is based on Mortimer (1996). The result will not be saved.

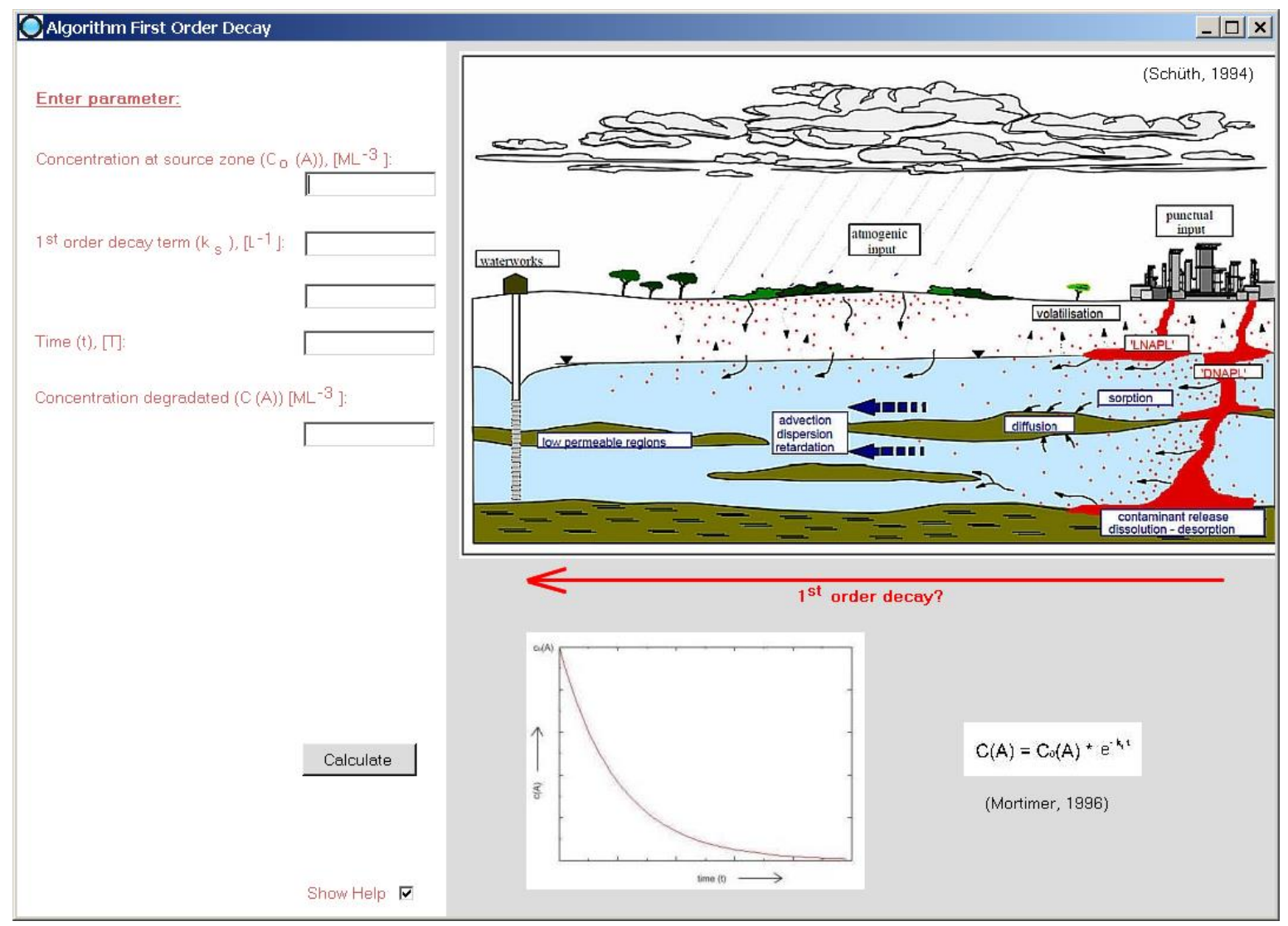

Fig. 3.3.2.2-7: $1^{\text {st }}$ order decay analytical function with parameter input fields. The composition formula and pollution distribution are given on the right site of the form.

In respect to pathlines of reactive compounds, the calculated or referenced lengths have to be picked up again to trim the original pathlines to its specific length. The underlying process calculates the distance between any segments of a line under consideration of a potential curvature and creates a new point as an endpoint at the location of specific length. The excessive part of the line is removed. Inside the command (g) Cut Pathlines (Fig. 3.3.2.2-8, Fig. 3.3.2.2-1) up to two lines can be edited simultaneously. The cutting length is limited to the accuracy of two decimal places and implies the curvature. After editing, the original lines are overwritten. The resulting polylines will be displayed in the Data Frame of Mod-Backs in a default colour and line width and will be saved temporarily. 


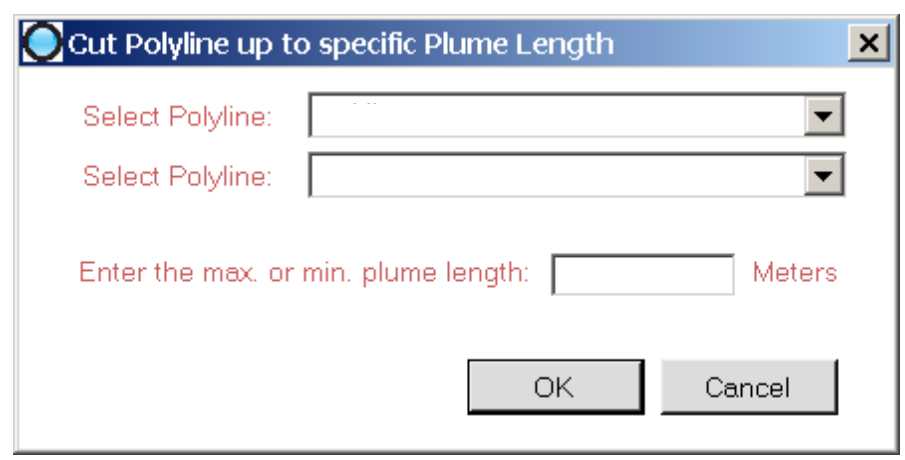

Fig. 3.3.2.2: Cut Pathlines command as input window.

The function Create Polygon (h) (Fig. 3.3.2.2-9, Fig. 3.3.2.2-1) enables to create polygons out of two polylines. The selection of the polylines is attainable in relative fields. Any added polylines to the map are listed as default, based on their order. The button OK verifies the input and shows the result automatically. The result is saved temporarily.

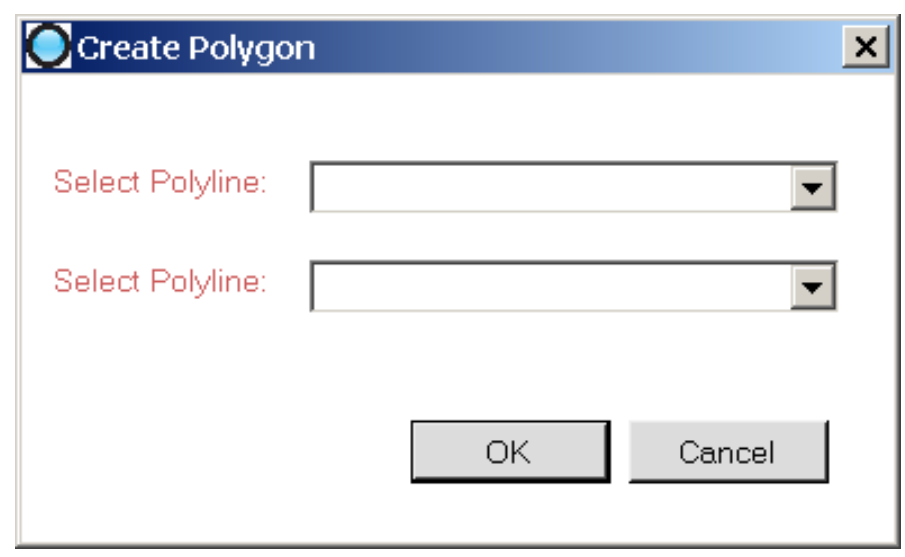

Fig. 3.3.2.2-9: Create Polygon.

To define possible contaminant source presence or source absence areas for inert and reactive contamination compounds, the feature (i) Delimit Source Zone combines pathlines to create areas as polygons with the help of the two functions (i-i) Source Zone and (i-ii) Source Zones Absence (Fig. 3.3.2.2-10, Fig. 3.3.2.2-1). This tool requires a unique input of pathlines for both features in order with their geographical range (black digits 1-4, Fig. 3.3.2.2-11). Under consideration of the endpoint of every line, the northern one is set up to position one, the direct underlying one in the southern the direction is set up to position two and so on.

The difference between reactive and inert pollutants only finds attention in pathline length. The source zones and their absence for reactive sources can be delimited by cutting pathlines. For inert compounds, pathlines in original length were considered. 


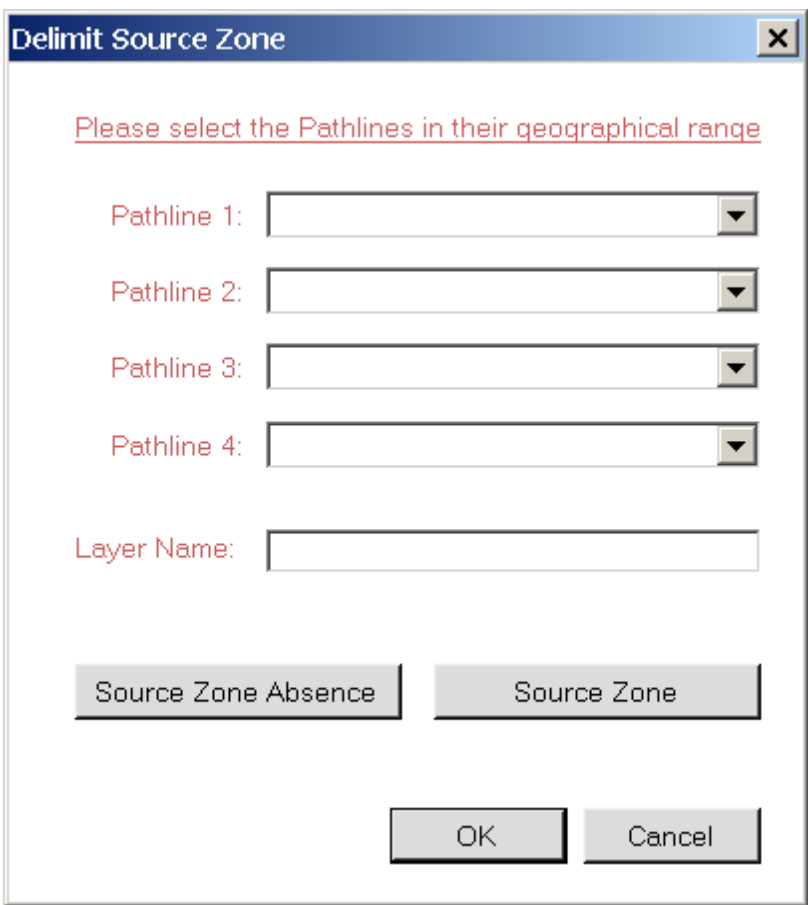

Fig. 3.3.2.2-10: Advanced tool Delimit Source Zone.

The calculation of the areas as polygons is executed by an abstract angle calculation. Starting at a central point and regarding a neutral axis $\left(0^{\circ}\right)$, the necessary pathlines will be computed in relation to that zero line (Fig. 3.3.2.2-11). Above the reference line, the angle information has to be added to $180^{\circ}$, beneath it, the angles have to be subtracted from $180^{\circ}$. At the beginning and the end of a line, the system recognizes and sets an imaginary point. In consideration of any possible curvature, the areas will be defined as an intersecting set or union of the pathlines, proceeding from imaginary items. The results are plotted instantaneously, but the layer is resided temporarily.

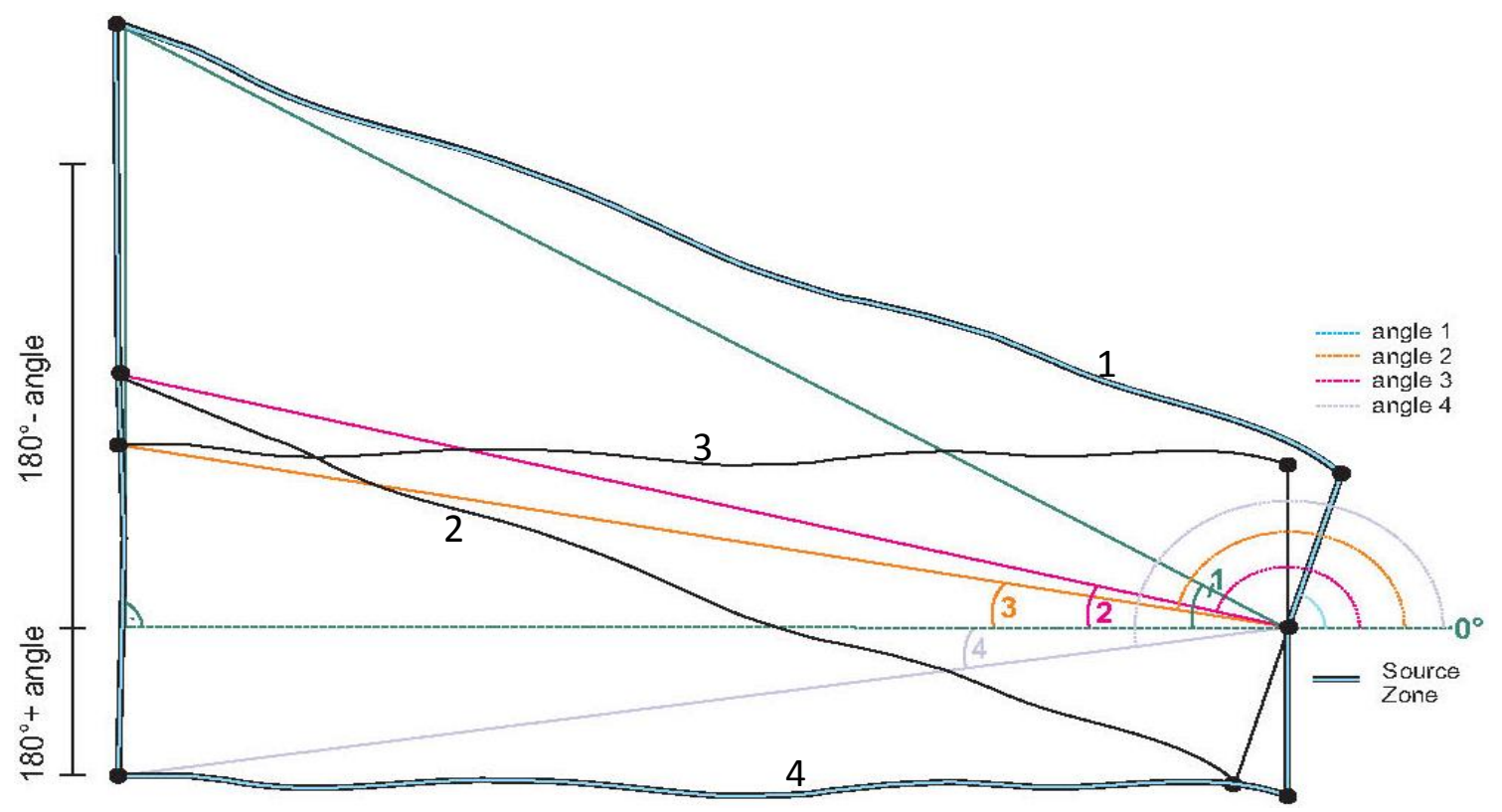

Fig. 3.3.2.11: Function of angle calculation in advanced tool Delimit Source Zone. 
Advanced features to simplify the handling of data in ModBack with respect to saving, removing or changing the symbology of data are also integrated, as explained in the following: To prevent a loss of data, any layer file is saveable as ESRI *.shp file.

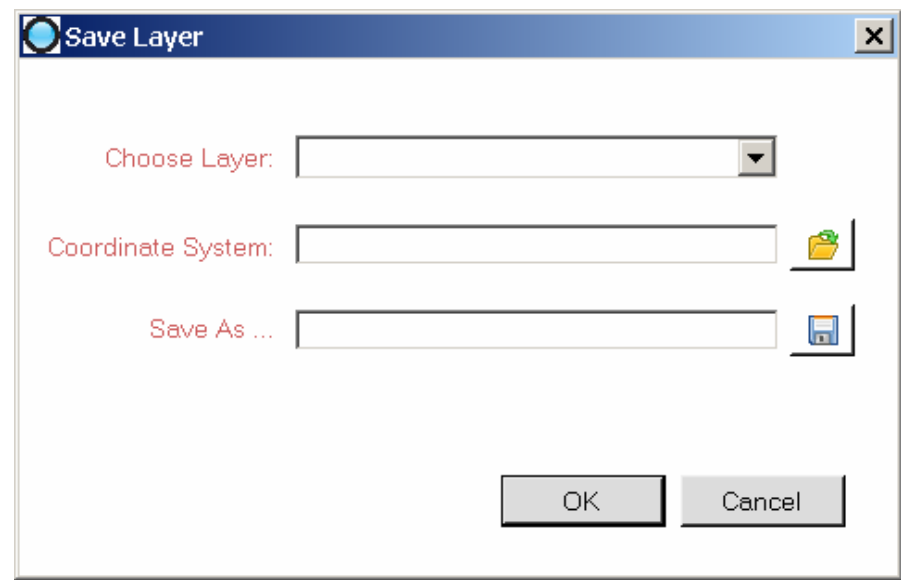

Fig. 3.3.2.2-12: Input Mask Save as Shapefile

The input mask Save Layer (Fig. 3.3.2.2-12) requires the layer selection and output location. Saving occurs in the background, the layer file will not be overwritten.

The colour of each created result (points, polylines, and polygons) is automatically assigned. Often the difference is barely visible. A modification of the symbols is possible by means of (j) Change Symbology (Fig. 3.3.2.2-13):

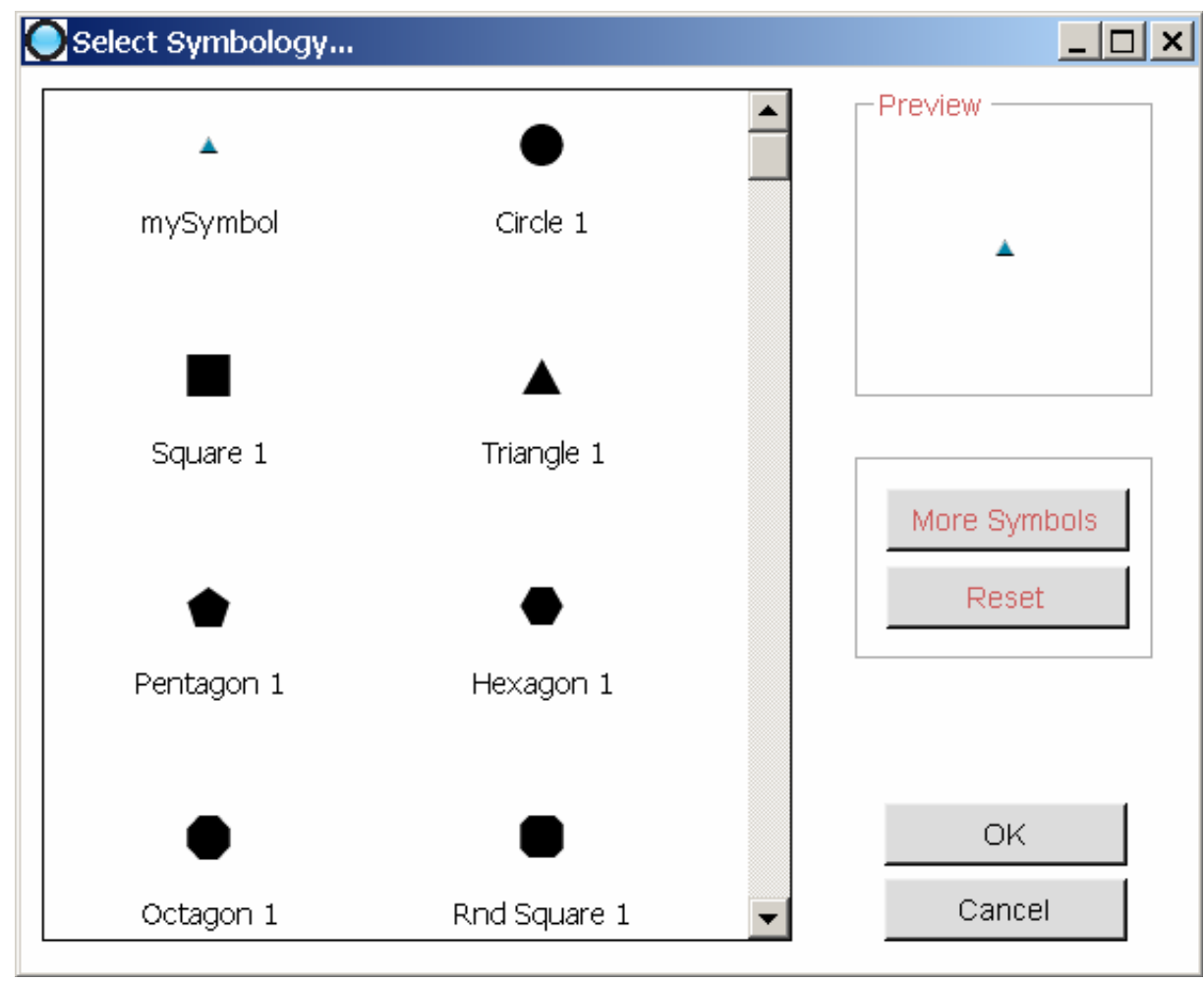

Fig. 3.3.2.2-13: Input Mask Select Symbology... 
Select Symbology changes the symbology, depending on the layer type (point, polyline or polygon). The symbol icons are displayed on the left side of the form. The actual symbol is marked in the symbol list and is shown with a preview on the upper right side of the form as "my Symbol". A symbol can be selected within the symbol list. The button "More Symbols" enables a selection from all symbols available in ArcGIS $^{\circledR}$, listed as groups, for the respective type of layer geometry. The "Reset" button returns the symbology to the initial value.

Each individual layer can be removed separately from ModBack by invoking the Remove Layer command. 


\subsubsection{Supplement}

Additional forms and tools complement ModBack in the help functions and appearance.

When launching ModBack a splash screen appears at first, showing the software name in central position. By means of a progress bar, the loading process of ModBack is visualised. Only after the program is completely loaded, the screen closes and the software is ready for use.

An About-Box (Fig. 3.3.3-1), called "About ModBack" is fitted with particulars of the software version, copyright, sponsoring, developer and supervisors. A brief description of the software is also given.

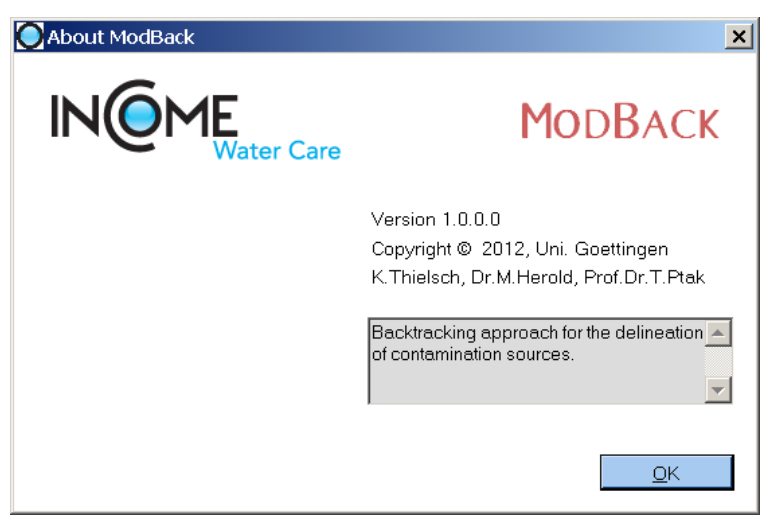

Fig. 3.3.3-1: About Box.

Shortcuts to user manuals in "Manuals" are given and structured according to the main menus in three parts (i) ModBack, (ii) Hydrogeological Model and (iii) Backtracking:

(i) ModBack: Opens the ModBack manual in *.pdf format.

(ii) Hydrogeological Model is divided into Analytical and Numerical model. These commands show the respective manual in *.pdf format.

(iii) Backtracking: This submenu is also organised in two parts. The commands Control Plane or Numerical show the specific manuals for the help of the Control Plane Excel sheet or the CSTREAM tutorial, both in *.pdf format. 


\subsection{Structure}

The following chapter serves as a summarising guideline to the structure of ModBack GUI and included tools, mainly based on the corresponding user manual after Thomas-Thielsch et al. (2012).

The general GUI structure, shortly described in section 3.1 as (i) Geographical data view / Input, (ii) Groundwater model, (iii) Backtracking model and (iv) Result illustration/ Output (Fig. 3.1-1, flow chart), has been extended as part of the development with several main tools and tasks, separated from each other into 4 sections, as graphically illustrated in Fig. 3.4-1 (1-4).

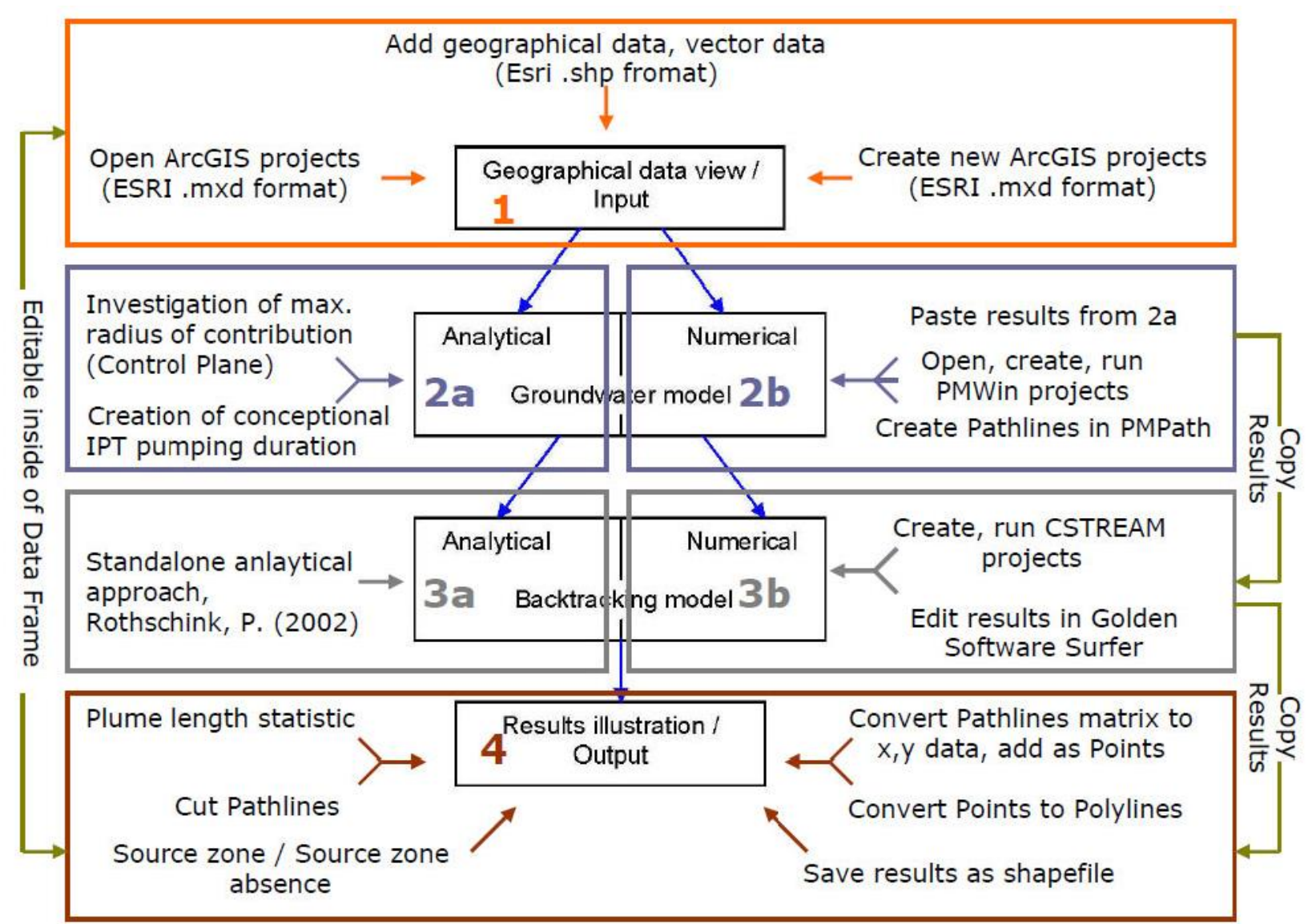

Fig. 3.4-1: Flow chart with integrated tools and tasks in four sections (1-4) and interactions (green and blue arrows). (Thomas-Thielsch et al., 2012).

According to Fig. 3.4-1, the first and fourth part $(1,4)$ are primarily concerned with the use of geographic data, such as the handling of major events. In most cases, geographical data of the respective test sites are provided. Any existing information in ESRI format (vector data or mapping projects) can be opened or added, created, edited and stored within the GUI. The presentation of the results and their interpretation is possible within the GUI. 
The Groundwater modelling in 2 combines analytical (2a) and numerical (2b) tools and provides an extended usage for source identification tasks. Highlighted herein is mainly the numerical generation of contaminant pathlines in PMPath (Wen-Hsing Chiang, 2005) across a well based control plane, defined by an analytical approach. A numerical groundwater model is a prerequisite. Its creation is possible in the independent software PMWIN as well as taking over an already existing one. Numerical Backtracking with CSTREAM in 3b builds on results of $2 \mathrm{~b}$ with the aim to calculate stream tubes and streamlines around a well, showing the distribution of contamination concentration. The result recognition is done automatically by internal call. An approximate analytical comparison represents the analytical approach after Rothschink (2007), attached in 3a. Part 4 moreover concentrates on advanced tools, explained in detail in chapter 3.3.2. Seven tools are acting with conversion and depiction of pathlines and resulting source zone areas (Convert Pathlines, Add Data, and Convert Points to Polyline, Plume length statistics, Cut Pathlines, Source zones and Source zones absences).

\subsubsection{Graphical User Interface (GUI)}

The four parts of procedures, explained above are incorporated in ModBacks GUI.

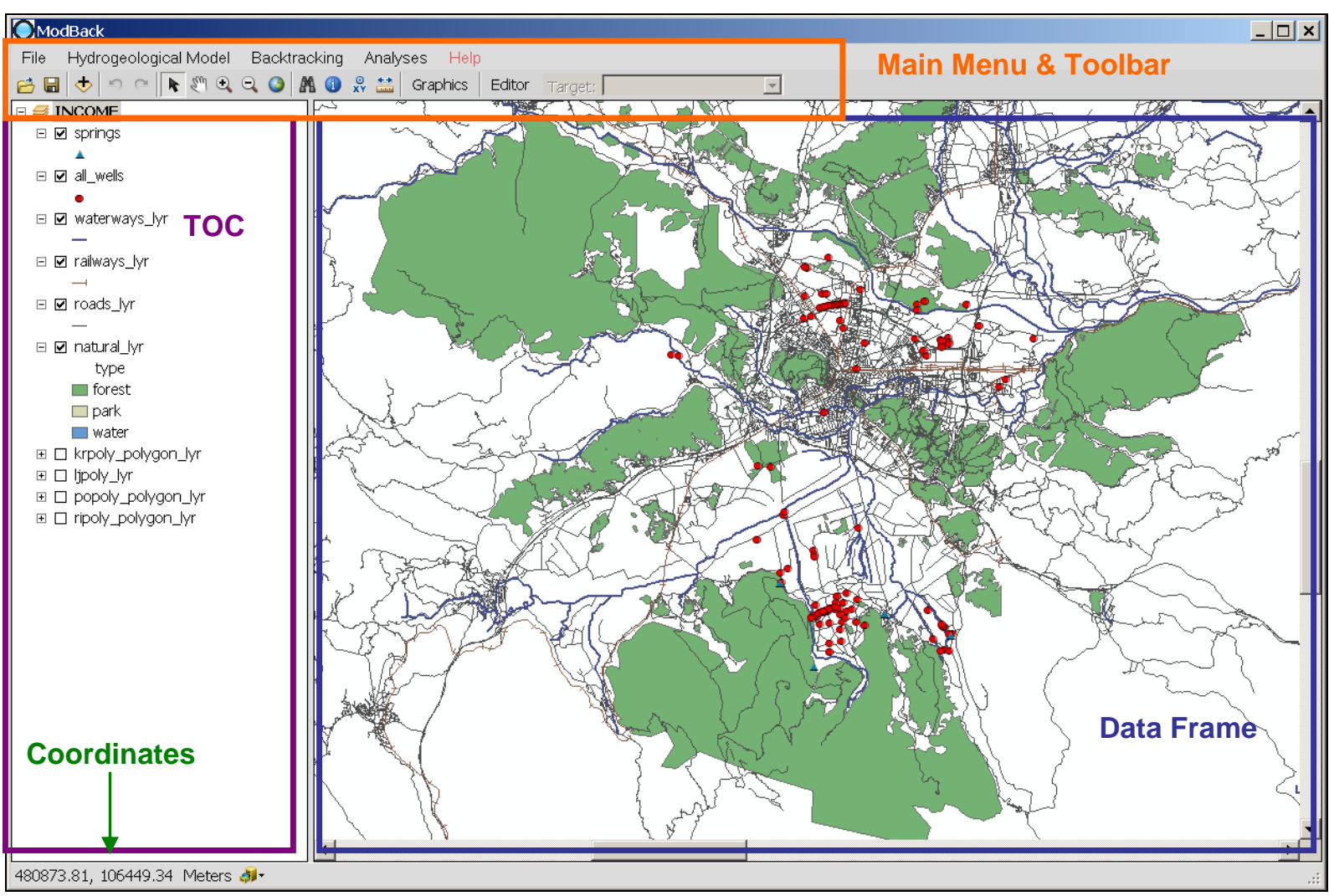

Fig. 3.4.1-1: ModBack - Graphical User Interface (main menu and toolbar in the the upper orange box, the Data Frame at the right-hand side (blue box), the TOC at the left-hand side (lilac box), coordinates in the lower left corner, green arrow ). (Modified after Thomas-Thielsch et al., 2012). 
The GUI is generally coded in semblance to ESRI ArcMap to aim at a certain familiarity to the user (Fig. 3.4.1-1). It is composed of two main sections: (i) Visualisation of geographical data as well as (ii) menus and tools. The Data Frame (right-hand side of the GUI), the Toolbar and the TOC (left-hand side of the GUI) are interactively linked (Buddy controlled). The Main menu is placed on top of the GUI. Shortcuts to the main menu, tools for modifying the map view submenus to edit existing data (Editor) or to create new graphics, such as curves, lines, points, circles or ellipses (Graphics) are positioned as Toolbar directly below. Also backing up individual projects in ESRI ArcGIS ${ }^{\circledR} *$.mxf format and the use of already existing projects is generalised. In the lower left corner of the GUI the coordinates of the current mouse position within the Data Frame are shown in a chosen format. The lower left part of ModBack shows mouse position specific coordinates. A shortcut to ArcCatalog is placed right beside it. Added geographical information like geographical vector data files, $\mathrm{x} / \mathrm{y}$ data tables and/ or *.dxf files are listed in a TOC and visualised within a data frame, according to their type of data (points, polylines, polygons), whereby the representation of input and output files is guaranteed.

\subsubsection{Table of Contents}

The TOC sequence of the arrangement from top to bottom reflects the position of the overlaying layers within the data frame. The type of each layer is predefined and symbolised below the layer names as point, line or square. The layer order, layer names as well as the colour, symbology (only for points and polylines) and visibility are not fixed within the code and are editable within the GUI. Any layer variation inside of the GUI does not have any implication on the original data. The original data are saved in the background. An integrated TOC Toolbar Menu (Fig. 3.4.1-1) enables commands for any layer within the TOC, referring only to the selected layer.

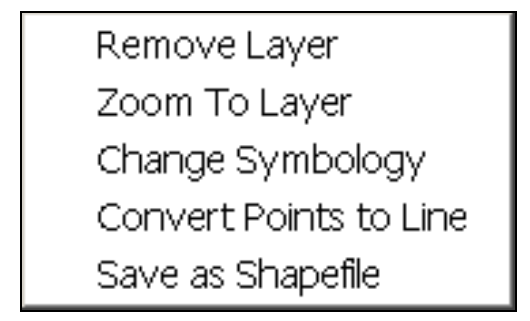

Fig. 3.4.1.1-1: TOC Toolbar Menu.

As shown in Fig. 3.4.1.1-1:1, this Toolbar Menu includes five commands (i) Remove Layer, (ii) Zoom To Layer, (iii) Change Layer symbology, (iv) Convert Points to Line, (v) Save as Shapefile. 
(i) Remove Layer: To delete the selected layer from the current map.

(ii) Zoom To Layer: To zoom to the selected layer in full extent.

(iii) Change Symbology: Opens a form to change the layer symbology, depending on the layer type.

(iv) Convert Points to Line: Automatically to create a line out of a pointset, for example an added pathline pointset. A minimum of two points is needed as input. This command only appears, if a usable pointset is added to ModBack.

(v) Save As Shapefile: To save the selected layer in ESRI *.shp format.

\subsubsection{Data Frame}

The Data Frame (Fig. 3.4.1-1) is a geographic data view, based on ESRI ArcGIS 10.0 ${ }^{\odot}$. It is only possible to view or edit geographical data, geographical maps or separate ESRI *.shp files. An existing map (as i.e. ESRI *.mxd-file) or vector data can be opened by shortcut buttons (see chapter 3.4.1.3 Toolbar. Changing the display view, zooming, shifting, editing of vector data is possible. The coordinates of the current mouse position within the Data Frame are displayed in the lower left corner of the window, according to the selected coordinate system of the map.

\subsubsection{Toolbar}

The toolbar contains several tools and is sorted according to three topics (i, ii and iii in Fig. 3.4.1.3-1) including (i) shortcuts of main menu, (ii) tools to modifying the map view, (iii) and (iv) submenus to edit or create data, as described below:

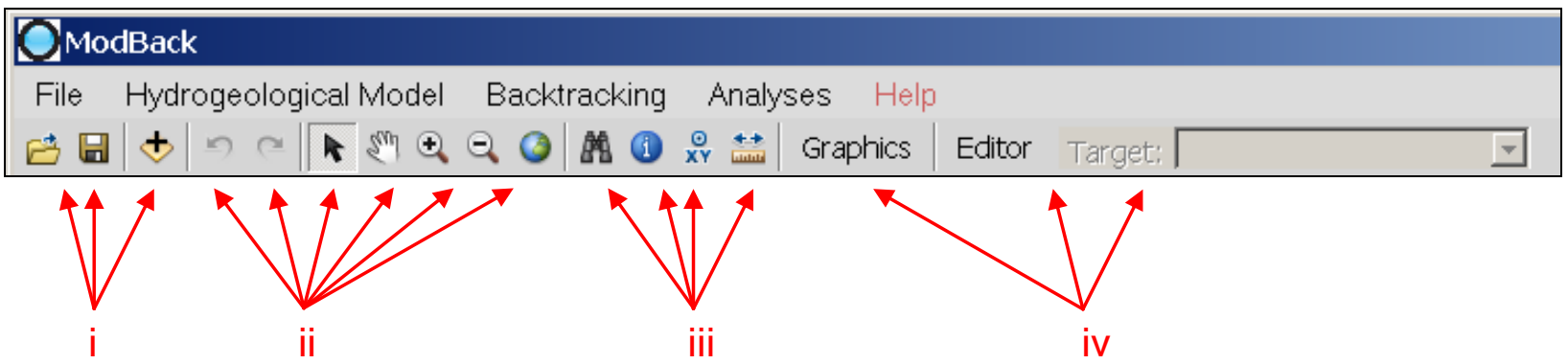

Fig. 3.4.1.3-1: Toolbar. The red arrows indicate the affiliation of the individual tools, grouped in i, ii, iii and iv.

(i) Main menu shortcut buttons to open and load an existing map ( ${ }^{*}$.mxd- file) into the Data Frame, to save a map as an ESRI *.mxd-File or to add data (vector data).

Open: Open and load an existing map (ESRI*.mxd-File) into the Data Frame.

Save Map: Save the map as an ESRI*.mxd-File. 
Add Data: Add data (vector data) into the Data Frame.

(ii) Tools to modify the map view: Zoom in, Zoom out, Pan, Cursor, Full Extent, as well as commands to show the last and previous working steps.

Zoom In: Zoom into the map.

Zoom Out: Zoom out of the map.

Pan: Shift a map in the Data Frame.

Cursor: Select data of the map.

Full Extent: Get a full extent map view.

(iii) Tools to identify any location.

Search tool: Find an ESRI*.Iyr or ESRI*.shp file.

Identify: Show information of selected feature.

Go to X/Y: Type an X/y location and/ or navigate to it.

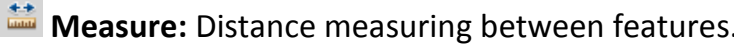

(iv) Submenus to edit existing data (Editor, Fig. 3.4.1.3-2) or to create new graphics, such as curves, lines, points, circles or ellipses (Graphics, Table 3.4.1.3-1). Depending on the description of function, different tools can be used. With the Edit Tool, for example, a selection of already existing layers is possible. These layers could be customised individually with respect to their length, direction, number of vertices, etc. The sketch tool, on the other hand, enables creating new features, which are already generated in ArcCatalog.

Table 3.4.1.3-1: Submenu Graphics

$N \approx \quad$ Line, Curve: Draw a line or curve graphic element on the map.

Graphics: This toolbox includes the graphical tools to draw graphical features onto the map such as, points, lines, curves, circles, ellipses, as followed:
- Select Element
- Create a new marker
Create a new rectangle
$\checkmark$ Create a new line
里
Nudge the created graphic up
पy Create a new curve
ij Nudge the created graphic down.
Ue Create a free hand graphic
G: Nudge the created graphic left.
$\checkmark$ Create a new ellipse
$\because \quad$ Nudge the created graphic right.
Create a new circle
Rotate the created graphic.
Create a new polygon
$\mathbb{L}_{\llcorner}^{\star} \quad$ Rotate the created graphic left.
R. Rotate the created graphic right.

Editor Target: ESRI*.shp-files or ESRI*.Iyr-files or to create new features. To create a new feature, the shape file has to 
be set up within the ArcCatalog, same as the ArcGIS ${ }^{\circledR}$ Editor. A short description of any tools is given in the following sketch (Fig. 3.4.1.3-2: 2):

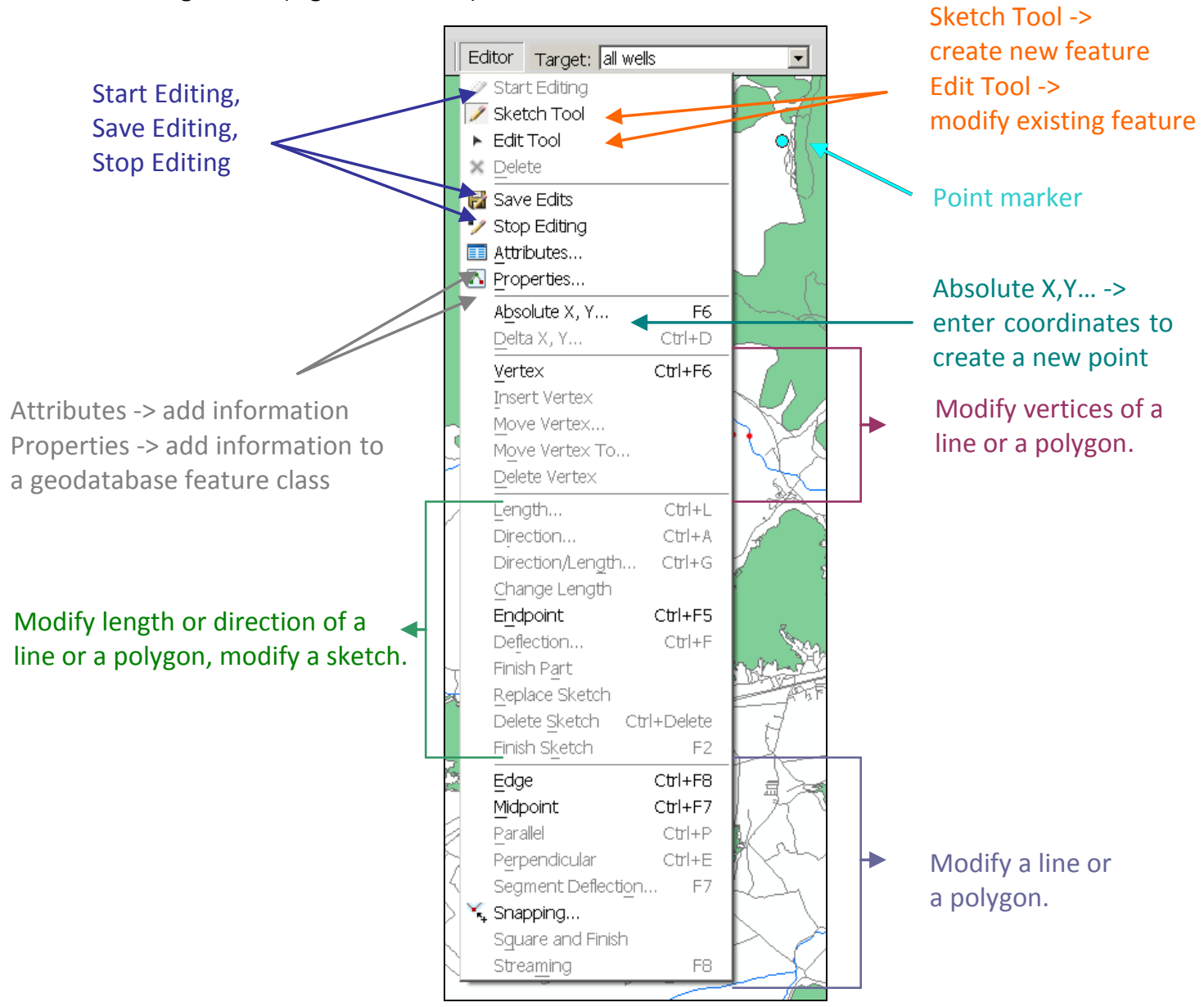

Fig. 3.4.1.3-2: Editor and descriptions in different colours for each theme.

\subsubsection{Main Menu}

ModBack

File Hydrogeological Model Backtracking Analyses Help

Fig. 3.4.1.4-1: Main Menu structure

The Main menu, Fig. 3.4.1.4-1 is structured in five individual menus: File, Hydrogeological Model, Backtracking, Analyses and Help, all of them provide various submenus, shortly described below. Their order from left to right reflects the general, probable sequence of procedures.

The Menu File, Fig. 3.4.1.4-2, consists of nine submenus to handle the document (New Document, Open Document, Save Document, Save As, Export Map, Exit), the data (Add Data, Add .$d x f$ files, Save Layer) as well as the program settings and software exit. 


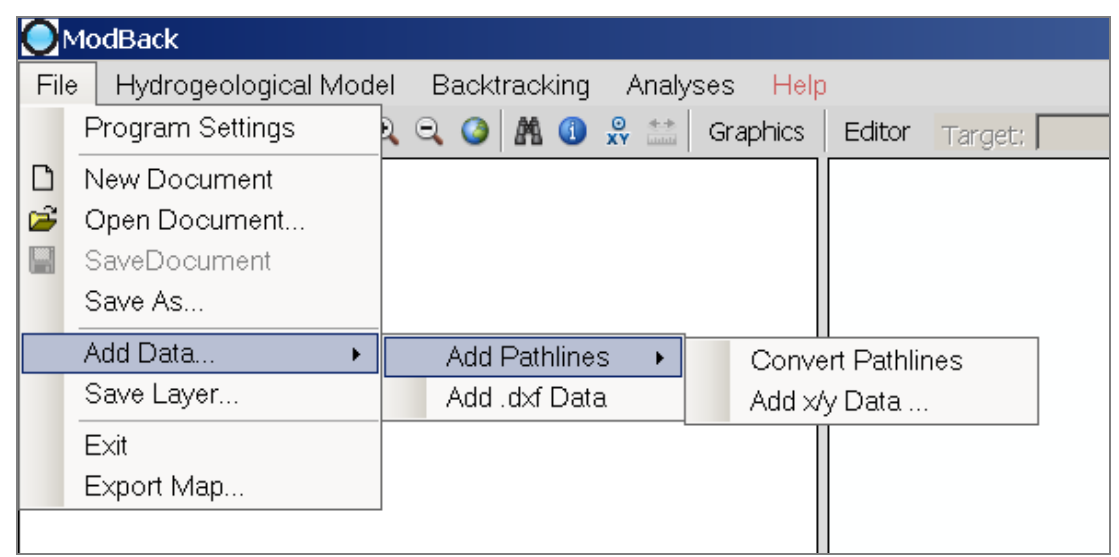

Fig. 3.4.1.4-2: Menu File, highlighted here is the Add Data... function with Add Pathlines header.

Hydrogeological Model, Fig. 3.4.1.4-3, integrates the principle of analytical as well as the numerical groundwater modelling approach in two submenus: Control Plane and Numerical Model, including two commands Create Model and Copy Results.
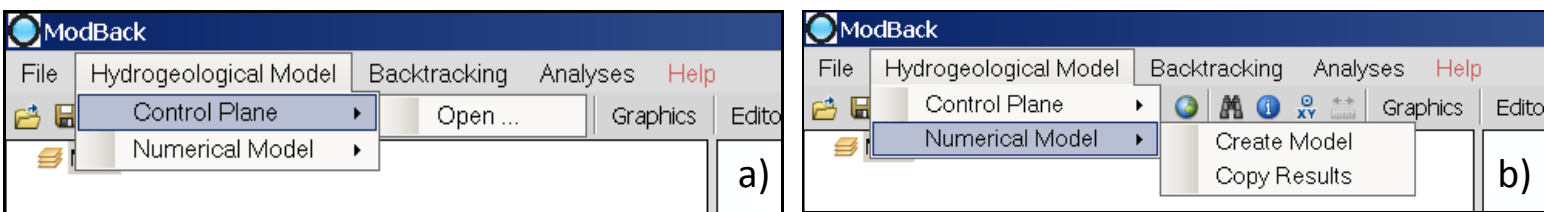

Fig. 3.4.1.4-3: Main Menu of Hydrogeological Model with submenus a) Control Plane and b) Numerical Model

The command Control Plane allows the analytical approach for defining the maximum radius of contribution (capture zone radius) of a single well at a certain pumping time. Numerical Model mainly refers to the groundwater modelling software PMWin. It includes commands to open and work in PMWin (Wen-Hsing Chiang, 2005) (Create Model) as well as to copy numerical modelling resulting files (Copy Results) needed (see chapter 3.3.2.1) in a predefined folder for further backtracking procedures.

The principle of the backtracking approach will be applied in Main menu Backtracking, divided into two submenus: Analytical Model and Numerical Model. The submenu Analytical Model shows the autonomous, analytical IPT tool, after Rothschink (2007). Numerical Model includes the use of the numerical inversion approach CSTREAM. Two related commands Run Model and Draw Results are integrated. The section Analyses allows for the further processing of the previous results from PMPath (Wen-Hsing Chiang, 2005) and CSTREAM within ModBack based on advanced tools (see chapter 3.3.2.2) and enables the graphical and geographical restriction of the potential contamination sources. The menu is divided into three recommended processing steps: Points to Line, Plume Length and Source Area. The Helpmenu provides User Manuals and Information of ModBack itself, PMWin (Wen-Hsing Chiang, 2005), CSTREAM and the IPT tool. 


\section{Chapter 4}

\section{ModBack Application}

ModBack has already been successfully tested in context of the EU Life ${ }^{+}$INCOME project, with the intension to realise the backtracking approach of contaminants at the local test site. The method was presented and accepted by Slovenian project partners as well as the contracting entity in Brussels.

In this thesis, ModBack is applied to the data of the KORA project in Southern Germany, relating to numerical modelling by Herold et al. $(2007,2008,2009)$. The handling of the individual tools is not described in the following section. For any question in this regard, the ModBack user manual can be referred to.

\subsection{Case Study}

The test site is located inside an area of old gasworks. According to Herold et al. (2009) the area extension amounts to $1000 \mathrm{~m}$ in the length from north $(\mathrm{N})$ to south $(\mathrm{S})$ and between 160 to $400 \mathrm{~m}$ in the width from west (W) to east (E), bounded by valley flanks in the $W$ and a river in the $\mathrm{E}$. The aquifer is contaminated by mono-aromatic hydrocarbons, PAHs, aliphatic hydrocarbons, phenols and heterocyclic aromatic hydrocarbons (HETs). The aquifer is heterogeneously constructed by Quaternary sediments like medium gravel deposits, locally occurring fine-grained layers covered by floodplain sediments or anthropogenic fills, therefore, corresponding to a porous aquifer. In relation to the topping sediments, the aquifer has either confined or unconfined conditions. IPTs were performed and resulted in concentration time series for every monitoring well. The decision to apply ModBack on this test site is mainly based on the amount of available data. Herold et al. (2009) investigated this test site by a numerical groundwater flow model and CSTREAM evaluations. This completed data was used within ModBack. A direct comparison to previous studies by Jarsjö et al. (2005) is provided in the next subchapter 4.2 .

The application of ModBack is generally equal to the flow chart in Fig. 3.4-0-1, following the structure of (i) geographical data input, (ii) groundwater modelling approach, (iii) backtracking methods and at last the result illustration and further analysis (iv): 


\subsubsection{Geographical Data Input}

The geographical input data enclosed information of 70 monitoring wells, topographical data and the positions of four cross-sections (control-planes). All data types are offered in ESRI.*shp format and are combined in one spatial database, cartographically normed to the projected coordinate system, DHDN Gauss-Krüger Zone 3. Presented information to any ESRI.*shp is listed as followed:

- Monitoring wells: a set of ESRI.point.shp files including information of the $x$ - and $y$ coordinates and well names.

- Topographical data: as dataset of topography as ESRI.polyline.shp files.

- Control planes: four cross-sections (CP1, CP2, CP2 neu and CP3) given as ESRI.polyline.shp files.

The integration of these ModBack files is possible by loading the data as predefined ESRI map project in ESRI*.mxd-format. A geographical overview of the test site is given in the Fig.

4.1.1-1, below:

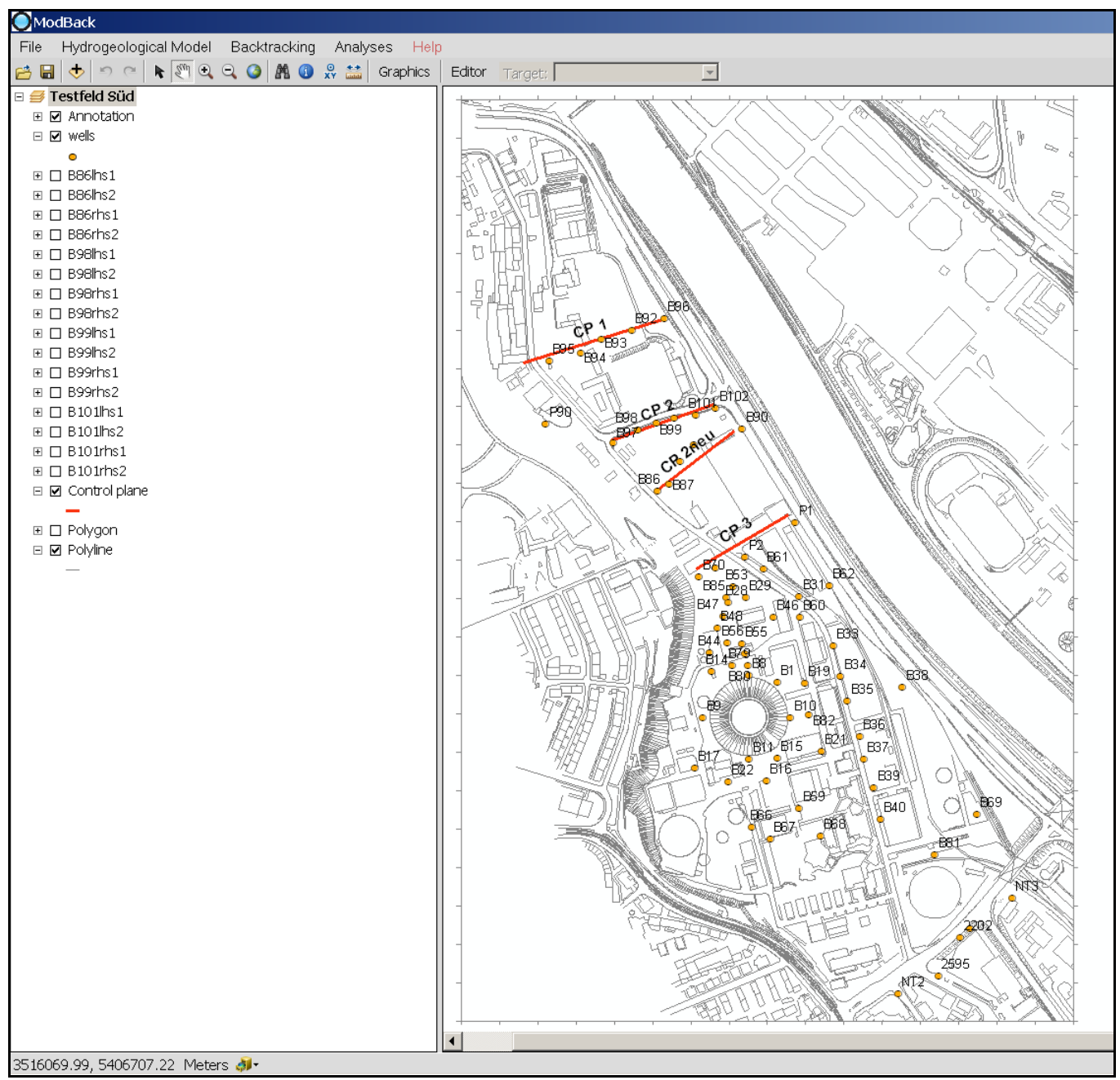

Fig. 4.1.1-1: Geographical overview of the test site in Southern part of Germany within ModBack. The monitoring wells are coloured in orange, the cross-sections (control-planes) are highlighted in red and the topographical base map is drawn in grey. The labelling of CP differs from Herold et al. (2009). 


\subsubsection{Groundwater Modelling}

In this case, the part of groundwater modelling within ModBack is limited to numerical modelling. An analytical approach is not necessary, due to IPTs results of the test site. A definition of the maximum radius of contribution as well as the estimation of the pumping duration is already given. The maximum radius of contribution as well as the duration of pumping are already estimated for every well, see Tab. 4.1.2-1.

Table 4.1.2-1: Pumping information. (Modified after Herold et al. 2009).

\begin{tabular}{cccc}
\hline Well & Pumping rate $\left[\mathrm{m}^{\mathbf{3}} \mathrm{s}^{-1}\right]$ & Pumping duration $[\mathrm{h}]$ & Radius of contribution $[\mathrm{m}]$ \\
\hline B86 & 0.0035 & 118 & 29.9 \\
B98 & 0.0025 & 95 & 27.9 \\
B99 & 0.004 & 117 & 31.02 \\
B101 & 0.004 & 80 & 27.7 \\
\hline
\end{tabular}

The supposed numerical groundwater model (Fig. 4.1.2-1) was set up in Processing MODFLOW and was taken from Herold et al. (2009). Within ModBack this model was autonomously opened. The input parameters are as following:

- Layer thickness: 3.3 [m] on average.

- Groundwater level: $4.1[\mathrm{~m}]$ below surface approximately.

- Hydraulic gradient: $0.002[-]$.

- Transport velocity: $2[\mathrm{~m} / \mathrm{d}]$.

- Effective porosity: $15 \%$.

- Hydraulic conductivities: heterogeneously distributed from the northern: $3.7 \times 10-3$ $\left[\mathrm{ms}^{-1}\right]$ to the southern part: $3.3 \times 10^{-3}\left[\mathrm{~ms}^{-1}\right]$, based on results from pumping tests.

- Boundary conditions: constant head in the northern southern borders and recharge boundary at the western border of the model. At the eastern border is an outfall.

- The mesh: $5[\mathrm{~m}] \times 5[\mathrm{~m}]$.

- Mesh refinement around the wells: $1[\mathrm{~m}] \times 1[\mathrm{~m}]$.

In total, this numerical groundwater model contained eight stress periods. Interchangeably, stress periods are defined, with a stress period given under steady state conditions without any pumping wells before or after another stress period under transient conditions that does include a pumping well with a predefined pumping duration (four predefined wells B86, B98, B99, and B101). As shown in Fig. 4.1.2-1, the wells B98, B99 and B101 are located on the control plane CP2, and B86 on the CP2-neu. Wells B97 and B102 of CP 2 are not under consideration, due to their proximity to the outfall and also to the recharge area. The maximum radius of contribution is given according to Herold et al. (2009). The groundwater flow direc- 
tion was detected from S-SE to N-NW.

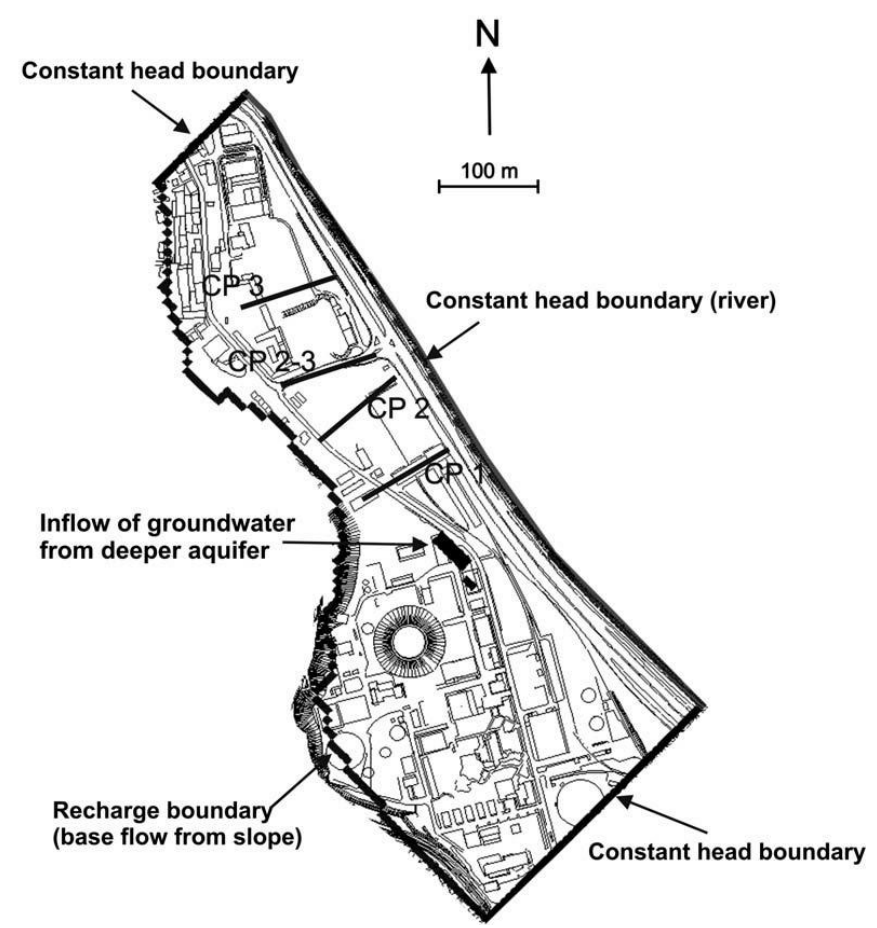

Fig. 4.1.2-1: Position of control planes at the test site, and boundary conditions of the original numerical flow and transport model. (Herold et al,. 2009).

The limitation of contamination and streamline uncertainty in groundwater modelling is described by two extreme models, constructed within Processing MODFLOW and directly called in ModBack, see Fig. 4.1.2-2:

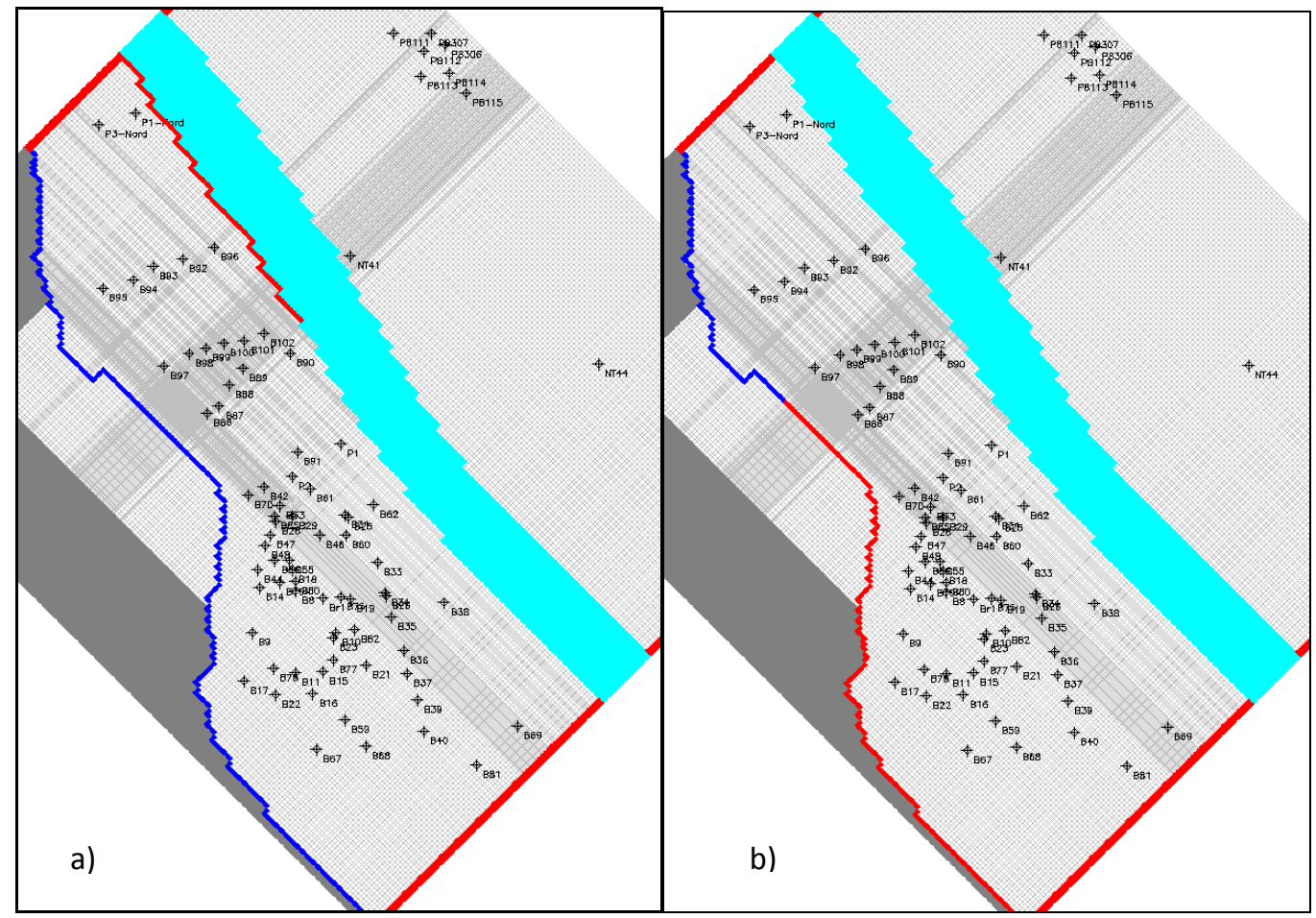

Fig. 4.1.2-2: Boundary conditions of the two extreme models of the test site in a) left hand site extreme model, b) right hand site extreme model, with: red lines as constant head boundaries, blue lines as recharge boundary, thick green line as river and grey lines as model mesh. 
The created models are based on the given, original numerical groundwater model above. Their properties did not differ from the original groundwater model except for modifications in boundary conditions. The first model Fig. 4.1.2-2 a) indicated a constant head boundary change of length to the northwest (coloured in red), the boundary (coloured in red) within the second extreme model the length is transformed to the southeast (Fig. 4.1.2-2 b). The models meshes are coloured in grey and the river is highlighted in lightly green. The blue lines in both figures symbolised the recharge boundary. These alterations affected a lateral change of the groundwater flow and generally limited the boundary and flow uncertainties. Consequently, the flow trend of the streamlines varied in all groundwater models. The advective backward transport of paths contamination was calculated in PMPATH for every well contained by the three groundwater models.

\subsubsection{Backtracking}

The backtracking approach for the original groundwater model is already done numerically by Herold et al. (2009). According to their result, the mass flux across CP2-neu is listed in the following, according to the wells included within the original groundwater model:

Table 4.1.3.1-1: Contaminant mass flux at control plane CP2 neu. (Modified after Herold et al., 2009).

\begin{tabular}{llllll}
\hline CP2 neu & B86 & B98 & B99 & B101 & Total \\
\hline Acenaphtene & 8.1 & 5.29 & 2.23 & 0.000822 & 15.62 \\
Methylbenzofurans & 1.01 & 0.86 & 0.565 & not detected & 2.435 \\
Dimethylbenzofurans & 3.41 & 3.04 & 2.45 & not detected & 8.90 \\
\hline
\end{tabular}

The numerical estimation for the extreme models was directly controlled within ModBack by means of CSTREAM and only for controlling the overlapping position of streamtubes and streamlines. The calculation of the embedded analytical approach could be omitted due to the existence of numerical data.

\subsubsection{Result illustration}

In this case study, the analysis is mainly focused on the assessment and investigation of calculated pathlines out of PMPath. To cover the total amount of possible pathways, only the pathlines from both extreme models are considered. Within ModBack, the pathfile matrices are converted within ModBack into $x / y$ tables (see appendix), added as pathpointsets and transformed into polylines. The contaminant pathways are detectable in their entire dimen- 
sions, based on numerical groundwater flow conditions (Fig. 4.1.4-1). A manual colour variation and adjustment to the layer arrangement entailed clearly distinguished paths. The contaminant pathlines are caused in: green pathlines at well B86, purple pathlines for well B98, blue pathlines at well B99 and brown pathlines at well B101.

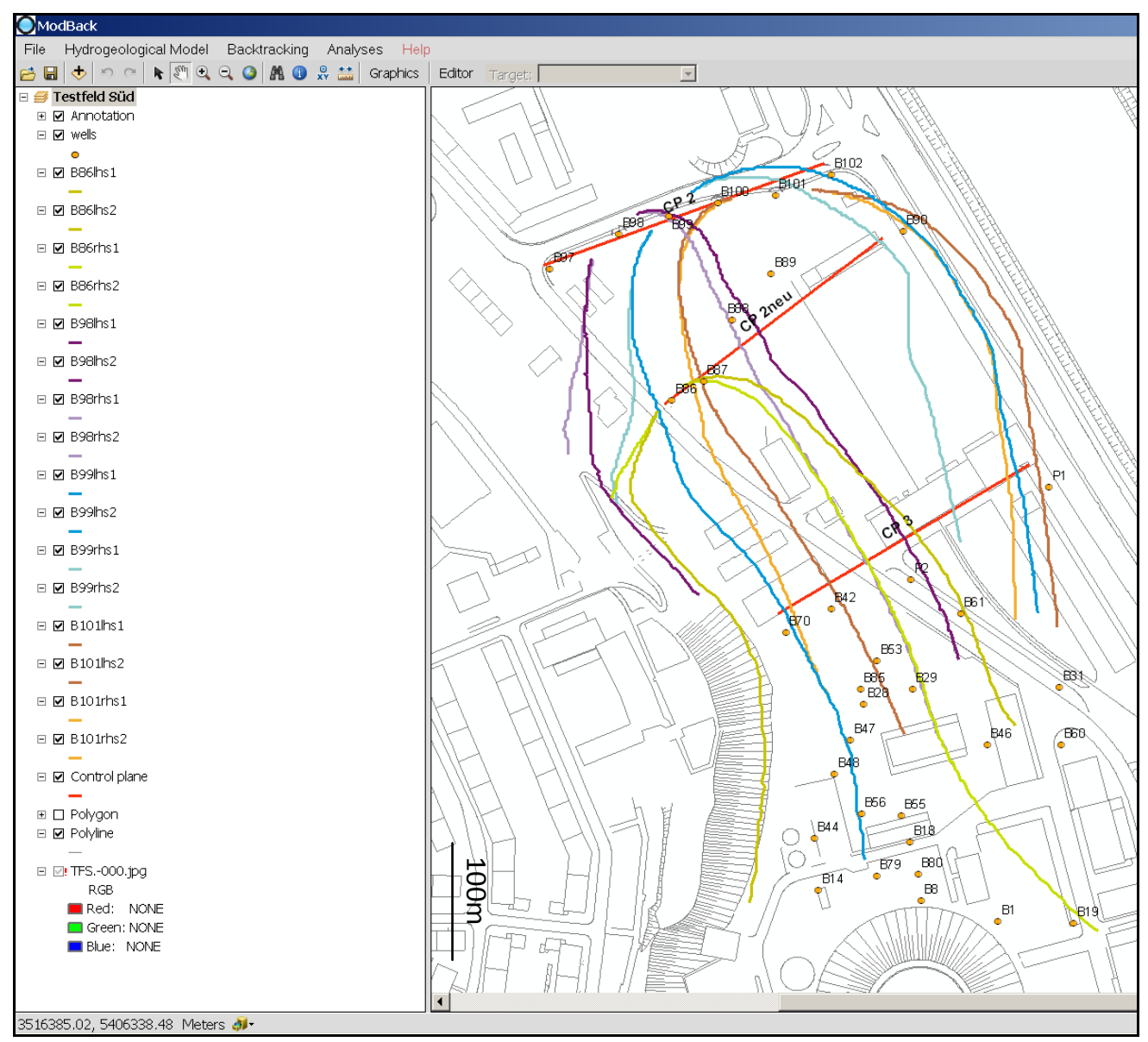

Fig. 4.1.4-1: Calculated contaminant transport in ModBack from both extreme models, with: B86 pathlines in green lines, B98 pathlines ins purple lines, B99 pathlines in blue lines and B101 pathlines in brown lines, wells as orange points, cross-sections as red lines, and topography as grey lines.

A consideration of generation and transport length is not given for the original length of pathlines. The minimum and maximum transport lengths for pollutants like Benzene and chlorides hydrocarbons ( $\Sigma \mathrm{CHCS}$ ) are expected in plume length statistics by Schiedeck et al. (1997). They valued the minimum length of a Benzene contaminant at 60 meters and the maximum at 420 meters. The total amount of $\mathrm{CHCs}$ could be transported at a maximum length of 200 meters and a maximum of 2150 meters. The selection of these contaminants was needed for the comparison to the results of Jarsjö et al. (2005) in next chapter. The integrated procedure of analytical plume length calculation after Liedl et al. (2005) is not possible at this test site due to missing input parameters. Under respect that the aquifer is con- 
taminated by reactive compounds, the pathlines have been adjusted to the appropriate length for both contaminants (cut pathlines).

The extremes of contaminant source zone presence and absence is calculated by cutting pathlines to minimum and maximum length after the method from Jarsjö et al. (2005). It revealed different possible locations in a dissimilar distribution for $\mathrm{\Sigma} C H C s$ and Benzene. A detailed overview for both pollutants at each considered monitoring well is shown in Fig. 4.1.4-2 ( $(\mathrm{CHCS})$ and Fig. 4.1.4-3 (Benzene).

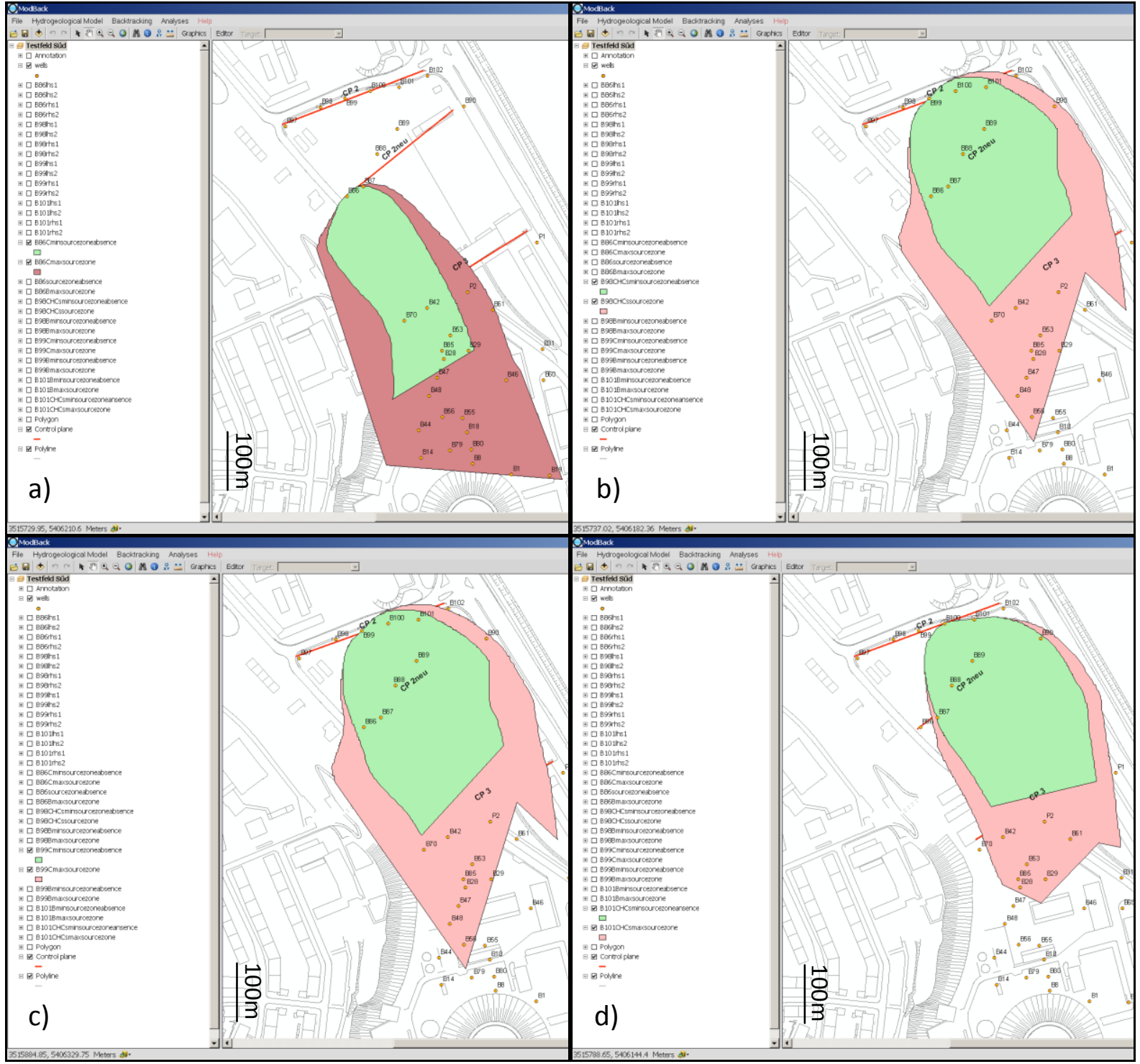

Fig. 4.1.4-2: Delineation of $\Sigma \mathrm{CHCS}$ source zone presence and absence, with: source zone presence as the red area and source zone absence as the green area for a) well B86, b) well B98, c) well B99 and d) well B101.

The possible area of source presence for $\Sigma \mathrm{CHCs}$ in in Fig. 4.1.4-2: 2 is highlighted in red, the possible source zone absence is shown in green. The source zone presence is calculated over the original length of the pathlines, because the possible maximum transport length is 
greater than the distance between the starting and ending points of the pathline. The area of possible zone presence is, compared with the absence zone, relatively small. The positions can be delimited downgradient in the SW direction of the control plane.

A similar source zone situation to Fig. 4.1.4-2 a-d is given in Fig. 4.1.4-3 a-d. The possible area of source presence for Benzene is coloured in red; the zone of absence is coloured in green. The possible maximum transport length of Benzene is greater than the resulting pathline based on the groundwater model. The source zone presence was also calculated over the original length of the pathlines. It is also noticeable that the possible source zone absence area, detected in the SW part of the wells, is smaller for Benzene in relation to those for $\Sigma \mathrm{CHCs}$, depending on the difference in minimum plume length. Fundamentally different to the analyses of $\Sigma \mathrm{CHCs}$ is the amount of a possible source zone presence or absence in relation to the Benzene origin.

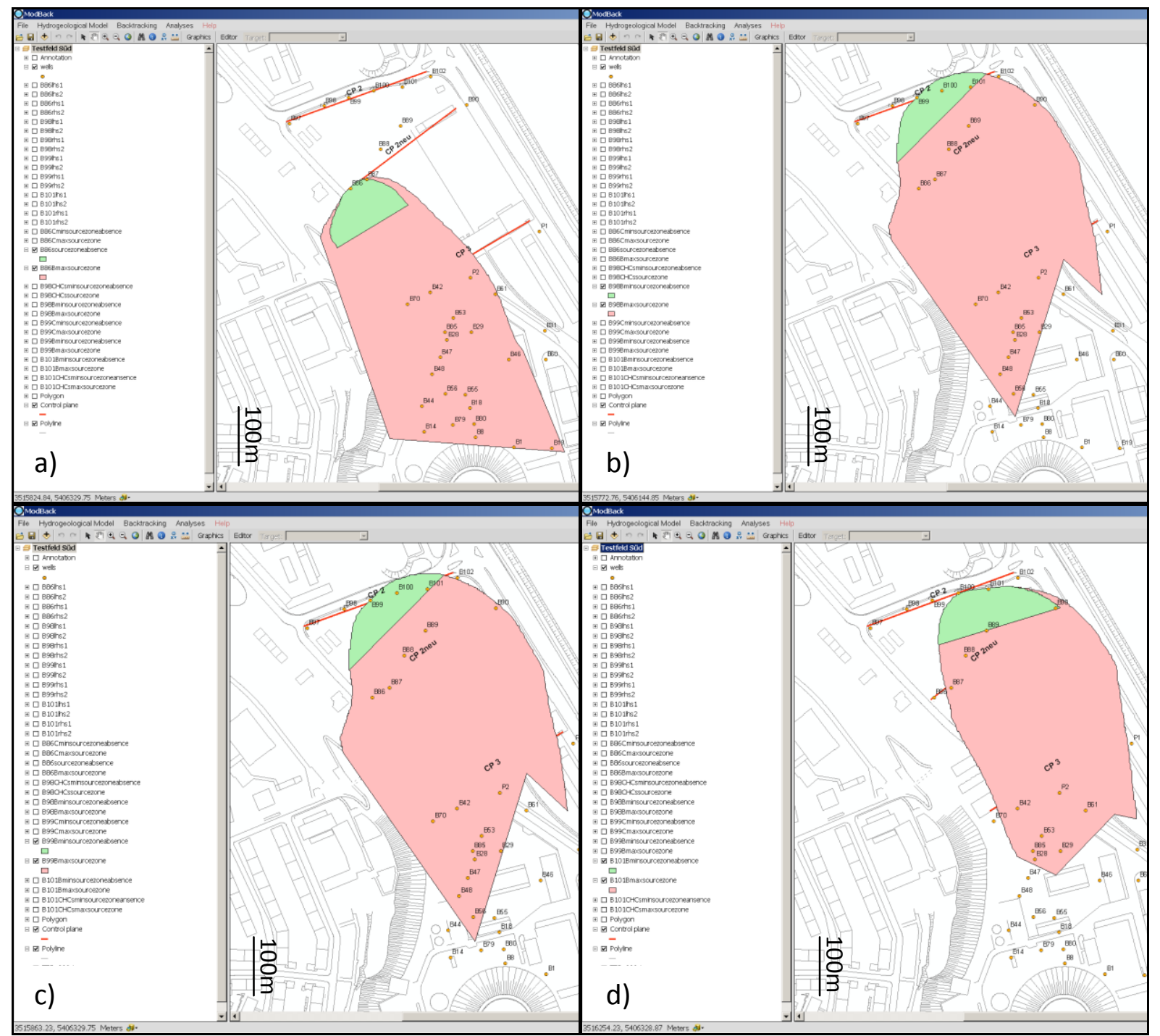

Fig. 4.1.4-3: Delineation of Benzene source zone presence and absence. With: Source zone presence as red area, source zone absence as green area for a) well B86, b) well B98, c) well B99, d) well B101. 
In total, the detailed pictures in Fig. 4.1.4-2 and Fig. 4.1.4-3 illustrate the amount of areas, where the contaminations could have their origin and where they can be excluded. The graphical indentation in e.g. Fig. 4.1.4-2 b+c or Fig. 4.1.4-3 b+c is caused by the combination of pathlines in different maximum lengths. A comprehensive and combined analysis of every single well analysis for both contaminants is given in Fig. 4.1.4-4 a and Fig. 4.1.4-4 b.

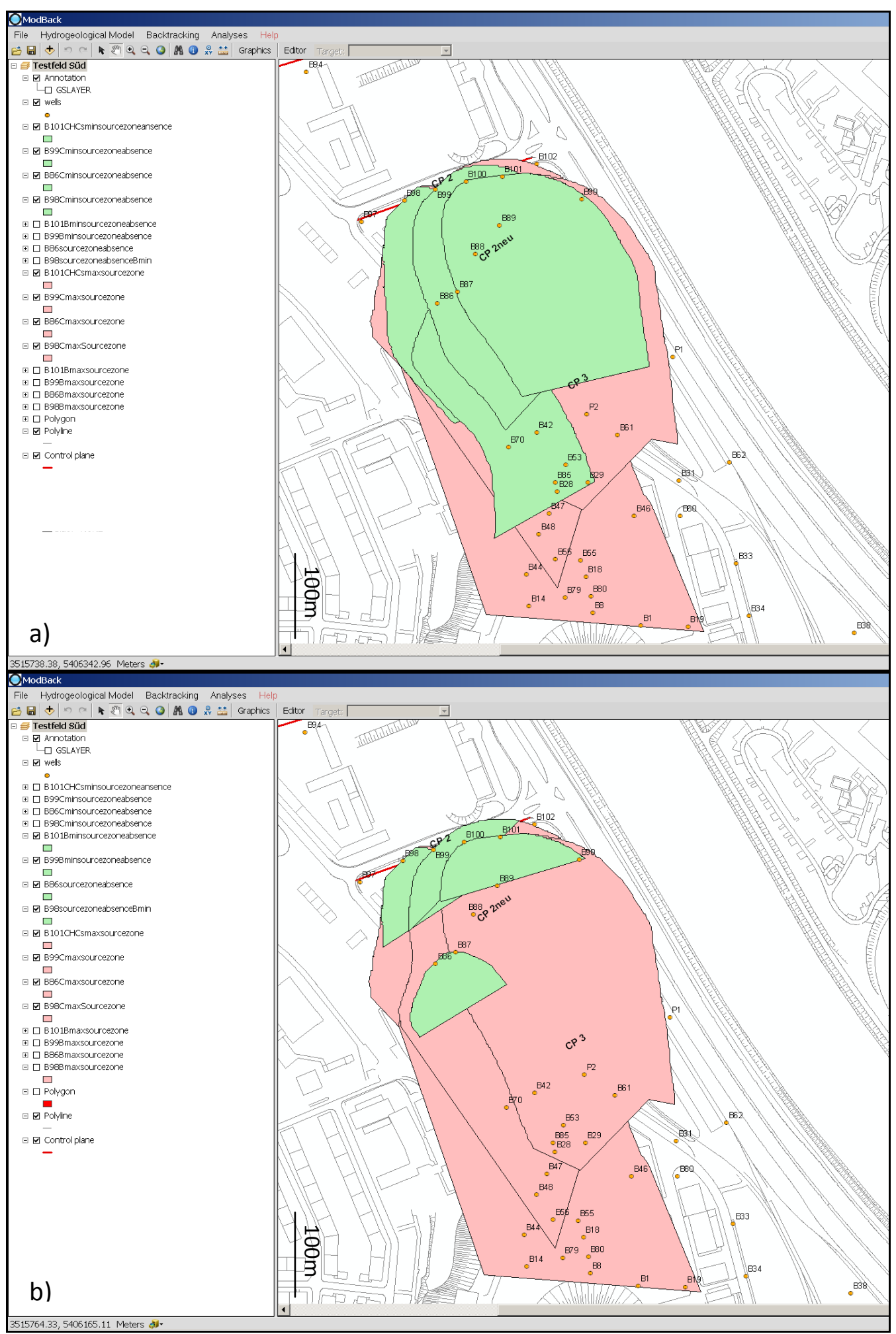

Fig. 4.1.4-4: Amount of source zone presence (red) and absence (green) for $\Sigma C H C s(a)$ and Benzene (b). 


\subsection{Comparative View}

Jarsö et al. (2005) researched the same test site and delimited the potential source zone presence and source zone absence for Benzene and $\mathrm{ECHCs}$. This was done in a down-gradient direction to the groundwater flow, based on IPTs. The number of their studied wells was a quintuple of those described in previous chapter 4.1. Their limitation of uncertainties in IPT evaluation for groundwater boundaries and streamlines was realised in the same method as provided in ModBack. The difference between both approaches is merely based upon the method management. For delimiting the contamination origin and their possible absence, Jarsö et al. (2005) carried out their assumptions by hand, not equipped with an automatic function. This section will show the results of both studies and the comparison between them.

The resulting areas for the source zone or the source zone absence of the test site, evaluated by Jarsjö et al. (2005) are displayed in the following Fig. 4.2-1.

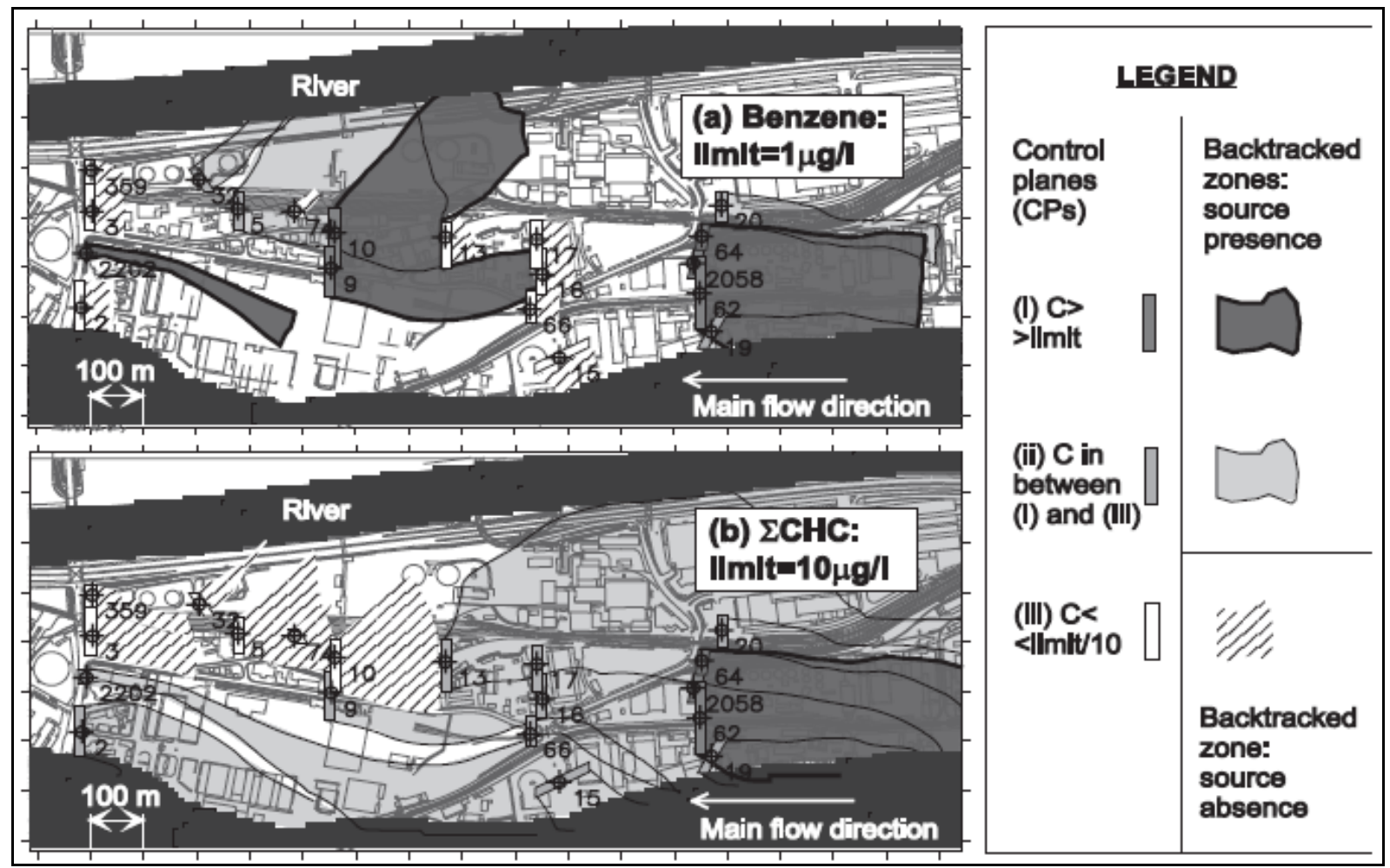

Fig. 4.2-1: Assessment of (a) Benzene and (b) $\Sigma \mathrm{CHCs}$ source zone presences and source zone absences in South Germany with altering concentration limits. (Jarsjö et al., 2005).

The possible zones are categorised in three classes of pollutant concentration, with: (i) the possible source zone for contaminants with a concentration greater than the detectable 
concentration limit (dark grey regions), (ii) the possible source zone for contaminants with a concentration between class (i) and (iii) (shadowed areas in light grey), whereby in (iii), the contaminant concentration class is smaller than the detectable concentration limit/10 (hatched lines) and is defined as source zone absence. Obviously, the general distribution of potential contamination source zones and pollution-free regions is not equal. In the case of Benzene, the considered concentration limit is about $1 \mu \mathrm{g} / \mathrm{L}$. The calculated parts for zone absence mainly covered the areas in the immediate vicinities of the monitoring wells. The extension of possible contamination sources could be determined as large as spreading to the downstream direction. For the $\Sigma \mathrm{CHCs}$, the limit of concentration detection is increased by a factor of 10 and was set at $10 \mu \mathrm{g} / \mathrm{L}$. The area of source zone absence is even placed downstream in the vicinity of each well, but more extended. The same result, regarding the greater spreading, is given for the possible source zone presence.

At first glance, the ModBack resulting areas for the source zone or the source zone absence (Fig. 4.1.4-4 a and Fig. 4.1.4-4 b) diverged to the resulting considerations by Jarsjö et al. (2005). A closer examination in Fig. 4.2-2 pointed out an equivalence of results. The area for source zone absence area is shadowed in light grey (Fig. 4.2-2 a), created in ModBack coloured in green Fig. 4.2-2 b).

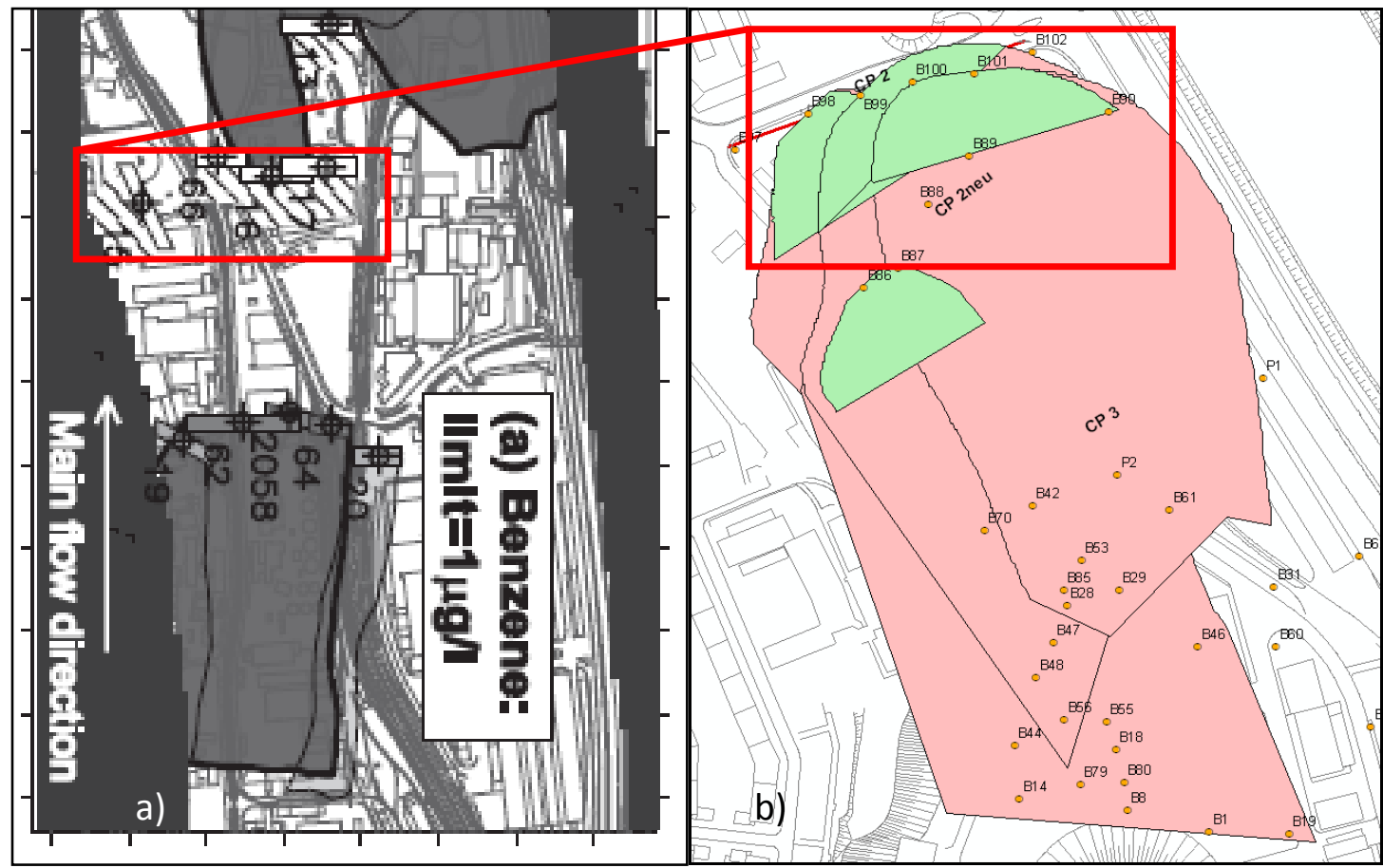

Fig. 4.2-2: Direct comparison of the source zone absences between (a) after Jarjsö et al. (2005) and (b) within ModBack show equivalent dimensions. 
The same comparison result is given for the possible source zone presence (Fig. 4.2-3). The potential source zone is in Fig. 4.2-3 a coloured in light grey and in Fig. 4.2-3 b coloured in red. The amounts of both zones are mainly identical.

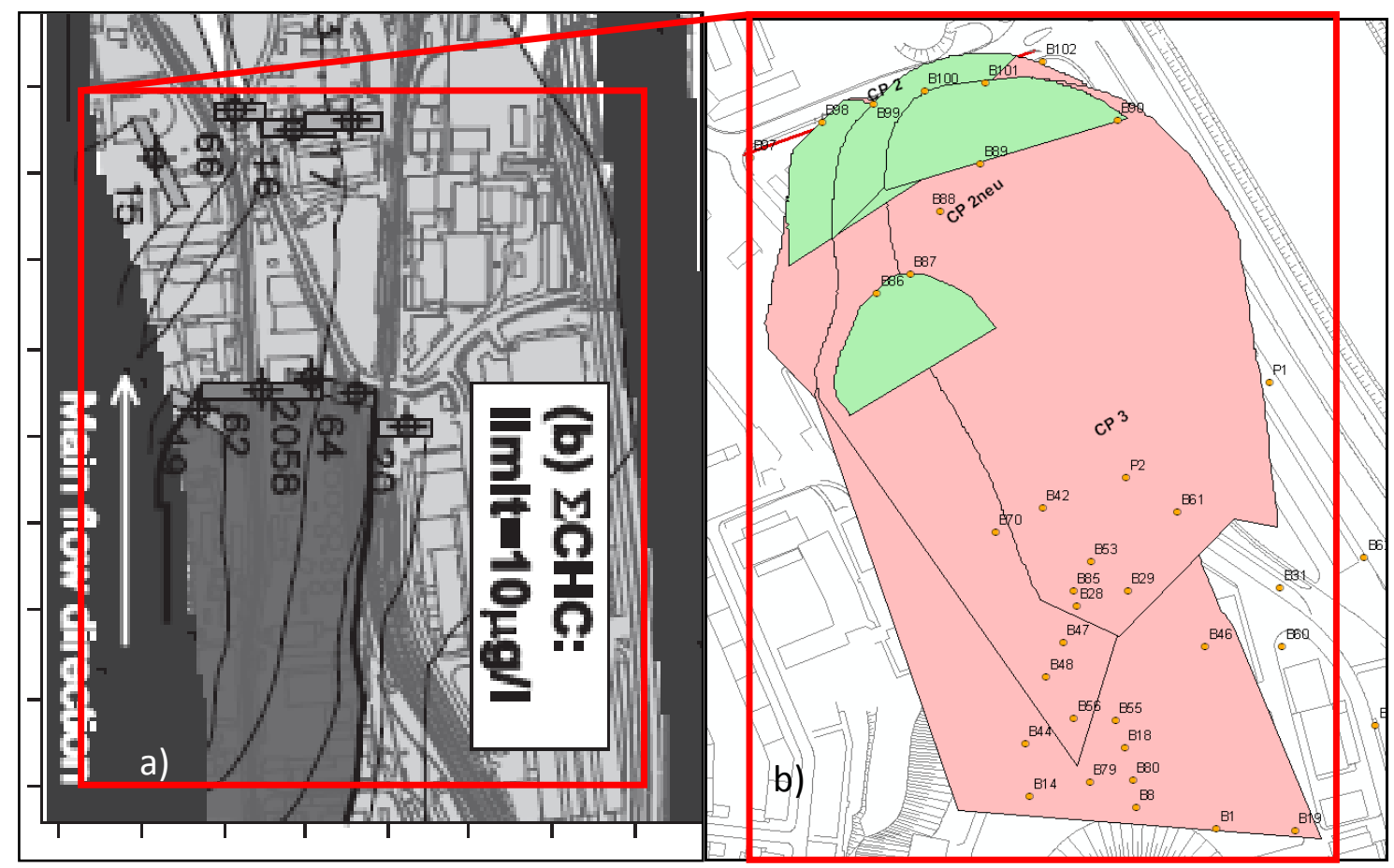

Fig. 4.2-3: Direct comparison of the source zone presences between (a) after Jarjsö et al. (2005) and (b) ModBack show equivalent dimensions.

Summarised, the distribution of source zone presences and absences can be recognised as equivalent in dimensions.

The variance in the figured results might be explained with the classification of the contaminants by Jarsjö et al. (2005) and non-classified analysis within this thesis, because of missing data. A similarity of source zones absence areas is especially given for Benzene contaminants. Visually, both pictures are created in a different horizontal scale. Also, the cartographic orientations in both pictures are different.

If a classification within this thesis would be adjusted to the considered classes as shown in Jarsjö et al. (2005), the results would not be distinguished. Also, an edition of the numerical model set up with consideration of 19 wells would produce a comparable result refinement. 


\section{Chapter 5}

\section{Discussion and Outlook}

The definition of the location of possible groundwater contaminants, their plume length, as well as the source origin was the main research task over the past ten decades. Under consideration of several approaches, the integral mass flux methods achieved the most use in a test site. The IPT method (Holder et al., 1998, Schwarz et al., 1998, Teutsch et al., 2000, Ptak et al., 2000 and Schwarz, 2002) in particular was the most common. In the combination with CSTREAM (Bayer-Raich, 2003a, Bayer-Raich, 2003b, Bayer-Raich, 2004) a well-established method for the determination of contaminant distribution within an aquifer is developed. Jarsjö et al. (2005) established a scheme, using IPT, MODFLOW, the numerical IPT inversion algorithm CSTREAM (Bayer-Raich, 2003a, Bayer-Raich, 2003b, Bayer-Raich, 2004) and analytical plume length statistics in order to delimit possible contamination source zone presences and /or contamination source zone absences. This approach is an easy to use, cost-effective engineering method for the identification of pollution sources. However, an automated application of the various tests, as well as immediate presentation of the results, is also not provided in this case. The analysis of previous studies has shown that the practical application of field work was significant for the creation of the software ModBack. Field work such as conducting Integral Pumping tests (IPT) for the analysis of limitation and spreading of pollutants, and the transport and mass flow estimations with IPTs after Jarsjö et al. (2002) and Jarsjö et al. (2005) were important for the software development. The numerical groundwater modelling is the basement for analytical studies. An inverse modelling, as well as backtracking procedure with CSTREAM (Bayer-Raich, 2003a, Bayer-Raich, 2003b, Bayer-Raich, 2004) completes the examinations. The determination of the real plume lengths were realised under consideration of the methods by Schiedeck et al. (1997) and Liedl et al. (2005).

The use of ModBack is advantageous for the localisation of previously unknown sources of pollutants in saturated, porous aquifers under confined and / or unconfined conditions. This tool allows for an interactive studying of numerical as well as analytical hydrogeological and backtracking approaches, which collectively represented a basic overview of the contamination distribution within the aquifer. As illustrated by the direct comparison of previous inves- 
tigations, the results from ModBack can be regarded as reliable and accurate. Its use is conceivable in engineering firms or government agencies, in addition to scientific research. The remediation costs in the event of a contamination should hereby be considerably reduced.

In general, ModBack can be used from the beginning of injury assessment to the final evaluations for every saturated and porous aquifer all over the world. With the help of the integrated calculations on the control plane, ModBack could be helpful by planning any IPTs. If it is financially impossible to perform in situ IPTs, a fictitious analytical simulation is possible. The best representable results are given by the combination of numerical groundwater and backtracking modelling in Processing MODFLOW, MODPATH (PMWin, PMPath) and CSTREAM, with the aim that heterogeneous subsurface conditions can also be taken into account. For the case that hydrogeological parameters are missing and a numerical model set up is not conceivable, analytical approaches are implemented. The delineation of possible contamination source presence and/or source zone absence can be easily applied by defined analysis tools for numerical results. It should be emphasized that the source zone delineation within ModBack is based on the transport paths calculated in PMPath. A conversion tool to transform original matrices from PMPath to an $x / y$ data column-based table with of the pathlines is included, to ensure the graphical representation in ModBack. Input functions to add ESRI.*shp files, ESRI.*mxd files or $x / y$ data are obtained in ModBack and are generally given. To contemplate a transport plume length, several functions are defined for statistical and analytical calculations. Natural attenuation and contaminant degradation controls are implemented. The analysis tool itself can be used for any Esri.*shp, as long as the respective format type is given. The result illustration is automatically generated within the ModBack data frame, based on $x / y$ coordinates. A change of data symbology is possible. Any resulting files are compatible and can be transferred to any other GIS-related application. As long as the data are contained in the same coordinate system, also a data cross-examination is possible.

The current limitations of ModBack are based on geological/hydrogeological aspects of numerical and/or graphical restrictions. An investigation of contaminations within ModBack is fundamentally restricted to the availability of any software products needed, such as ArcGIS, PMWIN, PMPath, Microsoft Excel, Golden Software Surfer, CSTREAM and NAS. A numerical approach within ModBack is based on the use of a hydrogeological model in PMWin. An ap- 
plication of unsaturated aquifers or fractured aquifers cannot be considered. Also, the extent of a saturated groundwater model is founded on the PMWin and PMPath software requirements. A model setup within PMWin generally expected a detailed knowledge of the subsurface to be given, with regards to the subsurface layer conditions as well as the hydrogeological parameters.

ModBack is written for one layer aquifer systems. An extension of adding the possibility create additional DataFrames would ensure a multilayer contemplation and evaluation.

Any expansions of ModBack with a groundwater tool such as the ArcGIS-based ArcHydro could at least simplify the representation of analytical considerations. Hereby, a coupling with tomographic analysis would be feasible. In order to calculate plume length statistics, an extension with the software NAFLA would also be possible, to cover the whole spectrum of plume length investigations. A detailed exploration of the subsurface as basis for the set-up of a numerical groundwater model could be improved through an addition of ArcScene for 3D illustrations. 


\section{Chapter 6}

\section{References}

A

Ababou, R., Bagtzoglou, A. C., MalletAbabou, A. (2010): Anti-diffusion and source identification with the 'RAW'scheme: A particle-based censored random walk. - Environmental Fluid Mechanics (2010) 10: 41-76.

Aghasi, A., Mendoza-Sanchez, I., Abriola, L. \& Miller, E. L. (2012): Joint electrical and hydrogeological inversion for reconstruction of subsurface contaminant source zones. -

Alberti, L., \& Lombi, S. \& Zanini, A. (2011): Identifying sources of chlorinated aliphatic hydrocarbons in a residential area in Italy using the integral pumping test method. - Hydrogeology Journal (19): 1253-1267.

Almasari, M. N. \& Kaluarachchi, J. J. (2011): Groundwater Quality: Fate and Transport of Contaminants. IN: Aral, M.M. \& Tylor, S.W. (2011): Groundwater Quantity and Quality Management. American Society of Civil Engineers: 36-80.

Anderson, C., Peltz, C., Nydick., K., Moore, E., Oliver, M. \& Livensperger, C. (2011): Source Pollution Identification: Colorado/S. Ute Reach Animas River Watershed. - B.U.G.S. Consulting - Mountains Studies Institute - Basin Hydrology: 1-39.

Atmadja, J \& Bagtzoglou, A. C. (2001): Pollution source identification. - Water Resources Research, 37 (8): 2118-2125.

Ayvaz, M. T. (2010): A linked simulation-optimization model for solving the unknown groundwater pollutions source identification problems. - Journal of Contaminant Hydrology 117 (2010): 46-59.

B

Bader, C. E., Davies, Ch., Gill, S., Jones, S., MacDonald, A., Meister, G., O'Neill, D., Reuland, A., Singh, R., Van Esch, S. \& Yu, Z. (2004): ArcGIS 9, - ArcGIS Server Administrator and Developer Guide.

Bagtzoglou, A., Tompson, A., Dougherty, D., (1991): Probabilistic simulation for reliable solute source identification in heterogeneous porous media. Water Resources Engineering Risk Assessment, NATO ASI Series G29: 189-201.

Bauer, S., Bayer-Raich, M., Holder, T., Kolesar, C., Müller, D. \& Ptak, T. (2004): Quantification of groundwater contamination in an urban area using integral pumping tests. - Journal of Contaminant Hydrology 75 (2004): 183- 213.

Bayer-Raich, M., Baumann, R. \& Ptak, T. (2003a): Application of pumping tests to estimate contaminant mass fluxes in a multi-layered aquifer: a numerically simulated field-scale experiment at the SAFIRA Bitterfeld site. IN: Thornton, S. F., Oswald, S. E. (Eds.), Ground- 
water Quality: Natural and Enhanced Restoration of Groundwater Pollution. - IAHS Publication, 275.

Bayer-Raich, M., Jarsjö, J., Holder, T. \& Ptak, T. (2003b): Numerical estimations of contaminant mass flow based on concentration measurements in pumping wells. - ModelCare 2002: A Few Steps Closer to Reality, 277.

Bayer-Raich, M., Jarsjö, J., Liedl, R., Ptak, T., Teutsch, G. (2004): Average contaminant concentration and mass flow in aquifers from time dependent pumping well data: analytical framework. - Water Resources Resources 40.

Bear, J. (1972): Hydraulics of Groundwater. - Hrsg.

Bear, J. \& Sun, Y. (1998): Optimization of pump-treat-inject (PTI) design for the remediation of a contaminated aquifer: multi-stage design with change constraints. - Journal of Contaminant Hydrology 29 (1998): 225-244.

Bear, J. \& Cheng 2010: Modeling Groundwater Flow and Contaminant Transport. - Hrsg.

Béland-Pelletier, C., Fraser, M., Barker, J. \& Ptak, T. (2010): Estimating contaminant mass discharge: A field comparison of the multilevel point measurement and the integral pumping investigation approaches and their uncertainties. - Journal of Contaminant Hydrology 122 (2011): 63-75.

Bertsch (1978): The Collision in Nuclear Matter at Zero Temperature. - Zeitschrift für Physik 289: 103-105.

Bird, R. B., Stewart, W. E. \& Lightfoot, E. N. (2007): Transport Phenomena - Hrsg. rev. ${ }^{2 \text { nd }}$ edition, New York: Wiley.

Bockelmann, A., Ptak, T. \& Teutsch, G. (2001): An analytical quantification of mass fluxes and natural attenuation rate constants at a former gasworks site. - Journal of Contaminant Hydrology 53 (2001): 429- 453.

Bockelmann, A, Zamfirescu, D., Ptak, T., Grathwohl, P, Teutsch, G. (2003): Quantification of mass fluxes and natural attenuation rates at an industrial site with a limited monitoring network: a case study. - Journal of Contaminant Hydrology 60 (2003): 97- 121.

van Breukelen, B. M. \& Rolle, M. (2012): Transverse Hydrodynamic Dispersion Effects on Isotope Signals in Groundwater Chlorinated Solvents Plumes. - Environmental Science Technology 46 (2012): 7700-7708.

Brooks, M. C., Wood A. L., Annable, M. D., Hatfield, K., Cho, J., Holbert, C., Suresh, P., Rao, C. X., Enfield, M. D., Lynch, K. \& Smith, R. E. (2008): Changes in contaminant mass discharge from DNAPL source mass depletion: Evaluation at two field sites. - Journal of Contaminant Hydrology 10 (2008): 140-153.

Buscheck, T. E. \& Alcantar, C. M. (1995): Regression techniques and analytical solutions to demonstrate intrinsic bioremediation. IN: Hinchee, R. E., Wilson, J. T., Downey, D., Intrinsic Bioremediation, 109-116.

Brusseau, M.L., Hatton, J., DiGuiseppi, W. (2011): Assessing the impact of source-zone remediation efforts at the contaminant-plume scale through analysis of contaminant mass discharge. - Journal of Contaminant Hydrology 126 (2011): 130-139. 
C

Cameron, E., Elkins, R., Gill, S., Jones, S., Laframboise, A., Meister, G. \& Van Esch, St. (2004a): ArcGIS 9. - ArcGIS Desktop Developer Guide.

Cameron, E., Davies, Ch., Elkins, R., Evans, K., Frankland, A., Gill, S., Hansen, N., Jones, S., Laframboise, A., Meister, G., O'Neill, D., Singh, R., Van Esch, S. \& Yu, Z. (2004b): ArcGIS 9, - ArcGIS Engine Developer Guide.

Chu, M., Kitanidis, P. K., McCarty, P. L. (2005): Modeling microbial reactions at the plume fringe subject to transverse mixing in porous media: when can the rates of microbial reaction be assumed to be instantaneous? - Water Resources Research 41(6): 1-15.

Cirpka, O. A., Olsson, A., Ju, Q., Rahman, Md. A. \& Grathwohl, P. (2006): Determination of Transverse Dispersion Coefficients from Reactive Plume Lengths. - Ground Water 44 (2): 212-221.

Cirpka, O. A. \& Valocchi, A. J. (2007): Two-dimensional concentration distribution for mixing-controlled bioreactive transport in steady state. - Advances in Water Research 30 (67): 1668-1679.

Crumbling, D. M., Lych, K., Howe, R., Groenjes, C., Shockley, J., Keith, L., Lesnik, B., Van Ee, J., McKenna, J. (2001): Managing uncertainty in environmental decisions. - Environmental Science Technology 35: 3225- 3230.

Dietze, M, Dietrich, P. (2011): A field comparison of BTEX mass flow rates based on integral pumping tests and point scale measurements. - Journal of Contaminant Hydrology 122 (2011): 1-15.

Dokou, Z. \& Pinder, G. F. (2009): Optimal search strategy for the definition of a DNAPL source. - Journal of Hydrology 376 (2009): 542-556.

Domenico, P. A. \& Robbins, G. A. (1986): A New Method of Contaminant Plume Analysis. Ground Water 23 (4): 476-485.

Domenico, P. A. \& Schwarz F. W. (1990): Physical and chemical hydrology. - Hrsg.

E

Einarson, M. D., Langdon, R. L. \& Barker, J. F. (2000): Hydraulic performance of a funneland- gate groundwater treatment system in a shallow tidally-affected aquifer. - Contract N47408-98-C-2210. Project Report to Naval Facilities Engineering Command, Conor Pacific/ EFW, Palo Alto, CA and University of Waterloo.

Einarson, M. D., \& Mackay, D. M. (2001): Predicting the impacts of groundwater contamination. - Environmental Science and Technology 35 (3): 67A-73A. 
F

Facchinelli, A., Sacchi, E. \& Mallen, L. (2001): Multivariate statistical GIS-based approach to identify heavy metals in soils. - Environmental Pollution 114 (2001): 313-324.

Falta, R. W., Rao, P. S. \& Basu, N. (2005a): Assessing the impacts of partial mass depletion in DNAPL source zones I. Analytical modeling of source strength functions and plume response. - Journal of Contaminant Hydrology 78 (2005) 259- 280.

Falta, R. W., Rao, P. S. \& Basu, N. (2005b): Assessing impacts of partial mass depletion in DNAPL source zones: II. Coupling source strength functions to plume evolution. - Journal of Contaminant Hydrology 79 (2005): 45- 66.

Farhat, S.K., Newell, C.J. and Nichols, E.M. (2006): Mass Flux Toolkit to evaluate groundwater impacts, attenuation, and remediation alternatives. In Proceedings of Battelle's Fifth International Conference on Remediation of Chlorinated and Recalcitrant Compounds, ed. B.M. Sass. Columbus, Ohio: Battelle Press.

Fetter, C.W. (1999): Applied Hydrogeology. - Hrsg.

Fick, A. (1855): On liquid diffusion. - Philosophy Magistrate, 294 (X), S. 30-39; Cambridge.

Flügel, W.-A. \& Michl, C. (1995): Using MODFLOW/MODPATH combined with GIS analysis for groundwater modelling in the alluvial aquifer of the River Sieg, Germany. - Models for Assessing and Monitoring Groundwater Quality (Proceedings of a Boulder Symposium July 1995). IAHS 227 (1995): 117-123.

Foddis, M. L. (2010): Application of Artificial Neural Networks in Hydrogeology: Identification of unknown pollution sources in contaminated aquifers. - Dissertation, University Strasbourg.

Franssen, H.J.H., Alcolea, A., Riva, M., Bakr, M., van der Wiel, N., Stauffer, F. and Guadagnini, A. (2009): A comparison of seven methods for the inverse modelling of groundwater flow. Application to the characterisation of well catchments. - Advances in Water Resources 32 (2009): 851-872.

Gasperikova, E, Hubbard, S.S., Watson, D.B. Baker, G.S., Peterson, J.E., Kowalsky, M.B., Smith, M. and Brooks, S. (2012): Long-term electrical resistivity monitoring of rechargeinduced contaminant plume behaviour. - Journal of Contaminant Hydrology 142-143 (2012): 33-49.

Grathwohl, P. (1997): Gefährdung des Grundwassers durch Freisetzung organischer Schadstoffe: Methoden zur Berechnung der in-situ Schadstoffkonzentrationen. - Grundwasser Zeitschrift der Fachsektion Hydrogeologie 4/97: 157-166. In German.

Grandjean, G. (2006): A seismic multi-approach method for characterizing contaminated sites. - Journal of Applied Geophysics 58 (2006): 87- 98.

Gnanapragasam, E. K., Yu, C., Whelan, G., Mills, W. B., McDonald, J. P., Lew, C. S., Hung, C. Y. \& Hoffmeyer, D. (2000): Comparison of multimedia model prediction for a contaminant plume migration scenario. - Journal of Contaminant Hydrology 46 (2000): 17-38. 
Goltz, M. N., Kim, S., Yoon, H. \& Park, J. (2007): Review of Groundwater Contaminant Mass Flux Measurement. - Environmental Engineers Resources 12(4): 176-193.

Gorelick, S, M., Evans, B. E. \& Remson, I. (1983): Identifying sources of groundwater pollution: An optimization approach. - Water Resources Research 19 (3): 779-790.

H

Ham, P. A. S., Schotting, R. J., Prommer, H. \& Davis, G. B. (2004): Effects of Hydrodynamic Dispersion on Plume Lengths for Instantaneous Bimolecular Reactions. - Advances in Water Resources Research 27 (2004): 803-813.

Harbaugh, A.W., McDonald, M.G., (1996): User's documentation for MODFLOW-96, an update to the U.S. Geological Survey modular finite-difference ground-waterflowmodel. U.S. Geological Survey.Open-File Report 96-485.

Hatfield, K., Rao, P.S.C., Annable, M.D. and Campbell T. (2002): Device and method for measuring fluid and solute fluxes in flow systems. - Patent US 6,402,547 B1.

Hatfield, K, Annable, M., Cho, J, Rao, P. S. C \& Klammer, H (2004): A direct passive method for measuring water and contaminant fluxes in porous media. - Journal of Contaminant Hydrology 75(3-4): 155-181.

Hemond, H. F. \& Fechner-Levy, E. J. (2000): Chemical Fate and Transport in the Environment. - Hrsg. San Diego: Academic Press. pp. 499.

Hornbruch, G., Schäfer, D. and Dahmke, A. (2009): Fallstudie zur Ableitung einer kritischen Messstellenanzahlzur Schadstofffahnencharakterisierung bei unterschiedlichen Qualitätsansprüchen. - Grundwasser - Zeitschrift der Fachsektion Hydrogeologie (2009)14: 81-95.

Herold, M., Ptak, T., Bayer-Raich, M., Wendel, T. \& Grathwohl, P. (2007): Integral quantification of contaminant mass flow rates in a contaminated aquifer: Conditioning of the numerical inversion of concentration-time series. - Journal of Contaminant Hydrology 106 (2009), 29-38.

Herold, M., Ptak, T., Grathwohl, P. (2008): Bestimmung der Schadstofffrachten an Kontrollebenen mithilfe von Punktkonzentrationsmessungen und Immissionspumpversuchen - ein Vergleich - Grundwasser - Zeitschrift der Fachsektion Hydrogeologie(2008) 13: 231-240.

Herold, M., Ptak, T., Bayer-Raich, M., Wendel, T. and Grathwohl, P. (2009): Integral quantification of contaminant mass flow rates in a contaminated aquifer: Conditioning of the numerical inversion of concentration-time series. - Journal of Contaminant Hydrology, 106(12), pp. 29-38.

Hossein, Md. M. \& Piantanakulchai, M. (2013): Groundwater arsenic contamination risk prediction using GIS and classification tree method. - Engineering Geology 156 (2013): 37 -5 .

Holder, T. H., Teutsch, G., Ptak, T., Schwarz, R. (1998): A new approach for source zone characterization: the Neckar Valley study. Groundwater quality: remediation and protection. - Proceedings of the GQ'98 Conference 250: 49-55.

Hölting, B. (1996): Hydrogeologie. - Hrsg. In German. 
Huang, J., Close, M. E., Pang, L., and Goltz, M. N. (2004): Innovative method to measure flux of dissolved contaminants in groundwater. - Proceedings of the Fourth International Conference on Remediation of Chlorinated and Recalcitrant Compounds Conference.

Illmann, W. A., Berg, S. J, Liu, X. \& Massi, A. (2010): Hydraulic / Partitioning Tracer Tomography for DNAPL Source Zone Characterization: Small-Scale Sandbox Experiments. - Environmental. Science Technology 44 (2010): 8609-8614.

Interstate Technology \& Regulatory Council (ITRC) (2010): Use and measurement of mass flux and mass discharge. Washington, DC: Interstate Technology \& Regulatory Council, Integrated DNAPL Site Strategy Team.

Jarsjö, J., Ptak, T., Bayer-Raich, M. \& Holder, T. (2002): Uncertainties in contaminant plume characterizations based on concentration measurements in pumping wells: the StuttgartNeckartalaue site. - Calibration and Reliability - IN: Groundwater Modelling: A Few Steps Closer to Reality (Proceedings of ModelCARE'2002. Prague, Czech Republic, June 2002). IAHS 277 (2002): 351-358.

Jarsjö, J., Bayer-Raich, M. \& Ptak, T. (2005): Monitoring groundwater contamination and delineating source zones at industrial sites: Uncertainty analyses using integral pumping tests. - Journal of Contaminant Hydrology 79(2005): 107- 134.

Jarsjö, J., Asokan, S.M., Prieto, C., Bring, A. and Destouni, G. (2011): Hydrological responses to climate change conditioned by historic alterations of land-use and water-use. - Hydrological Earth System Sciences Discussion 8: 7595-7620.

K

Kalbus E., Schmidt, C., Bayer-Raich, M., Leschik, S., Reinstorf, F., Balcke, G. U. \& Schirmer, M. (2007): New methodology to investigate potential contaminant mass fluxes at the stream - aquifer interface by combining integral pumping tests and streambed temperatures. - Environmental Pollution 148(2007): 808-816.

Kao, C. M. \& Wang, Y. S. (2001): Field investigation of the natural attenuation and intrinsic biodegradation rates at an underground storage tank site. - Environmental Geology $\mathbf{4 0}$ (4-5): 622-631.

Keely, J. F. \& Wolf, F. (1983): Field applications of chemical time-series sampling. - Ground Water Monitoring Rev. 3: 26-33.

Kim, S. J. (2005): Validation of an innovative groundwater contaminant flux measurement method. - Master thesis, AFIT/GES/ENV/05-02, Department of System and Engineering Management, Air Force Institute of Technology, Wright-Patterson AFB OH. 
King, M., Barker, W. G., Devlin, J. F. \& Butler, B. J., (1999): Migration and natural fate of a coal tare creosote plume: 2 . Mass balance and biodegradation indicators. - Journal of Contaminant Hydrology 39(1999), 281- 307.

Kofler, M. (2008): Visual Basic 2008, Grundlagen, ADO.NET, - Hrsg., Windows Presentation Foundation. In German.

Kolb, A. (2004): Analysis of Possible Sources and Pathways of Methyltertiary-Butyl Ether (MTBE) in the Aquatic Environment. - Dissertration, Universität Frankfurt/Main. In German.

Konecny, F. \& Fürst, J. (2007): The simulation of groundwater flow velocity random fields by the method of partitioning and randomization of the spectrum - Computers \& Geosciences 33 (2007): 159-171.

König, C. (1996): Einsatz und Entwicklung numerischer Methoden zur Berechnung von Transportvorgängen im Grundwasser. - Tagungsheft zur 6. Baustatik, Baupraxis Fachtagung; Weimar. In German.

Kornikow (2011): The Secret to Successful Solute-Transport Modeling. - Groundwater 49(2): 144-159.

Kurtzman, D., Netzer, L., Weisbrod, N., Nasser, A., Graber, E. R \& Ronen, D. (2012): Characterization of deep aquifer dynamics using principal component analysis of sequential multilevel data. Hydrological Earth System Science 16: 761-771.

Kübert, M. \& Finkel, M. (2006): Contaminant mass discharge estimation in groundwater based on multi-level point measurements: A numerical evaluation of expected errors. Journal of Contaminant Hydrology 84(2006): 55-80.

$\mathbf{L}$

Leschink, S. (2010): Groundwater contamination from urban line sources -monitoring and evaluation approach with integral pumping tests. - Dissertation, Neuchâtel.

Leven, C. \& Dietrich, P. (2004): Zeitliche Variabilität von Grundwasserfließbedingungen. Conference presentation, Arbeitskreis Qualitätssicherung 01. April 2004. In German.

Liedl, R., Valocci, A. J., Dietrich, P. \& Grathwohl, P. (2005): Finiteness of steady state plumes. - Water Resources Research 41 (2005): 1-8.

Liedl, R., Yadav, P. K. \& Dietrich, P. (2011): Length of 3-D mixing-controlled plumes for a fully penetrating contaminant source with finite width. - Water Resources Research 47 (2011): 1-5.

Liu, X. \& Kitanidis, P. K. (2011): Large-scale inverse modeling with an application in hydraulic tomography, Water Resources Research 47, W02501, doi:10.1029/2010WR009 144.

Liu, J. and Wilson, J.L. (1995): Modeling travel tome and source location probabilities in twodimensional heterogeneous aquifer. - Proceedings of $5^{\text {th }}$ Annual WERC Technology Develop Conference, LasCruces. 59-67. 
Luciano, A., Viotti, P. \& Petrangeli Papini, M. (2012): On Morphometric Properties of DNAPL Sources: Relating Architecture to Mass Reduction. - Water Air Soil Pollution 223(2012): 2849-2864.

M

Mahar, P., Datta, B. (1997): Optimal monitoring network and ground-water-pollution source identification. - Journal of Water Resources Planning and Management, ASCE 123(4): 199-207.

Michalak, A. M. \& Kitandis, P. K. (2004): Estimation of historical groundwater contaminant distribution using the adjoint steate method applied to geostatistical inverse modelling. Water Resources Research 40. W08302.doi: 10.29/2004WR003214.

Milnes, E. \& Perrochet, P. (2007): Simultaneous identification of a single pollution pointsource location and contamination time under known flow field conditions - Advances in Water Resources 30 (2007): 2439-2446.

Mirghani, B. Y., Mahinthakumar, K. G., Tryby, M. E., Ranjithan, R. S., Zechman, E.

M. (2009): A parallel evolutionary strategy based simulation- optimization approach for solving groundwater source identification problems. - Advances in Water Resources 32(2009): 1373-1385.

Mortimer, Ch. E. (1996): Chemie. - Hrsg.

Mohrlock, U. (2009): Bilanzmodelle in der Grundwasserhydraulik. Quantitative Beschreibung von Strömung und Transport im Untergrund. - Habilitation, Karlsruhe. 195 pp. In German.

N

Neupauer, R. M., Wilson, J., (1999): Adjoint method for obtaining backward-in-time location and travel time probabilities of a conservative groundwater contamination. - Water Resources Research 35 (11): 3389-3398.

Neupauer, R. M., Borchers, B. \& Wilson, J. L., (2000): Comparison of inverse methods for reconstructing the release history of a groundwater contamination source. - Water Resources Research 36 (9): 2469-2475.

Neupauer, R. M., Lin, R., O'Shea, H., (2007): Conditional backward probability modelling to identify sources of groundwater contaminants subject to sorption and decay. - Water Resources Research 43 (11): 1-11.

Newell, C. J., Farhat, S. K., Adamson, D. T. \& Looney, B. B. (2011): Contaminant Plume Classification System Based on Mass Discharge. - Ground Water 49(6): 914-919. 
O'Riordan, Th. \& Stasch, A. (1994): Environmental Science for Environmental Management - Hrsg, Translated, in German: Umweltwissenschaften und Umweltmanagement.

Orozco, A.F., Kemna, A., Oberdörster, C., Zschornack, L., Leven, C, Dietrich, P. and Weiss, H. (2012): Delineation of subsurface hydrocarbon contamination at a former hydrogenation plant using spectral induced polarization imaging. - Journal of Contaminant Hydrology 136-137 (2012): 131-144.

Puls, R. W. \& Paul C. J. (1997): Multi-layer sampling in conventional monitoring wells for improved estimation of vertical contaminant distributions and mass. - Journal of Contaminant Hydrology 25(1997): 85-111.

Peter, A., Steinbach, A., Liedl, R., Ptak, T., Michaelis, W. \& Teutsch., G. (2004): Assessing microbial degradation of o-xylene at field-scale from the reduction in mass flow rate combined with compound-specific isotope analyses. - Journal of Contaminant Hydrology 71(2004): $127-154$.

Pollock, D. (1994): User's guide for MODPATH/MODPATH-PLOT, Version 3: A particle tracking post-processing package for MODFLOW, the U.S. Geological Survey finite-difference ground-water flow model. U. S. Geological Survey.

Ptak, T. \& Teutsch, G. (2000): Development and application of an integral investigation method for the characterization of groundwater contamination. - In: Telford, T.: Contaminated Soil 2000: 198-205.

Ptak, T., Schwarz, R., Holder, T. \& Teutsch, G. (2000): Ein integrales Verfahren zur Quantifizierung der Grundwasserimmission, Teil II: Numerische Losungen und Anwendung in Eppelheim. - Grundwasser 4 (2000): 176-183. In German.

Ptak, T., Bayer-Raich, M., Bauer, S. (2004): Tiefenorientierte integrale Erkundung der Schadstoffbelastung in großräumig kontaminierten Aquiferen. - Grundwasser 4 (2004): 235247. In German.

$\mathbf{R}$

Rao, M.V.V, Sharma, S.P. and Meyyappa, M. (2002): Mass spectrometric measurements ininductively coupled CF4/Ar plasmas. Plasma Sources Science Technology 11 (2002) 397406.

Rivett, M. O., Feenstra, S., Cherry, J. A. (2001): A controlled field experiment on groundwater contamination by a multicomponent DNAPL: creation of the emplaced-source and overview of dissolved plume development. - Journal of Contaminant Hydrology 49(2001): $111-149$.

Rivett, M. O., Allen-King, R. M. (2003): A controlled field experiment on groundwater contamination by a multicomponent DNAPL: dissolved-plume retardation. - Journal of Contaminant Hydrology 66 (2003): 117- 146. 
de Rooij, R., Graham, W., Maxwell, R.M. (2012): A particle-tracking scheme for simulating pathlines in coupled surface-subsurface flows. - Advances in Water Resources (2012), doi: http://dx.doi.org/10.1016/j.advwatres.2012.07.022

Ronen, D., Magaritz, M, Levy, I. (1987): An In Situ Multilevel Sampler for Preventive Monitoring and Study of Hydrochemical Profiles in Aquifers. - Groundwater Monitoring \& Remediation 7(4): 69-74.

Rothschink, P. (2007): IPV Tool, Landesamt für Umwelt, Messungen und Naturschutz, Baden Würtemberg.

Rügner, H. \& Teutsch, G. (2001): Literature study "Natural Attenuation of organic pollutants in groundwater". - Final Report for EU-FP5 project INCORE.

Rügner, H., Teutsch, G., Grathwohl, P. \& Kohler, W. (2001): Natural attenuation organischer Schadstoffe in Grundwasser. Stand der Technik, Methoden zur Implementierung. - Altlastenforum 5 (2001): 1-40.

$\mathbf{S}$

Seferou P., Soupios, P., Candasayar E., Papadopoulos, N., Sarris, A. \& Aktarakçi, H. (2012): Monitoring of contaminant transport by using geo-electrical resistivity tomography. Conference report. $3^{\text {rd }}$ international conference on industrial and hazardous waste management. - Journal of Contaminant Hydrology

Skaggs, T. H. \& Kabala, Z. H. (1994): Recovering the release history of a groundwater contaminant. - Water Resources Research 30 (1): 71-79.

Soga, K., Page, J. W. E. \& Illangasekare, T. H., (2004): A review of NAPL source zone remediation efficiency and the mass flux approach. - Journal of Hazardous Material 110(2004): 13-27.

Sun, A., Painter, S.L. and Wittmeyer, G.W. (2006): A robust approach for iterative contaminant source location and release history recovery. - Journal of Contaminant Hydrology 88(3-4): 181-196.

Su, C., Puls, R.W., Krug, T.A., Watling, M.T., O’Hara, S.K., Quinn, J.W. and Ruiz; N.E. (2012): A two and half-year-performance evaluation of a field test on treatment of source zone tetrachloroethene and its chlorinated daughter products using emulsified zero valent iron nanoparticles. - Water Research 46(2012): 5071-5084.

\section{$\mathrm{SCH}$}

Schüth; Ch. (1994): Sorptionskinetik und Transportverhalten von polyzyklischen aromatischen Kohlenwasserstoffen (PAK) im Grundwasser, Laborversuche. - Dissertation, Tübingen, Germany.

Schwarz, R. (2002): Grundwasser-Gefährdungsabschätzung durch Emissions- und Immissionsmessungen an Deponien und Altlasten. - Ph.D. thesis, 120 pp., Univ. Tübingen, Tübingen, Germany. - In German. 
Schwede, R.L. and Cirpka, O.A. (2010): Stochastic evaluation of mass discharge from pointlike concentration measurements. - Journal of Contaminant Hydrology 111, 1-4: 36-47

Schiedeck, T., Teutsch, T. \& Grathwohl, P. (1997): Literaturstudie zum natürlichen Rückhalt / Abbau von Schadstoffen im Grundwasser. - Handbuch Altlasten und Grundwasserschadensfälle- Texte und Berichte zur Altlastenbearbeitung 35(97): 1-55. In German.

\section{$\mathbf{T}$}

Teutsch, G., Ptak, T., Schwarz, R., Holder, T., (2000): Ein neues integrales Verfahren zur Quantifizierung der Grundwasserimmission. Teil 1: Beschreibung der Grundlagen. Grundwasser 4(5): 170-175. In German.

Teutsch, G. \& Rügner, H. (1999): Entwicklung von Bewertungskriterien natürlicher Schadstoffabbauprozesse in Grundwasserleitern als Grundlage für Sanierungsentscheidungen bei Altstandorten". Zwischenbericht des Lehrstuhls für Angewandte Geologie, Universität Tübingen (im Auftrag der LfU Baden-Württemberg), - unpublished, 1999. In German.

Thomas-Thielsch, K., Herold, M., Ptak, T (2012): ModBack User Manual. — unpublished.

V

Vesselinov, V V. \& Harp, D R. (2010): Contaminant source identification using adaptive hybrid optimization of inverse groundwater transport model. - Draft for Water Resources Research 01(2010).

\section{W}

Wagner, B. (1992): Simultaneous parameter estimation and contaminant source characterization for coupled groundwater flow and contaminant transport modeling. - Journal of Hydrology 135 (1-4): 275-303.

Weiß, H., Teutsch, G. \& Daus, B. (2004): Zusammenfassender Abschlussbericht Projektverbund Safira. - UFZ- Bericht 13 (2004): 1-368. In German.

Weber, K. C. (2002): Bilanzierung und Modellierung des BTEX-Austrags aus dem Grundwasser eines Gaswerksgeländes. - Dissertation, Karlsruhe. In German.

Wen-Hsing Chiang (2005): 3D Grounwater Modeling with PMWIN: A Simulation System for Modeling Groundwater Flow and Transport Processes. - Hrsg. Pp. 397.

Wiegert, Ch., Aeppli, C., Knowles, T., Holmstrand, H., Evershed, R., Pancist, R. D. \& Macháčková, J. (2012): Dual Carbon-Chlorine Stable Isotope Investigation of Sources and Fate of Chlorinated Ethenes in Contaminated Groundwater. - Environmental Science \& Technology, accepted paper.

Wilson and Liu (1994): Backward tracking to find the source of pollution. - Proceedings of $4^{\text {th }}$ Annual WERC Technology Develop Conference, Las Cruces. 
Wilson, R.D., Thornton, S.F and Mackay, D.M. (2004): Challenges in monitoring the natural attenuation of spatially variable plumes. - Biodegradation 15: 359-369.

\section{$Y$}

Yadav, P. K., Händel, F., Müller, C., Liedl, R. \& Dietrich, P. (2013): NAFLA - Ein Simulationswerkzeug zur analytischen Abschätzung von Schadstofffahnenlängen. Technische Mitteilung. - Grundwasser 18 (2013): 47-53. In German.

Yang, J.H. and Lee, K.K. (2012): Locating plume sources of multiple chlorinated contaminants in groundwater by analyzing seasonal hydrological responses in an industrial complex, Wonju, Korea. - Geosciences Journal 16(3): 301 - 311.

Yare, B. (1975): The Use of a Specialized Drilling and Ground-water Sampling Technique for Delineation of Hexavalent Chromium Contamination in an unconfined aquifer, Southern New Jersey Coastal Plain. - Ground Water, 13 (2): 151-154.

\section{Z}

Zeru, A. and Schäfer, G. (2005): Analysis of groundwater contamination using concentration-time series recorded during an integral pumping test: Bias introduced by strong concentration gradients within the plume. - Journal of Contaminant Hydrology 81 (2005): 106124.

Zhou, Y. (1996): Sampling frequency for monitoring the actual state of groundwater systems. - Journal of Hydrology 180 (1996): 301-318. 



\title{
CURRICULUM VITAE
}

\section{Persönliche Daten}

\author{
Name Katrin Thomas-Thielsch \\ geboren am 29. Juli 1980 \\ in Georgsmarienhütte (Ldkr. Osnabrück, Nds.) \\ Nationalität Deutsch
}

\section{Hochschulausbildung und Berufserfahrung}

\section{Studium}

Grundstudium Lehramt Biologie/Chemie, Sekun-

$10 / 2000-10 / 2002$

darstufe II an der

Georg-August Universität Göttingen

Grundstudium Geowissenschaften an der

Georg-August Universität Göttingen

Abschluss: Bachelor of Science

Hauptstudium Geowissenschaften an der

Georg-August Universität Göttingen

Abschluss: Diplom

Promotionsstudium an der

Georg-August Universität Göttingen

$10 / 2002-04 / 2008$

$04 / 2008-03 / 2010$

04/2010-07/2013

\section{Berufsweg (neben dem Studium)}

Studentische Hilfskraft in der

$06 / 2006-01 / 2010$

Abt. Angewandte Geologie der

Georg-August Universität Göttingen

Aushilfe in Ingenieurbüro AWIA Umwelt GmbH, Göttingen

Tutorin Lehrveranstaltung „Geowissenschaftliche Informationssysteme (GIS)“, am GZG der Georg-August Universität Göttingen

Tutorin Lehrveranstaltung „Geowissenschaftliche Informationssysteme (GIS)“, am GZG der Georg-August Universität Göttingen

\section{Lehrauträge}

Lehrveranstaltung „Geowissenschaftliche Informationssysteme (GIS)“, am GZG der $10 / 2010-04 / 2011$ $10 / 2011-04 / 2012$ 